\title{
TEMPERATURE, VELOCITY AND SPECIES PROFILE MEASUREMENTS FOR REBURNING IN A PULVERIZED, ENTRAINED FLOW, COAL COMBUSTOR
}

Grant Number DE-FG22-95PC95223

Brigham Young University

Grant Date: September 1, 1995

Completion Date: August 31, 1998

No Cost Extension Date: February 28, 1999

\author{
Program Manager \\ Paula Flenory
}

Principal Investigator

Dale R. Tree

Contracting Officers Representative (COR)

Louis E. Dalverny

Reporting Period

September 1, 1995 - April 28, 1999

U.S./DOE Patent Clearance is not required prior to the publication of this document. 


\section{DISCLAIMER}

This report was prepared as an account of work sponsored by an agency of the United States Government. Neither the United States Government nor any agency thereof, nor any of their employees, makes any warranty, express or implied, or assumes any legal liability or responsibility for the accuracy, completeness, or usefulness of any information apparatus, product, or process disclosed or represents that its use would not infringe privately owned rights. Reference herein to any specific commercial product, process, or service by trade name, trademark, manufacturer, or otherwise does not necessarily constitute or imply its endorsement, recommendation, or favoring by the United States Government or any agency thereof. 


\section{ABSTRACT}

Nitrogen oxide emissions from pulverized coal combustion have been and will continue to be a regulated pollutant for electric utility boilers burning pulverized coal. Full scale combustion models can help in the design of new boilers and boiler retrofits which meet emissions standards, but these models require validation before they can be used with confidence. The objective of this work was to obtain detailed combustion measurements of pulverized coal flames which implement two NO reduction strategies, namely reburning and advanced reburning, to provide data for model validation. The data were also compared to an existing comprehensive pulverized coal combustion model with a reduced mechanism for $\mathrm{NO}$ reduction under reburning and advanced reburning conditions.

The data were obtained in a $0.2 \mathrm{MW}$, cylindrical, down-fired, variable swirl, pulverized coal reactor. The reactor had a diameter of $0.76 \mathrm{~m}$ and a length of $2.4 \mathrm{~m}$ with access ports along the axial length. A Wyodak, sub-bituminous coal was used in all of the measurements. The burner had a centrally located primary fuel and air tube surrounded by heated and variably swirled secondary air. Species of $\mathrm{NO}, \mathrm{NO}_{\mathrm{x}}, \mathrm{CO}, \mathrm{CO}_{2}$ and $\mathrm{O}_{2}$ were measured continuously. Aqueous sampling was used to measure $\mathrm{HCN}$ and $\mathrm{NH}_{3}$ at specific reactor locations. Samples were drawn from the reactor using water quenched suction probes. Velocity measurements were obtained using two component laser doppler anemometry in back-scatter mode. Temperature measurements were obtained using a shielded suction pyrometer. A series of six or more radial measurements at six or more axial locations within the reactor provided a map of species, temperature, and velocity measurements.

In total, seven reactor maps were obtained. Three maps were obtained at baseline conditions of $0,0.5$ and 1.5 swirl and $10 \%$ excess air. Two maps were obtained under reburning conditions of 0.78 stoichiometric ratio and 1.5 swirl and 0.9 stoichiometric ratio and 0.5 swirl. And finally, two maps were obtained under advanced reburning conditions both at the same operating condition of 1.05 stoichiometric ratio in the reburning zone followed by ammonia injection. Numerous effluent measurements were obtained to study the affect of natural gas injection location, stoichiometric ratio, and injection velocity on effluent NO. For advanced reburning, effluent measurements were obtained for a similar matrix of operating conditions with the additional variable of ammonia nitrogen to nitrogen in NO or nitrogen stoichiometric ratio (NSR).

Baseline maps and effluent measurements were useful in establishing the flow patterns of the reactor and determining the effect of swirl on NO. At zero swirl the flame appeared to be lifted and therefore created higher NO. At 0.5 swirl the flame had transitioned to an attached flame with a central recirculation zone and produced lower NO. Detailed velocity measurements of the quarl were obtained which provided boundary conditions for modeling and helped explain why the flame was not attached at zero swirl. Effluent NO measurements were found to correlate well with the transition in flow seen in the quarl.

Reburning results showed that a maximum reduction in NO of approximately $70 \%$ was possible with a reburning stoichiometric ratio of 0.78 . Initially, the addition of $\mathrm{NH}_{3}$ 
produced a fairly linear reduction in NO but as the stoichiometric ratio in the reburning zone decreased below 0.9 , additional reburning fuel was less beneficial. The effectiveness of reburning was not affected much by reburning zone location as long as the residence time prior to tertiary air burnout was sufficient, approximately $700 \mathrm{~ms}$. This indicates that reburning is not very sensitive to the temperature at the point of fuel injection. The maps obtained were self consistent in that the species appeared to behave as would be expected, thus supporting the usefulness of the data for model validation.

Advanced reburning measurements demonstrated that the combination of natural gas injection followed by ammonia injection can be very effective at reducing NO. One advanced reburning condition produced greater than $90 \% \mathrm{NO}$ reduction. The effectiveness of advanced reburning was, however, found to be very dependent on the location of ammonia injection and the combination of reburning zone stoichiometric ratio and NSR. The location sensitivity of ammonia injection was reasoned to be a sensitivity to the temperature at the point of injection. The detailed maps of advanced reburning indicated that the greatest $\mathrm{NO}$ reduction was occurring in the reactor at conditions similar to those used in Selective Non-Catalytic Reduction (SNCR) of NO in stack gases, namely small amounts of $\mathrm{O}_{2}(0.5 \%)$, temperature in the range of $1200-1300 \mathrm{~K}$ and at least 1 ammonia nitrogen for each NO nitrogen (NSR $>1$ ). The data suggest that advanced reburning can be successfully modeled using reaction mechanisms which are also successful at describing SNCR chemistry.

Modeling of the pulverized coal reactor was accomplished using PCGC-3 a comprehensive, pulverized-coal, combustion code developed at Brigham Young University. Non-reacting flow was also modeled using FLUENT, a commercially available CFD code. The results showed that the stronger recirculation of the swirling burner was extremely difficult to predict. Without the basic flow structure being correctly predicted the rest of the combustion solution was not relevant for comparison. A technique was developed to force a more correct solution on the code with selected boundary conditions. With the fluid flow corrected, the code produced a reasonably good prediction of the advanced reburning results. The advanced reburning model was used to describe NO reduction and demonstrates that the possibility of using CFD based codes to design improved boilers with regard to $\mathrm{NO}$ emissions is promising. 


\section{TABLE OF CONTENTS}

1 EXECUTIVE SUMMARY ....................................................................................

1.1 Primary Accomplishments...................................................................................1

1.2 Publications and Presentations..............................................................................2

1.2.1 Peer Reviewed Journal Articles ..................................................................... 2

1.2.2 Conference Papers - Abstract Reviewed ....................................................... 2

1.2.3 Presentations........................................................................................... 3

1.2.4 Requests For Data For Model Validation .................................................. 3

1.3 Graduate and Undergradute Students Supported ............................................3

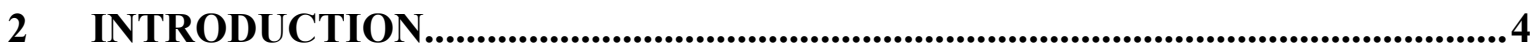

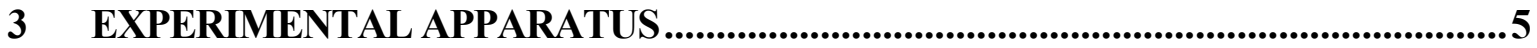

3.1 Combustion Facility ...................................................................................5

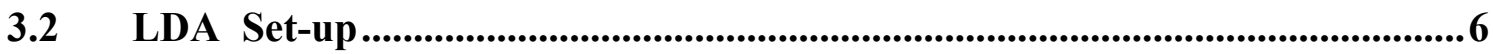

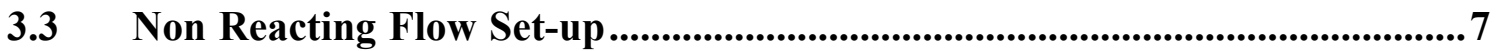

3.4 Gas Sampling ....................................................................................................8

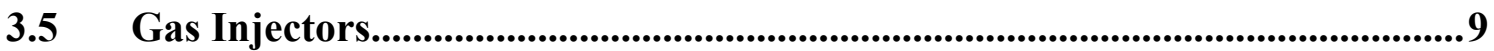

4 BASELINE OPERATING CONDITIONS AND RESULTS.................................10

4.1 Particle Velocity Slip Investigation..............................................................10

4.2 Non Reacting, Inlet Results...........................................................................15

4.3 Coal Flame Velocity Results .............................................................................20

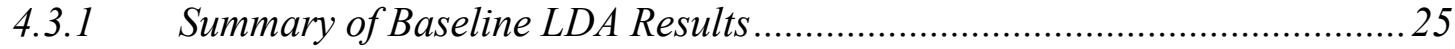

4.4 Species Profile Results ..........................................................................................26

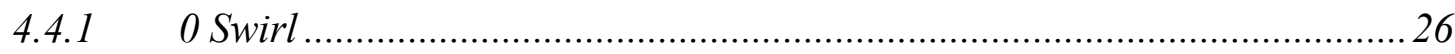

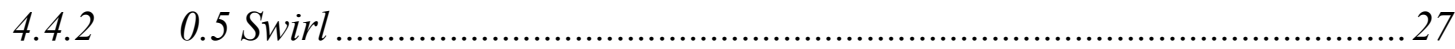

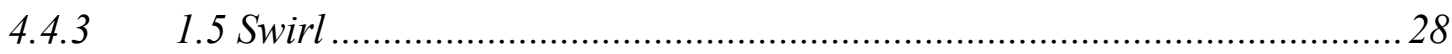

4.5 Gas Temperature Profiles ..........................................................................29

4.6 Baseline Species Measurement Conclusions..................................................31

5 REBURNING OPERATING CONDITIONS AND RESULTS...........................31

5.1 Measurement Conditions...................................................................................31

5.2 Reburning Results and Discussion..........................................................32

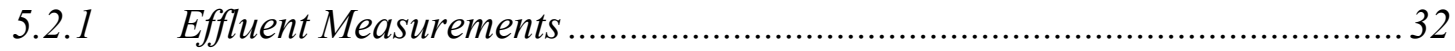

5.2.2 Detailed In-Situ Combustion Measurements ................................................. 36

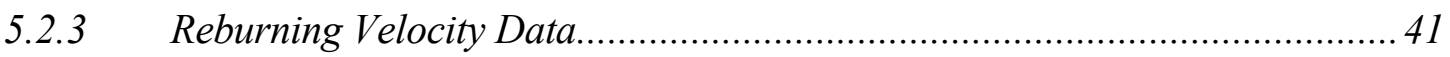

5.3 Reburning Summary..........................................................................................42

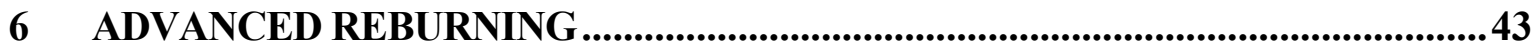


6.1 Introduction ...................................................................................................................4 43

6.2 Advanced Reburning Method and Set-Up ...................................................... 44

6.3 Advanced Reburning Results and Discussion ................................................46

6.3.1 Effluent NO Measurements..................................................................... 46

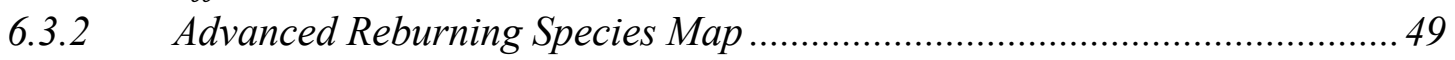

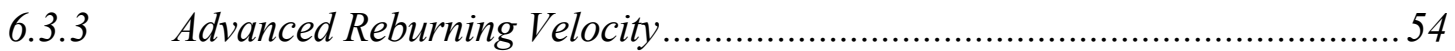

6.4 Advanced Reburning Summary and Conclusions ......................................55

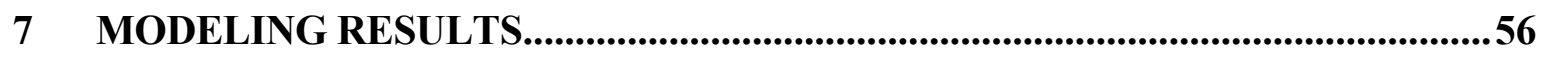

7.1 Baseline Flow Modeling Efforts.....................................................................57

7.1.1 Turbulence Models .............................................................................. 57

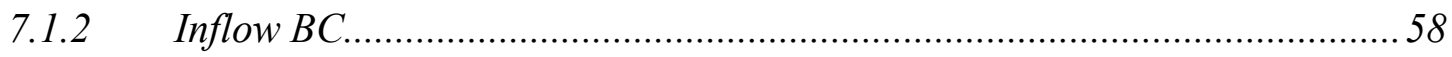

7.1.3 Matching Baseline Flow Data with The Model.............................................59

7.2 Reburning and Advanced Reburning Modeling.........................................62

7.2.1 A Four-Step Reduced Mechanism for Advanced Reburning Process........... 62

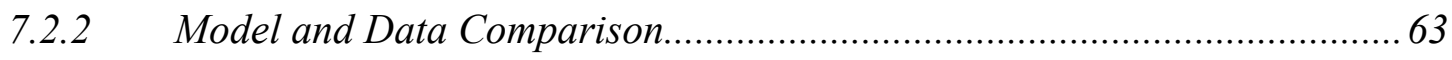

7.3 Modeling Summary....................................................................................667

8 CONCLUSIONS AND RECOMMENDATIONS ........................................67

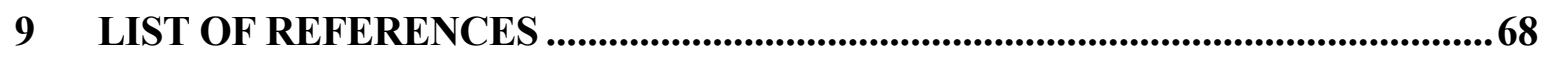




\section{EXECUTIVE SUMMARY}

A list of objectives set forth in the original proposed research work is shown in Table 1.1 The tables details tasks involving measurements and modeling of pulverized coal flames which employ reburning and advanced reburning $\mathrm{NO}_{\mathrm{x}}$ reduction technologies. All of the major objectives of the study have been completed with the exception of the advanced temperature measurements through the efforts of four graduate students as shown. The measurement results have been very successful, exceeding original expectations in quantity, quality, and interest. The data have provided new insight into the details of reburning and advanced reburning which should allow better engineering of these technologies. The modeling comparison to the data has been fruitful in identifying modeling weaknesses and difficulties with existing codes. Progress has been made toward more believable numerical modeling of reburning and advanced reburning.

Table 1.1 Timetable for the accomplishment and assignment of milestones.

\begin{tabular}{|c|c|c|c|c|c|c|c|c|c|c|c|c|c|c|c|c|c|c|c|c|c|c|c|c|c|c|}
\hline & 159 & 99 & & & & & 199 & 95 & 6 & & & & & & 19 & 997 & 7 & & & & & & & & & \\
\hline Task(s) & $\mathrm{ST}$ & $\mathrm{O} / \mathrm{N}$ & D & $\mathrm{J}$ & $\mathrm{M}_{1}$ & \begin{tabular}{l|l}
$A$ & $M$ \\
\end{tabular} & प1 & $\mathrm{J}$ A & & $0 \mid \mathrm{N}$ & $\mathrm{N} D$ & $\mathrm{~J}$ & $\mathrm{~F}$ & $\mathrm{M} \mid \mathrm{A}$ & $\mathrm{M} J$ & $\mathrm{~J} / \mathrm{A}$ & \begin{tabular}{|l|l|l}
$A$ & $S$
\end{tabular} & 0 & $\mathrm{~N}[\mathrm{~L}$ & $\mathrm{D}$ & $\mathrm{J} / \mathrm{F}$ & & & MJ & & A \\
\hline 1 Baseline Map & $\mathrm{G} / \mathrm{C}$ & $\mathrm{G} G$ & & & & & & & & & & & & & & & & & & & & & & & & \\
\hline 2 Baseline Prediction & $\mathrm{J}$ & & J & & & & & & & & & & & & & & & & & & & & & & & \\
\hline 3 Baseline LDA & & & & $\mathrm{P}$ & $\mathrm{P}$ & \begin{tabular}{l|l}
$\mathrm{P}$ & $\mathrm{P}$ \\
\end{tabular} & & & & & & & & & & & & & & & & & & & & \\
\hline 4 Model Eval. & & & & & $\mathrm{J}$ & \begin{tabular}{|l|l|l|l}
$J$ & $J$ \\
\end{tabular} & $\mathrm{~J}$ & & & & & & & & & & & & & & & & & & & \\
\hline 5 Reburning Design & $\mathrm{N} / \mathrm{I}$ & $\mathrm{N} / \mathrm{N}$ & $\mathrm{N}$ & $\bar{N}$ & $\mathrm{~N} \mid \mathrm{N}$ & $\bar{N}$ & & & & & & & & & & & & & & & & & & & & \\
\hline 6 Test Reburning & & & & & & $\mathrm{N} / \mathrm{N}$ & $\mathrm{N} / \mathrm{N}$ & & & & & & & & & & & & & & & & & & & \\
\hline 7 Map with Reburning & & & & & & $\mathrm{G}$ & $\mathrm{G} G \mathrm{G}$ & $\begin{array}{ll}\mathrm{G} & \mathrm{G} \\
\mathrm{n}\end{array}$ & $\mathrm{G}$ & $\mathrm{G}$ & $\mathrm{G}$ & & & & & & & & & & & & & & & \\
\hline 8 LDA with Reburning & & & & & & $\mathrm{P}$ & \begin{tabular}{l|l}
$\mathrm{P}$ & $\mathrm{P}$ \\
\end{tabular} & \begin{tabular}{l|l}
$P$ & $J$ \\
\end{tabular} & $\mathrm{~J}$ & \begin{tabular}{l|l}
$J$ & $J$ \\
\end{tabular} & $\mathrm{~J}$ & & & & & & & & & & & & & & & \\
\hline 9 Converge Model & & & & & & & & & J & \begin{tabular}{|l|l}
$\mathrm{J}$ & $\mathrm{J}$ \\
\end{tabular} & J & & & & & & & & & & & & & & & \\
\hline 10 Eval. Reburning Model & & & & & & & & & & & & $\mathrm{J}$ & $\mathrm{J}$ & $\mathrm{J} J \mathrm{~J}$ & & & & & & & & & & & & \\
\hline 11 Adv. Reburning Design & & & & & & & & & & & $\mathrm{C}$ & $\mathrm{C}$ & $\mathrm{C}$ & \begin{tabular}{|l|l|l}
$C$ & $C$ \\
\end{tabular} & & & & & & & & & & & & \\
\hline 12 Test Adv. Reburning & & & & & & & & & & & & C & $\mathrm{C}$ & $\mathrm{C} \mid \mathrm{C}$ & & & & & & & & & & & & \\
\hline 13. Map Adv. Rbrng & & & & & & & & & & & & & & & $\mathrm{G} / \mathrm{G}$ & $\mathrm{s} \mid \mathrm{G}$ & $\overline{\mathrm{G}}$ & & & & & & & & & \\
\hline 14 LDA with Adv. Rbrng & & & & & & & & & & & & & & & $\begin{array}{lll}\mathrm{J} & \mathrm{J} \\
\end{array}$ & $\mathrm{J} \mathrm{J}$ & \begin{tabular}{|l|l|l}
$J$ & $J$ \\
\end{tabular} & $\mathrm{~J}$ & & & & & & & & \\
\hline 15. Conv. Adv. Rbrng. Mode & & & & & & & & & & & & & & & & $\mathrm{J} / \mathrm{J}$ & \begin{tabular}{|l|l|}
$J$ & $J$ \\
\end{tabular} & $\mathrm{~J}$ & \begin{tabular}{|l|l}
$\mathrm{J}$ & $\mathrm{J}$ \\
\end{tabular} & $\mathrm{J}$ & & & & & & \\
\hline 16. Comp. Adv. Rbrng. Mode & & & & & & & & & & & & & & & & $\mathrm{J} / \mathrm{J}$ & \begin{tabular}{|l|l|l}
$J$ & $J$ \\
\end{tabular} & $\mathrm{~J}$ & \begin{tabular}{|l|l}
$\mathrm{J}$ \\
$\mathrm{J}$
\end{tabular} & & & & & & & \\
\hline 17. Adv. Temp. Meas. & & & & & & & & & & & & & & & & & & & & & & & & & & \\
\hline 17a. Map 0.5 Swirl Rebrne & & & & & & & & & & & & & & & & & & & & & $\mathrm{J} / \mathrm{J}$ & & & & & \\
\hline
\end{tabular}
Key: G- Group Assignment
J - Robert Jackson
P - Lyle Pickett
$\mathrm{N}$ - Waseem Nazeer
C - Adam Clark

\subsection{Primary Accomplishments}

A summary of some of the primary accomplishments are listed below. Details on published articles presentation and graduate students are given in the subsequent sections.

1. Complete maps a species, temperature, and velocity have been obtained for three swirl settings of a pulverized coal flame.

2. Complete maps of species, temperature and velocity have been obtained at two swirl settings for a pulverized coal flame with reburning.

3. Complete maps of species, temperature and velocity have been obtained at one swirl setting for a pulverized coal flame with advanced reburning.

4. Advanced reburning measurements demonstrated that greater than $90 \%$ reduction of NO is possible. 
5. Modeling results suggest full scale simulation is a valuable tool for implementation of reburning and advanced reburning and that recently developed advanced reburning sub models can give reasonable predictions of NO reduction.

6. These data have been compiled in a data book which is available to industry, universities, and government researchers who wish to validate comprehensive combustion codes. A copy of the data book is available upon request in hard copy format. To date, two companies, four universities and one foreign government laboratory have requested and received all or portions of the data. All are apparently using the data or a portion of the data for code and engineering development of pulverized coal systems. A list of researchers using the data is also given below.

7. Three master's degree students who have graduated and one Ph.D. student whose graduation is pending have been supported by the grant. The students names and thesis topics are found in Section 1.3 below.

8. Four archival journal articles have been published or accepted for publication with one more in progress. Four conference papers and seven conference presentations have also been given in order to disseminate the information obtained under this grant. A listing of publications and presentations resulting from this grant is given below in Section 1.2

\subsection{Publications and Presentations}

Information obtained from this study has been successfully shared with industry, academia and government through peer reviewed journal articles, conference papers and conference presentations. Several researchers have requested data obtained from this study. The following sections detail the dissemination of information.

\subsubsection{Peer Reviewed Journal Articles}

The following is a list of peer reviewed journal articles which have been written and accepted as of the writing of this report. A fourth article is planned which involves a comparison of the measured and modeling results but is not yet completed. An asterisk beside the author indicates a graduate student author who was supported by this contract.

1. Nazeer*, W.A., Jackson*, R.E., Peart*, J.A. and Tree, D.R. (1999) "Detailed Measurements in a Pulverized Coal Flame With Reburning," Fuel, Vol. 78:6 pp 689699.

2. Pickett*, L.M., Jackson*, R.E. and Tree D.R. (1999) "LDA Measurements in a Pulverized Coal Flame at Three Swirl Ratios," Combustion Science and Technology, March, 1998. (In press)

3. Nazeer*, W.A., Pickett*, L.M. and Tree D.R. (1999) "In-Situ Species, Temperature and Velocity Measurements in a Pulverized Coal Flame," Combustion and Science Technology, March, 1998. (In press)

\subsubsection{Conference Papers - Abstract Reviewed}

The following abstract reviewed conference papers have been published with accompanying presentations at the Western States Section of the Combustion Institute. An asterisk indicates student authors supported by the contract.

1. Clark*, A.W., Tree, D.R. (1998) "Detailed In-Situ Measurements of Temperature and Species in a Pulverized Coal Flame with Advanced Reburning, Western States Section, The Combustion Institute, Fall, 1998. 
2. Pickett*, L.M., Jackson*, R.E. and Tree, D.R. (1997) "LDA, Gas Species and Temperature Measurements in a Pulverized Coal Flame," Western States Section, The Combustion Institute, Spring 1997.

3. Jackson*, R.E., Pickett*, L.M., and Tree, D.R. (1997) "Comprehensive Combustion Code Predictions of the Flow Field for Pulverized Coal Combustion," Western States Section, The Combustion Institute, Spring 1997.

4. Nazeer*, W.A., Jackson*, R.E. and Tree, D.R. (1997) "Detailed Species and Temperature Measurements in a Pulverized Coal Flame with Natural Gas Reburning," Western States Section, The Combustion Institute, Fall 1997.

\subsubsection{Presentations}

In addition to presentations at conferences for the papers listed above, presentation have been given without formal papers at the following meetings.

1. Tree, D.R., Haneberg, A., Pickett, L.M., Nazeer, W. (1998) "In-Situ Species and Temperature Measurements of Pulverized Coal Flames with Reburning and Advanced Reburning," ACERC Annual Conference, March 25, 1998.

2. Tree, D.R. and Haneberg*, A. "Optical Soot Measurements in a Pulverized Coal Flame," Submitted to: Twenty-seventh Symposium (International) on Combustion, The Combustion Institute, Aug., 1998.

3. Tree, D.R., Haneberg, A., Pickett, L.M., Nazeer, W. "Velocity, Soot and Reburning Measurements in a Pulverized Coal Reactor," ACERC Annual Conference, March 13, 1997.

\subsubsection{Requests For Data For Model Validation}

The following research groups or individuals have requested data which have resulted from this work for use in testing or developing comprehensive combustion codes.

1. Texas A\&M University, College Station Texas, Dr Kalyan Annamalia,

2. Reaction Engineering Incorporated, Salt Lake City, Utah, Dr. Eric Eddings

3. University of Utah, Salt Lake City, Utah, Dr. Eric Eddings

4. ABB Power Plant Laboratories, Windsor Connecticut, Dr. Woodrow Fiveland

5. Queen Mary and Westfield College, London England, Dr. Xu Zhou

6. Vinca Institute of Nuclear Sciences, Belgrade Yugoslavia, Srdjan Belosevic

\subsection{Graduate and Undergraduate Students Supported}

The following graduate and undergraduate students have been supported through this research contract.

1. Lyle Pickett, Master's Degree, December, 1996 
Thesis Title: Velocity Measurements in a Pulverized Coal Flame Using Laser Doppler Anemometry (LDA)

2. Waseem Nazeer, Master's Degree, August, 1997

Thesis Title: Species and Temperature Measurements in a Pulverized Coal Controlled Profile Reactor with Natural Gas Reburning

3. Adam Clark, Masters Degree, August, 1998

Thesis Title: In-Situ Species and Temperature Measurements in a Pulverized Coal Flame with Advanced Reburning

4. Jacob Peart, Undergraduate, BSME, April, 1998

Co authored Reburning Publication Nazeer et al. (1999)

Currently working on a DOE sponsored Masters Degree

5. Robert Jackson, Ph.D., Expected August, 1999

\section{INTRODUCTION}

Reburning and advanced reburning are very promising $\mathrm{NO}_{\mathrm{x}}$ reduction strategies which have been proven experimentally in small scale reactors and demonstrated on full scale boilers. One particularly important advantage of these techniques is the potential for retrofit on existing boilers. More information is needed, however, both empirically and fundamentally on how reburning and advanced reburning should be implemented in full scale boilers. A model for reburning and advanced reburning has been developed at BYU as reported by Xu et al. (1997) and by other researchers such as Brauwer et al. (1996). These models are in need of validation and further development before they may be accepted as useful tools. Over the past three years detailed measurements in a coal reactor with reburning and advanced reburning have been completed. The data have been used as part of this project and by other universities, industry and labs to develop computational combustion codes.

The first step in the data acquisition process was to obtain baseline data of the pulverized coal flame before the addition of reburning and advanced reburning fuels. In addition to on-line gaseous species data, this baseline data set involved aqueous sampling for the measurement of $\mathrm{NH}_{3}$ and $\mathrm{HCN}$ and Laser Doppler Anemometry (LDA) measurements to obtain the velocity flow field. This baseline data set was obtained at three swirl settings $(0,0.5$ and 1.5$)$ in order to characterize the flow of the reactor and provide a foundation of data from which to compare reburning and advanced reburning. In using LDA to measure the velocity with coal as the seed particle in the reactor it became necessary to verify the accuracy. This was done by comparing LDA results with coal (90 $\mu \mathrm{m}$, mass mean) and $1 \mathrm{~mm}$ alumina as seed particles. This also allowed a study of the velocity profile at the inlet of the primary fuel tube in non reacting flow situations.

A reburning data set at two swirls was obtained next. In order to identify operating conditions for the mapped species, velocity, and temperature data a matrix of operating conditions was investigated while monitoring only the effluent data. Initially, only one 
mapped reburning condition was planned but a second map was obtained in response to industrial input and interest after seeing the results of the first map. A similar sequence followed for advanced reburning. First, a matrix of operating conditions was investigated with effluent species measurements followed by a detailed map at a single operating condition. In the case of advanced reburning, a second map at the same operating condition was obtained to demonstrate repeatability.

Modeling comparisons were made during each phase of the experimental work. The model was first compared to the baseline data. The model was not able to produce the flow patterns measured in the reactor with LDA suggesting that the turbulence model was insufficient to describe the flow. For reburning and advanced reburning, the flow patterns were forced to match the measured baseline data while the NO reduction and formation models for reburning and advanced reburning were left alone to determine their ability to describe the measurements.

The procedure described above is summarized in Table 1.1. The report which follows will first review the reactor and experimental apparatus. A section will then follow on detailing results on each of the four major areas discussed above, namely: 1. Baseline Measurements 2. Reburning Measurements 3. Advanced Reburning Measurements and 4. Modeling Results.

\section{EXPERIMENTAL APPARATUS}

\subsection{Combustion Facility}

A schematic diagram of the $0.2 \mathrm{MW}$, down-fired, pulverized coal combustion facility called the Controlled Profile Reactor (CPR), is shown in Figure 3.1. Coal was delivered from an auger and mixed with primary air above the reactor. The secondary air was preheated $(600 \mathrm{~K})$ before passing through a swirl generator and mixing with the primary air and fuel. The swirl generator consisted of two interlocking sets of movable plates with triangular shaped blocks as described by Beer and Chigier (1972). Swirl was created by rotating one of the plates which changed the angle between the blocks and generated a tangential velocity component in the air.

The quarl expansion can be subject to severe mineral deposition and slagging which can affect the aerodynamics of the flame. Consequently, a slag-laden quarl has been attributed as the cause for asymmetry and unexpected flame shapes as well as changing geometry over time (Abbott, 1989). To prevent slagging, a water-cooled quarl was installed on the CPR. Because of the cool wall temperatures, slagging did not occur, but the high rate of heat transfer in the quarl reduced the maximum flame temperature. The reduced temperature can also affect flame stability but this did not appear to be a problem in this study.

Each section of the CPR has access ports in every quarter of the reactor. These ports were used to make flame measurements, including temperature, gas species, and velocity, along radial profiles of the reactor. Wall temperatures, primary and secondary air flow rates, and coal feed rates were monitored with a computer-based data acquisition system. 
Primary and secondary air flow rates were controlled with choked flow orifice flow meters by adjusting the back pressure.

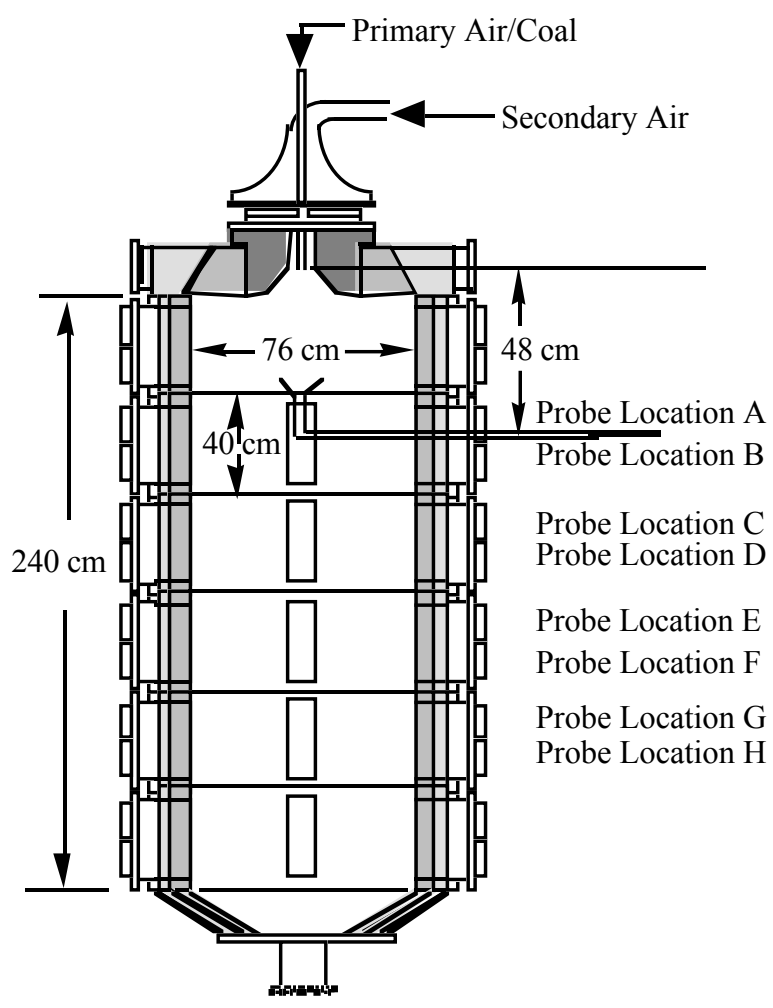

Figure 3.1 Schematic diagram of the Controlled Profile Reactor (CPR) showing some basic dimensions and probe locations used for reburning measurements.

\subsection{LDA Set-up}

A two-color Laser Doppler Anemometer was used for cold flow boundary condition tests in forward scatter mode and coal flame tests in back scatter mode. The system consisted of a $6 \mathrm{~W}$ Argon-Ion Laser, LDA optics, two Bragg cells, and two photomultipliers. The laser beams were expanded with a $3.75 \mathrm{x}$ beam expander and then focused with a transmitting lens with a focal length of $762 \mathrm{~mm}$ to form a $2.3 \mathrm{~mm}$ by 0.13 mm measurement volume. Two TSI model 1980 counter-type signal processors were used for data validation.

The set up for coal flame measurements was accomplished by mounting the laser, transmitting optics, and receiving optics together on a rigid breadboard as shown in Figure 3.2. The breadboard was mounted on an adjustable table with wheels that would roll along rails on the floor to make measurements at different radial positions. Vertical adjustments were made to the table to take data at different axial positions, but the optics and laser had to be removed from the table, setup again, and realigned for each axial height. Optical access was gained by removing the refractory plugs and placing a metal plate on the port with a hole large enough for the laser beams to pass. Windows were not used because of ash deposits that accumulate with coal and concerns about signal attenuation. 


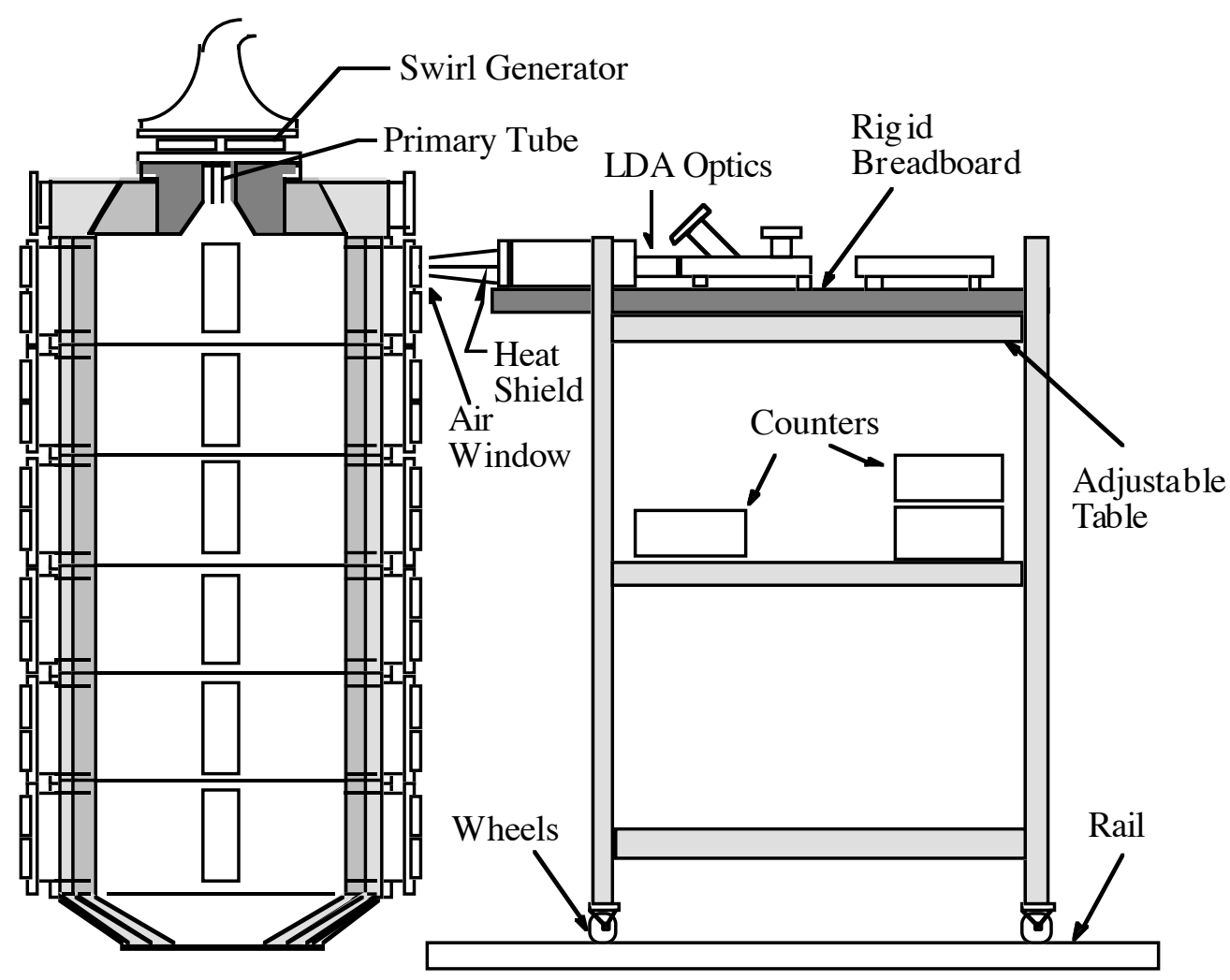

Figure 3.2 Schematic diagram of the CPR and LDA system in back-scatter mode.

Coal flame velocity profiles were measured at 4 axial locations in the near burner region at the top of the CPR ( $80 \mathrm{~cm}$ axial location and above) at burner theoretical swirl settings of $0,0.5$ and 1.5 swirl. Measurements at 24 and $39 \mathrm{~cm}$ were collected on the same day while those at $80 \mathrm{~cm}$ were collected the following day without any adjustments made to the swirl generator. Data at $65 \mathrm{~cm}$ were collected after the reactor had been used for other experiments and was returned to the original settings. Black Thunder coal is a highly volatile coal that proved to burn quickly, therefore, locations below $80 \mathrm{~cm}$ produced a flat flame profile. Other than coal particles, no additional LDA seed material was added.

\subsection{Non Reacting Flow Set-up}

Before data was obtained in the CPR with reacting flows, the error in velocity slip caused by using coal particles as the scattering media for the LDA measurements needed to be quantified. This was performed using a geometrically identical quarl built for optical access which was mounted to the swirl generator. The same primary and secondary flow rates and temperatures were used as in the reacting flow studies allowing the data to be used as the boundary condition for the reactor at the primary inlet. Because the measurements in this study were taken upstream of anticipated combustion reactions, the velocities measured were assumed to be representative of those at the inlet of the CPR; 
however, there was no coal added to the primary stream except where it was studied as a seed particle and therefore some differences in the flow may exist.

For optical access, it was desired to make as little intrusion into the geometry as possible to prevent flow disturbance. As shown in Figure 3.3, a $10 \mathrm{~mm}$ sapphire window was placed in a countersunk hole flush with the wall on one side of the quarl model and small slits the size of the laser beam were cut into the wall. The beams entered the quarl model from one side and forward-scattered light was collected on the opposite side. The entire swirl generator and model quarl were mounted on a movable platform. Seeding of the air for the inlet boundary plane data was accomplished by introducing $1 \mu \mathrm{m}$ sized alumina particles into the air stream. Data was collected directly below the primary inlet at six different burner swirl settings. Additional cold flow data were gathered at several axial locations in the quarl region and in the CPR at the same locations as the coal flame data.

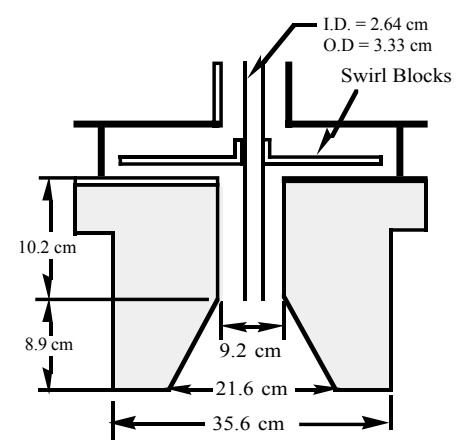

(a) Swirl generator, burner and quarl

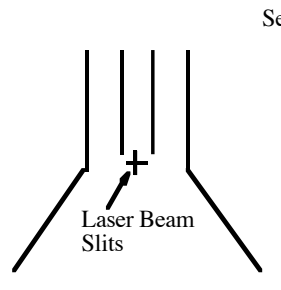

Left Side View
Secondary Air Primary Air

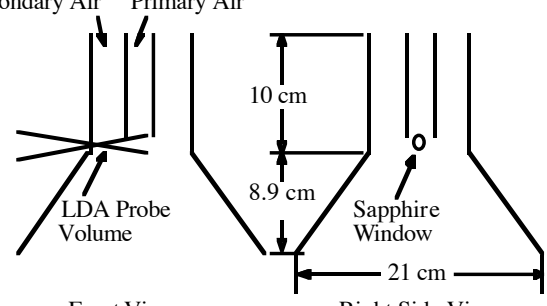

Front View

Right Side View

(b) Location of windows and slits used in LDA measurments

Figure 3.3 Schematic diagram of the (a) swirl generator burner and quarl and (b) quarl test section used for LDA measurements.

\subsection{Gas Sampling}

Gas samples inside the CPR were collected with a water-cooled and water-quenched stainless steel probe. Samples were drawn through the probe and the sample line with a four head suction pump. The gas samples were passed through two ice baths to condense the aqueous solution and then passed through a desiccant to remove any remaining moisture for dry gas analysis. Condensed water and quench water were separated from the gas samples in a water trap and preserved for ammonia and solid sample analysis. The aqueous samples were separated into three containers. Two containers were tested for 
$\mathrm{NH}_{3}$ and $\mathrm{HCN}$ using ion selective electrodes (ISE) and the remainder was filtered and the solid particles collected for elemental analysis. The dry gas was sent to on-line gas analyzers for $\mathrm{NO}$ and $\mathrm{NO}_{\mathrm{x}}$ (chemiluminescence), $\mathrm{CO}$ and $\mathrm{CO}_{2}$ (NDIR), and $\mathrm{O}_{2}$ (paramagnetic) analysis. A stainless steel, water-cooled, shielded, suction pyrometer equipped with an S-type (platinum, platinum-10\% rhodium) thermocouple was used to obtain gas temperature data.

$\mathrm{CO}, \mathrm{CO}_{2}$ and $\mathrm{O}_{2}$ concentrations exiting the reactor were continuously monitored and routinely checked for consistency with the fuel flow rate. For each stoichiometric ratio (typically 1.10) expected $\mathrm{O}_{2}$ and $\mathrm{CO}_{2}$ concentrations were calculated assuming complete combustion. If a relative error of greater than $10 \%$ was observed between the expected and measured values of these products, data acquisition was suspended until the problem was resolved. At a S.R. of 1.10 for example, $\mathrm{O}_{2}$ was held between 1.7 and $2.1 \%$. This theoretically held variations in the combined fuel and air flow to $\pm 1 \%$. The most significant source of error in this regard was the coal feed rate. Over time coal feed was found to drift by as much as $5 \%$ due to compaction in the vibrating auger feed bin. Monitoring of the exhaust gas concentration allowed the auger speed to be adjusted slightly to maintain constant feed even though compaction had occurred. Given the uncertainties involved in the analyzers, and fuel and air flow measurements, the overall accuracy of the S.R. was calculated to be approximately $\pm 2.5 \%$.

\subsection{Gas Injectors}

During the reburning and advanced reburning tests it was necessary to inject natural gas and/or ammonia into the reactor. In order to maintain symmetry, it was decided that the gas would be introduced at the centerline of the reactor and that the spray should be delivered using a pintle type nozzle. Three gas injectors were designed and built with identical geometry's to accommodate simultaneous injection of natural gas, ammonia and tertiary air. The pintle design section of the injectors in shown in Figure 3.4. The figure shows the a gap of $0.6 \mathrm{~mm}$ for the pintle opening. This is the opening used in all of the nozzles unless specified otherwise.

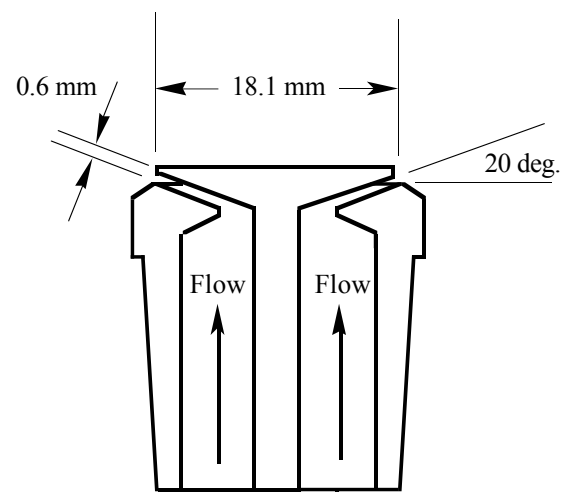

Figure 3.4 Schematic diagram of the injector nozzle used on all gas injectors. 


\section{BASELINE OPERATING CONDITIONS AND RESULTS}

\subsection{Particle Velocity Slip Investigation}

Anticipating that coal would not exactly follow the gas flow in some locations, a study was performed in cold flow to quantify the velocity slip. Particles with three different size distributions were used as LDA seed to determine their ability to represent the true gas velocity. The experiment was designed at the primary inlet right at the area expansion of the quarl in the same location as the inlet condition tests. In a cold flow environment this location had maximum deceleration due to the area expansion of the quarl and therefore provided a good test of whether the particle's momentum could change with the gas flow. From model predictions, it was estimated that the decelerations in this region would be larger than those experienced in hot flow at the testing locations.

The size distributions of the seed materials, alumina $\left(\mathrm{Al}_{2} \mathrm{O}_{3}\right)$, aluminum, and coal, are shown in Figure 4.1 with mass mean size distributions of $1 \mu \mathrm{m}, 25 \mu \mathrm{m}$, and $90 \mu \mathrm{m}$, respectively. Sizing measurements were made with a Coulter-type size counter which measures the volume occupied by particles of different sizes. The bulge in the alumina particle distribution at $6 \mu \mathrm{m}$ is likely due to agglomerates that were not broken up before the size measurement test. If the coal particles are assumed to be spherical, a size distribution by number can also be calculated from the volume frequency data. As shown in Figure 4.1, the number distribution of coal particles is dominated by sub-10 $\mu \mathrm{m}$ sizes. The figure shows that while the mass mean size of the coal particles is relatively large, there are very few large particles.

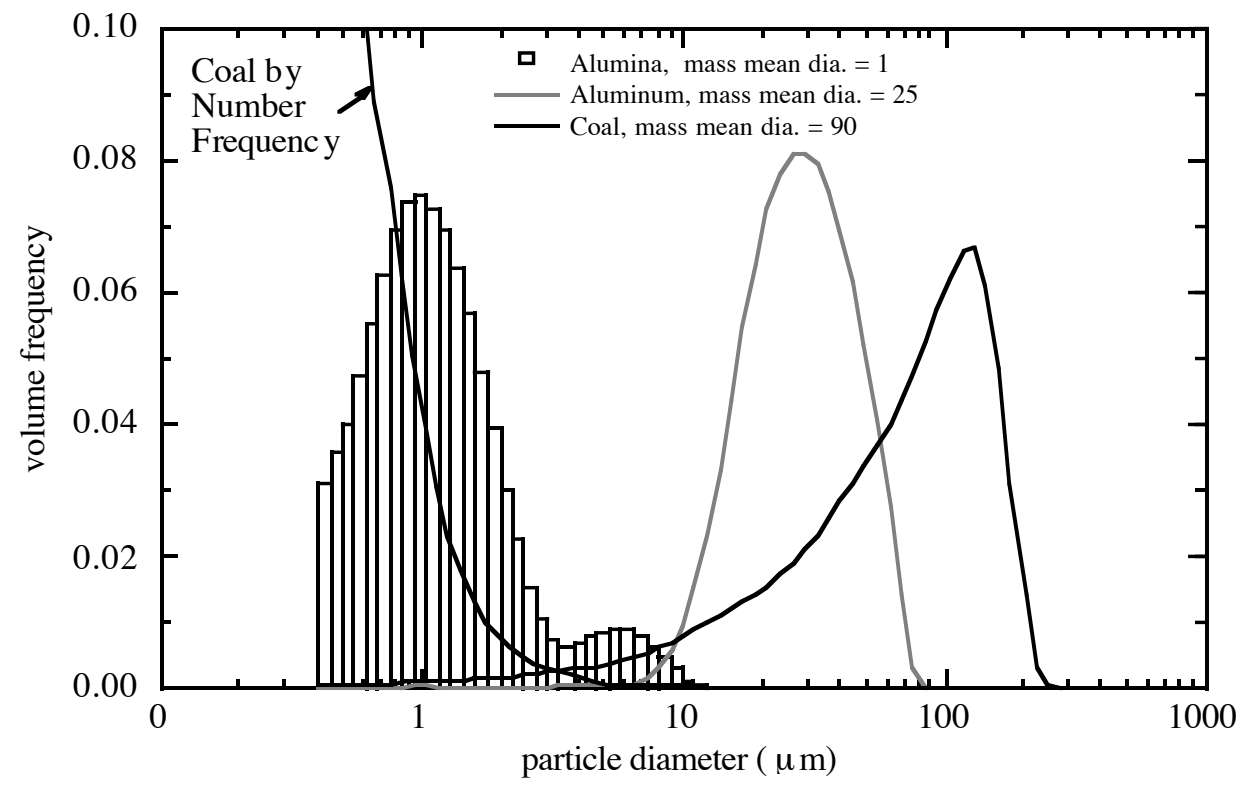

Figure 4.1 Size distribution of aluminum, alumina, and coal used in the velocity slip study. 
Velocity results at 0 and 1.5 swirl with each seed material are shown in Figures 4.2 and 4.3 for 0 and 1.5 swirl, respectively. The rapid deceleration of both the secondary and primary streams is shown by a positive velocity slip with the larger particles. In the secondary stream at the peak 0 swirl measurement, the velocity difference in the small alumina and coal particles is 7\%; at 1.5 swirl, 3\%. The generally close agreement between coal and the gas phase velocities in the secondary region is believed to be caused by the high probability that small coal particles will be measured. Since LDA data is collected by number of particles, the probability that a small coal particle will be measured is high, reducing the error of velocity slip in the measurements. This is consistent with the number distribution of coal shown in Figure 4.1. Schnell et al. (1993) report that in a coal flame the probability that LDA signals come from particles less than $10 \mu \mathrm{m}$ is $95 \%$. A size discrimination technique used by Abbott (1989) in a coal flame also showed little difference in LDA velocity when large particles were filtered out compared to all particles included. Weber et al. (1992) come to similar conclusions. This does not mean that gas and particle velocities are the same, but rather the LDA technique records an overwhelming number of small particles which follow the gas velocity in comparison to the larger coal particles which change momentum more slowly. Thus the few larger particles are seen equally with the numerous smaller particles.

The RMS velocities closely agree in the secondary region at both swirl settings, but there is significant difference in the primary region. Investigation of the probability distribution functions (PDF) for LDA data within the primary region, $5 \mathrm{~mm}$ below the primary tube showed particle bias as evidenced by a bimodal particle size distribution. The larger particles produce a velocity that is higher than the gas phase velocity because they do not decelerate as rapidly. On the other hand, the accelerations of the gas phase in the secondary stream are small enough that particle bias is insignificant. The secondary stream may also contain only those particles which were small enough to be accelerated from their original straight trajectory into the secondary stream. 


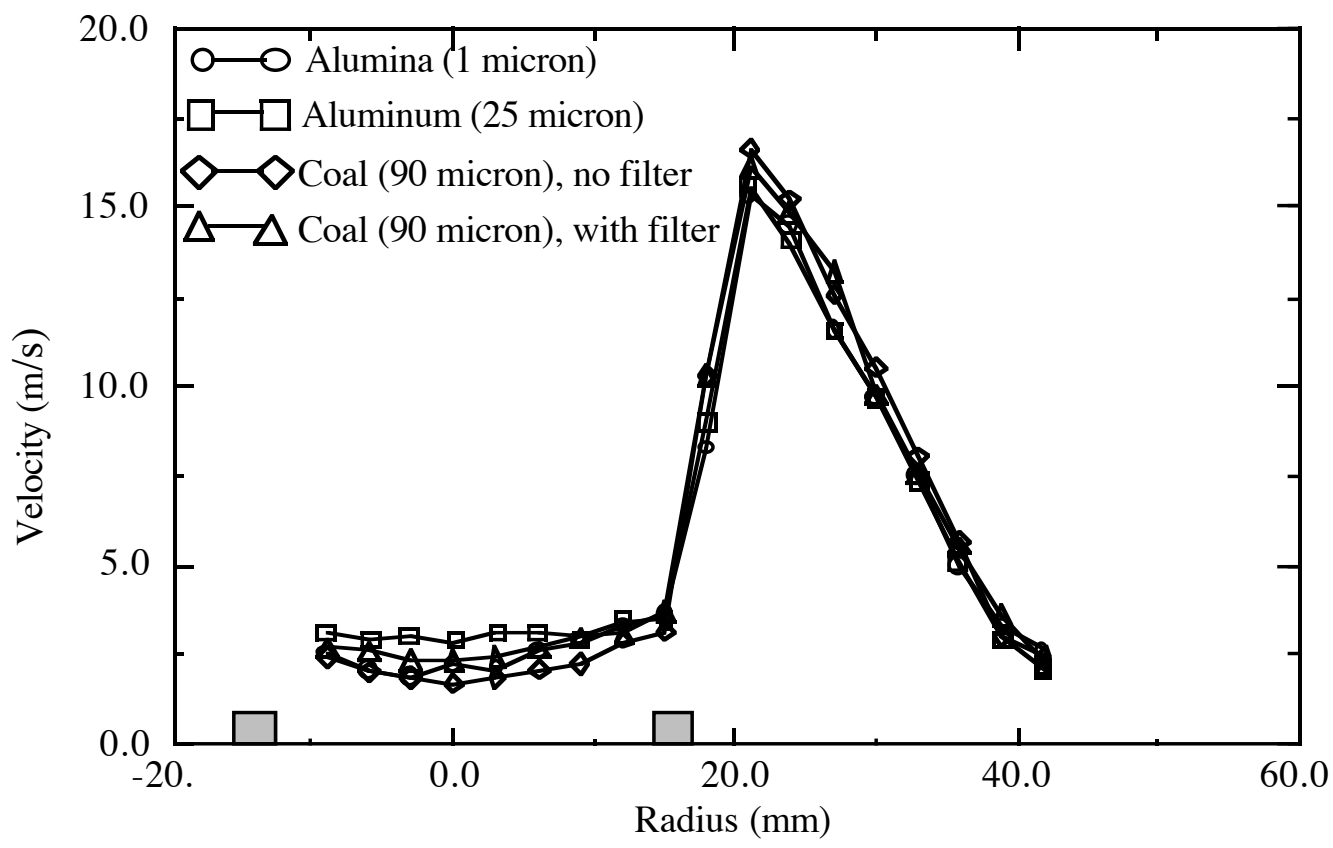

A) Average Axial Velocity

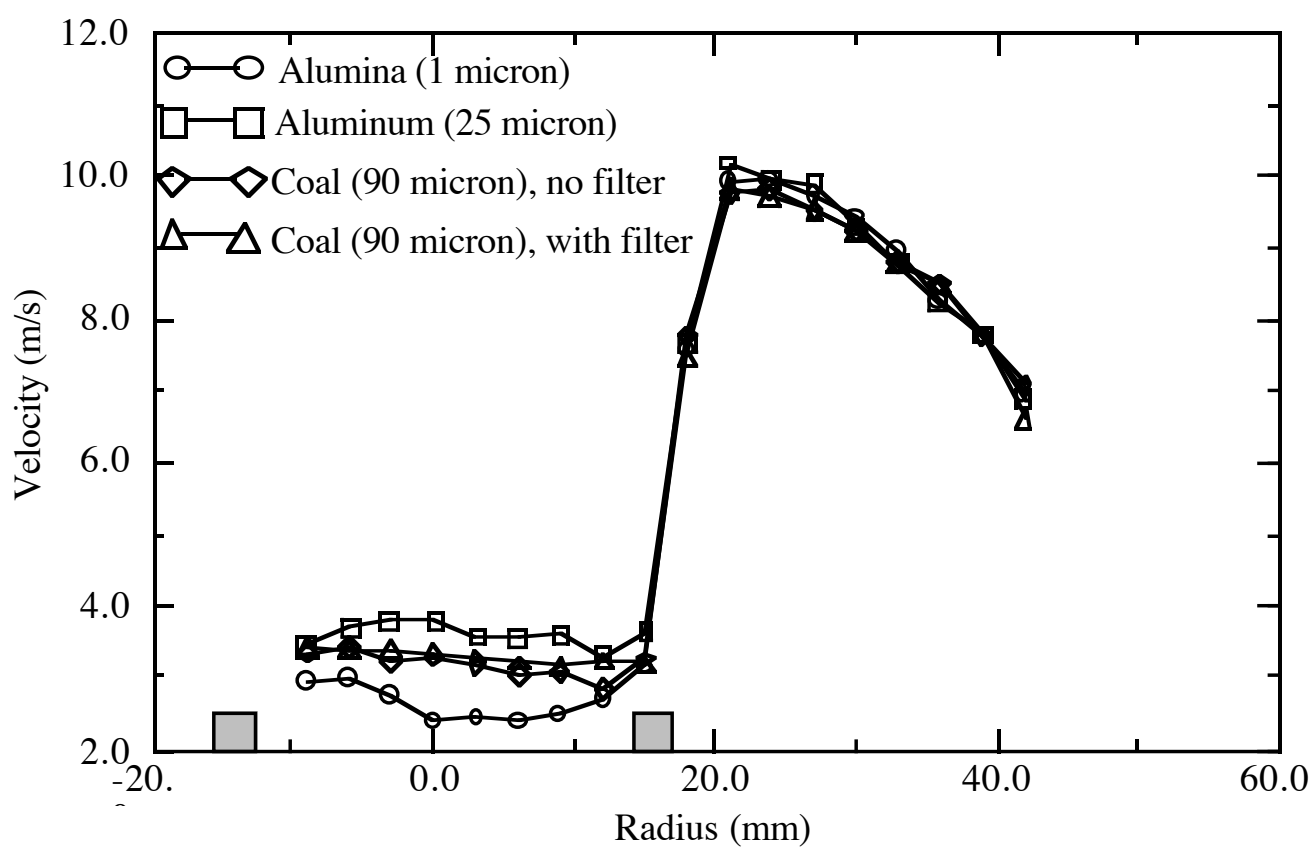

B) RMS Axial Velocity

Figure 4.2 Axial average and RMS velocities of different particles at 0.0 swirl (5 mm below primary inlet). 


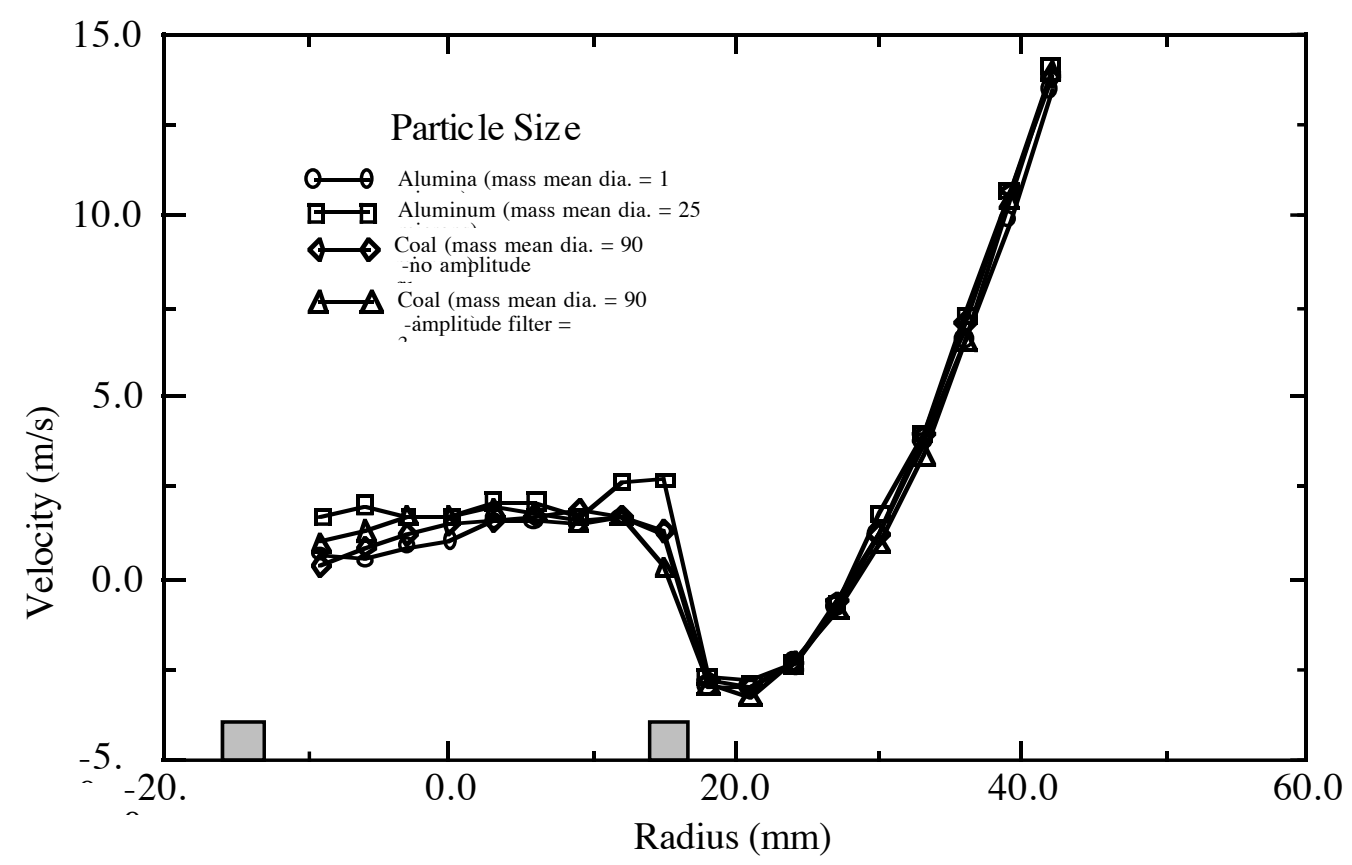

A) Average Axial Velocity

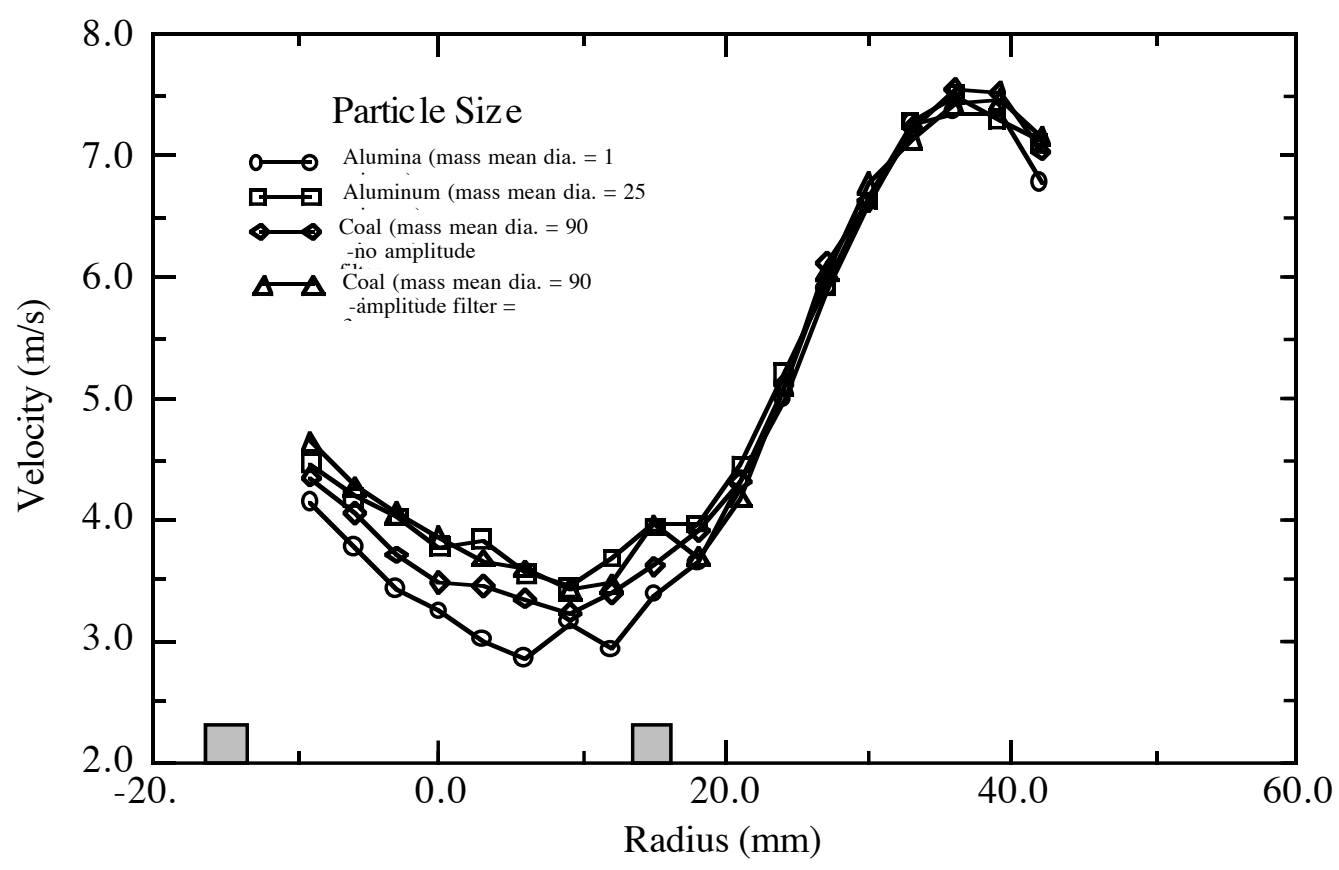

B) RMS Axial Velocity

Figure 4.3 Axial average and RMS velocities for different particles at 1.5 swirl (5 mm below the primary inlet). 
In order to determine the extent of particle slip at different locations in the CPR, analysis was done using existing particle slip equation from the literature and the measured accelerations in the reactor. A common correlation (TSI manual, 1980; Probstle and Wenz, 1988; Durst et al., 1980), as derived from the Basset equation for a sphere in a fluid, was used to express the particle slip as shown in Equation 4.1. The time constant, $\tau$, can be approximated by Equation 4.2 and $d$ is particle diameter, $\rho$ is particle density, and $\mu$ is gas viscosity.

$$
\begin{aligned}
& \mathrm{s}=\mathrm{e}^{-\mathrm{t} / \tau} \\
& \tau=\frac{\mathrm{d}^{2} \rho}{18 \mu}
\end{aligned}
$$

Berman (1972) has shown that in regions where there is stationary flow experiencing a non uniform change in velocity in the $\mathrm{x}$ direction, the maximum slip can be given by Equation 3 .

$$
\mathrm{s}_{\max }=\frac{\tau(\mathrm{du} / \mathrm{dx})}{1+\tau(\mathrm{du} / \mathrm{dx})}
$$

The regions of highest acceleration occur where the quarl expands or where combustion begins. If deceleration in the quarl region for the cold flow experiment is assumed to decelerate uniformly as a function of the area expansion, the slip for various sized particles can be predicted. The measured deceleration, as taken from LDA measurements, in the primary region can also be used to predict slip. Likewise, velocity acceleration prediction, from combustion models at several locations in the hot flame, can be used to predict particle slip. Table 4.1 summarizes the results with coal particles of various sizes using measured velocity decelerations.

The slip of the largest particles greatly over predicts the actual slip seen by LDA as the majority of measured particles will be small because of the size distribution as already noted. Note that beneath the quarl exit, the errors of velocity slip are minimal. It should be emphasized that this is only a theoretical result for a uniform flow-field. The actual interactions in the flame at a particular location might be quite different and are difficult to predict (Abbott, 1989). 
Table 4.1 Summary of particle slip results for various locations in the CPR.

\begin{tabular}{|lcccc|}
\hline Location & $\begin{array}{c}\mathrm{du} / \mathrm{dx} \\
(1 / \mathrm{sec})\end{array}$ & $50 \mu \mathrm{m}$ & $20 \mu \mathrm{m}$ & $10 \mu \mathrm{m}$ \\
\hline \hline $\begin{array}{l}\text { Secondary Air Inlet, } \\
\text { Boundary Condition }\end{array}$ & 220 & 0.121 & 0.022 & 0.005 \\
\hline $\begin{array}{l}\text { Measured Deceleration In } \\
\text { Primary }\end{array}$ & 1200 & 0.429 & 0.107 & 0.029 \\
\hline $\begin{array}{l}\text { Centerline Acceleration at } 0 \\
\text { Swirl }\end{array}$ & 80 & 0.048 & 0.008 & 0.002 \\
\hline $\begin{array}{l}\text { Quarl Exit at 1.5 Swirl } \\
\text { Thermal Expansion }\end{array}$ & 100 & 0.059 & 0.01 & 0.002 \\
\hline Acceleration & 300 & 0.158 & 0.029 & 0.007 \\
\hline
\end{tabular}

\subsection{Non Reacting, Inlet Results}

Figure 4.4 shows average axial velocities measured at $5 \mathrm{~mm}$ below the exit of the primary inlet. The axial velocity profiles indicate that as swirl is increased the flow tends to be directed more toward the outer wall of the secondary exit with a transition occurring in the flow between 0.5 and 0.75 swirl. This tendency is typical for annular swirled flows as observed by Gupta et al. (1984). At the highest swirl, 1.5, the axial velocity direction actually reverses near the primary wall, forming a recirculation zone along the annulus, even though the measurement is taken only $5 \mathrm{~mm}$ below the primary inlet. The data of Weber et al. (1992) at 0.92 swirl show similar results to the 1.5 theoretical or 0.87 measured swirl data. Weber's data show a negative velocity of approximately $-4 \mathrm{~m} / \mathrm{s}$ at the center that increases to approximately $22 \mathrm{~m} / \mathrm{s}$ while this project's data at a slightly lower swirl are approximately $-2 \mathrm{~m} / \mathrm{s}$ near the centerline and increases to $17 \mathrm{~m} / \mathrm{s}$ near the quarl wall.

The negative velocities at the fuel inlet preclude this data set from being used as a boundary condition for most modeling programs. The data suggest that modeling boundaries conditions must be placed further upstream. The data may be used to verify the selection of boundary conditions by comparison with modeled and measured data prior to combustion. Other researchers have also shown that injection nozzles that precede an area expansion may have a recirculation zone extend into the nozzle itself (Syred et al., 1971). To validate the accuracy of the measurements, the velocity profiles were integrated to determine the total mass flux for each swirl condition. The results showed the integrated mass flow agreed with the average mass flow rate to within $\pm 3 \%$. 

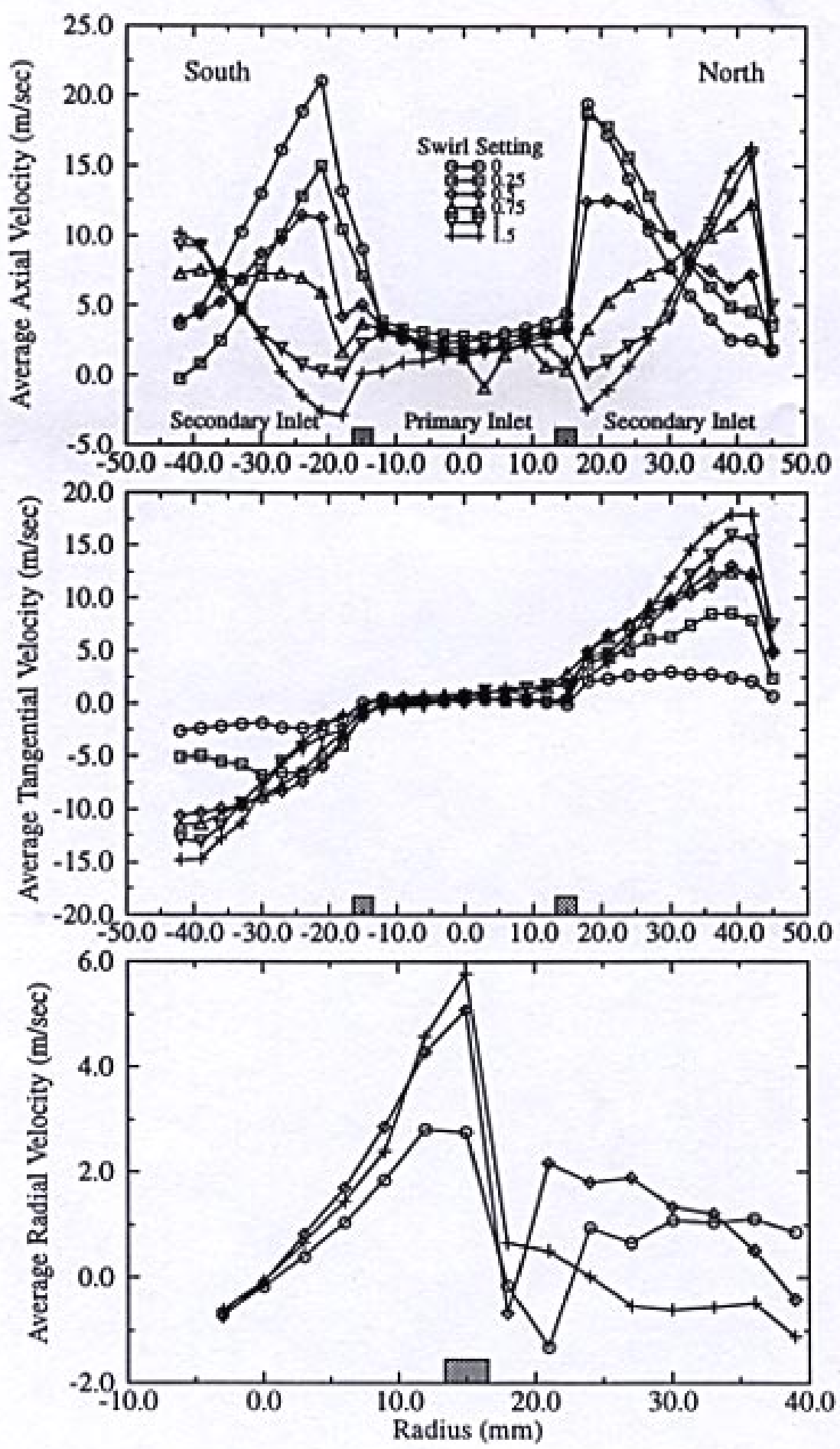

Figure 4.4 Average axial, tangential and radial velocities $5 \mathrm{~mm}$ below the primary fuel inlet tube. 
Tangential velocity measurements show, as expected, an increase in tangential velocity as the swirl increased. The tangential velocity profile in the secondary stream formed a forced vortex flow field. The figure shows that as swirl in the secondary jet increased the primary jet also gained a tangential component.

A positive radial velocity in Figure 4.4 indicates flow from the center out towards the wall. Radial velocity measurements at $0,0.5$, and 1.5 theoretical swirl show that radial velocities are relatively weak along the secondary air stream channel for all three swirl settings, when compared to the axial and tangential velocities which have magnitudes approaching $20 \mathrm{~m} / \mathrm{sec}$. Radial velocities in the primary region show a strong pull towards the edge of the primary tube indicating a strong pressure gradient between the primary and the secondary streams. As a result, the axial velocities in the primary stream are also rapidly reduced, falling from an average velocity of $8 \mathrm{~m} / \mathrm{s}$ to just $2 \mathrm{~m} / \mathrm{s}$ after in the $5 \mathrm{~mm}$ distance from the fuel inlet.

The velocity flow field and transition in the flow field with increasing swirl had a direct effect on pollutant formation. Figure 4.5 shows $\mathrm{NO}_{\mathrm{x}}$ measurements in the effluent at various swirl numbers. The figure shows a significant decrease in $\mathrm{NO}_{\mathrm{x}}$ between 0.5 and 0.75 swirl which corresponds to the transition in the flow field measured at the boundary. The formation of $\mathrm{NO}_{\mathrm{x}}$ is explained by considering the interaction of the fuel as it exits the primary tube. Most of the $\mathrm{NO}_{\mathrm{x}}$ formed in coal flames comes from nitrogen which is already in the fuel. This fuel- $\mathrm{NO}_{\mathrm{x}}$ usually makes up $80 \%$ of the $\mathrm{NO}_{\mathrm{x}}$ formed in the flame (Pershing and Wendt, 1977). Fuel $\mathrm{NO}_{\mathrm{x}}$ is formed when nitrogen devolatilizes from the coal and readily combines with oxygen. At swirls from 0 to 0.5 , Figure 4.4 shows that the oxygen rich air jet is in close proximity to the fuel as the fuel exits the primary inlet. It is expected that the fuel mixes rapidly with oxygen, perhaps prior to combustion, creating a lifted flame and forming high levels of $\mathrm{NO}_{\mathrm{x}}$. As the flow transitions at 0.75 swirl, the fuel first mixes with recirculating burned gases, attaching the flame to the fuel inlet and burns under more fuel rich conditions. This allows devolatilization of nitrogen in a region of lower oxygen concentration resulting in lower $\mathrm{NO}_{\mathrm{x}}$ at the effluent. Smart and Weber (1989) discuss how these types of concepts form the basis for design of "low- $\mathrm{NO}_{\mathrm{x}}$ " burners that use nitrogen rich fuels. 


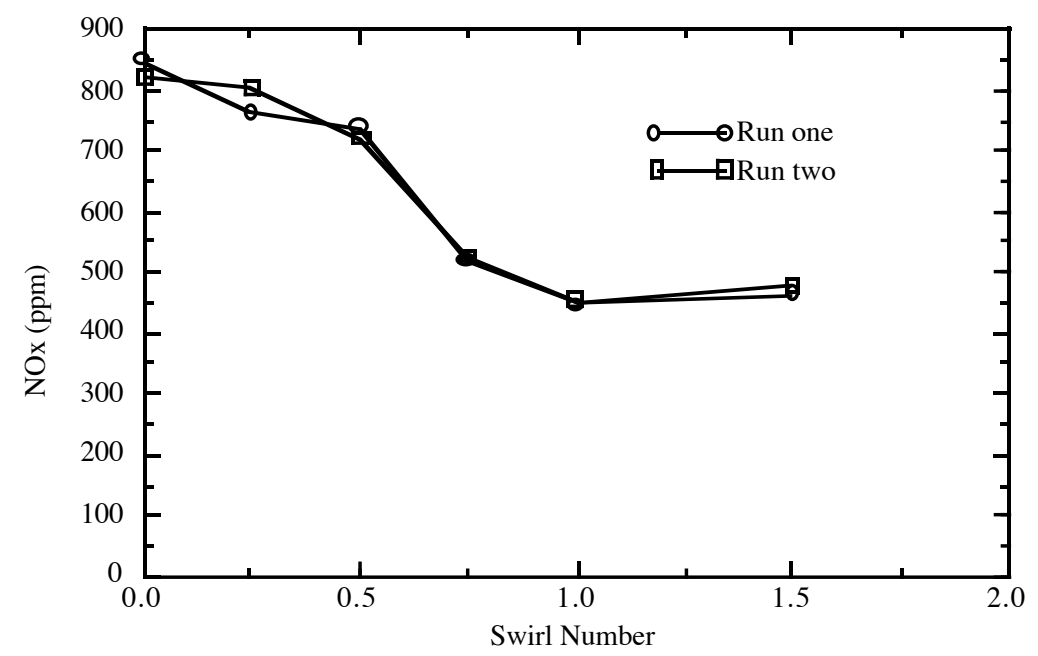

Figure 4.5 Effluent $\mathrm{NO}_{\mathrm{x}}$ measurements as a function of theoretical swirl.

All swirl numbers reported here were determined from theoretical calculations based on the geometry of the swirl generator and assumptions of flat velocity profiles and no dissipation losses. Pickett (1996) compared theoretical swirl with the measured swirl obtained from the LDA velocity data in Figure 4.4. The swirl calculated from the data used the mean and fluctuating velocity components but did not include the pressure term. The theoretical swirl was also compared with swirl calculated from measured tangential momentum using a honeycomb flow straightener. The results are shown in Table 4.2. The table shows that the actual swirl measured by LDA is considerably lower than the theoretical value. This is primarily because the axial profiles are not flat as assumed in theoretical calculations. Variations in the profile of the axial velocity increase the axial momentum flux relative to a flat profile, thus reducing the ratio of axial to tangential momentum flux. Swirl values obtained by measuring the tangential momentum with a flow straightener also do not account for axial profiles and therefore are closer to the theoretical values. Swirl is most often reported based on theoretical calculations or tangential momentum flux measurements alone. The LDA data point out the ambiguity of these swirl values which are commonly used because velocity data are not available. In addition to large differences between theoretical and actual swirl, Sloan et al. (1986) points out that vastly different velocity profiles may have identical swirl number yet produce different flow fields.

Table 4.2 Comparison of theoretical and measured swirl values.

\begin{tabular}{|lcccc|}
\hline Theoretical Swirl & 0 & 0.5 & 1.0 & 1.5 \\
\hline Swirl From Flow Straightener & 0 & 0.45 & 1.20 & 1.45 \\
\hline Swirl Calculated From Velocity & 0.1 & 0.36 & 0.68 & 0.87 \\
\hline
\end{tabular}


RMS velocities of axial, tangential, and radial velocities are plotted in Figure 4.6. In all dimensions, it is clear that the RMS velocities are higher in the secondary air stream than the primary stream. The axial fluctuations in the secondary stream generally rise from 0 swirl, are maximum at 0.5 swirl, and then decrease successively to a minimum at 1.5 swirl. The 0.5 swirl case has high turbulence because it is the swirl where the flow transitions as depicted by the average axial profiles. The primary inlet region has minimum turbulence at 0 and 0.25 swirl.

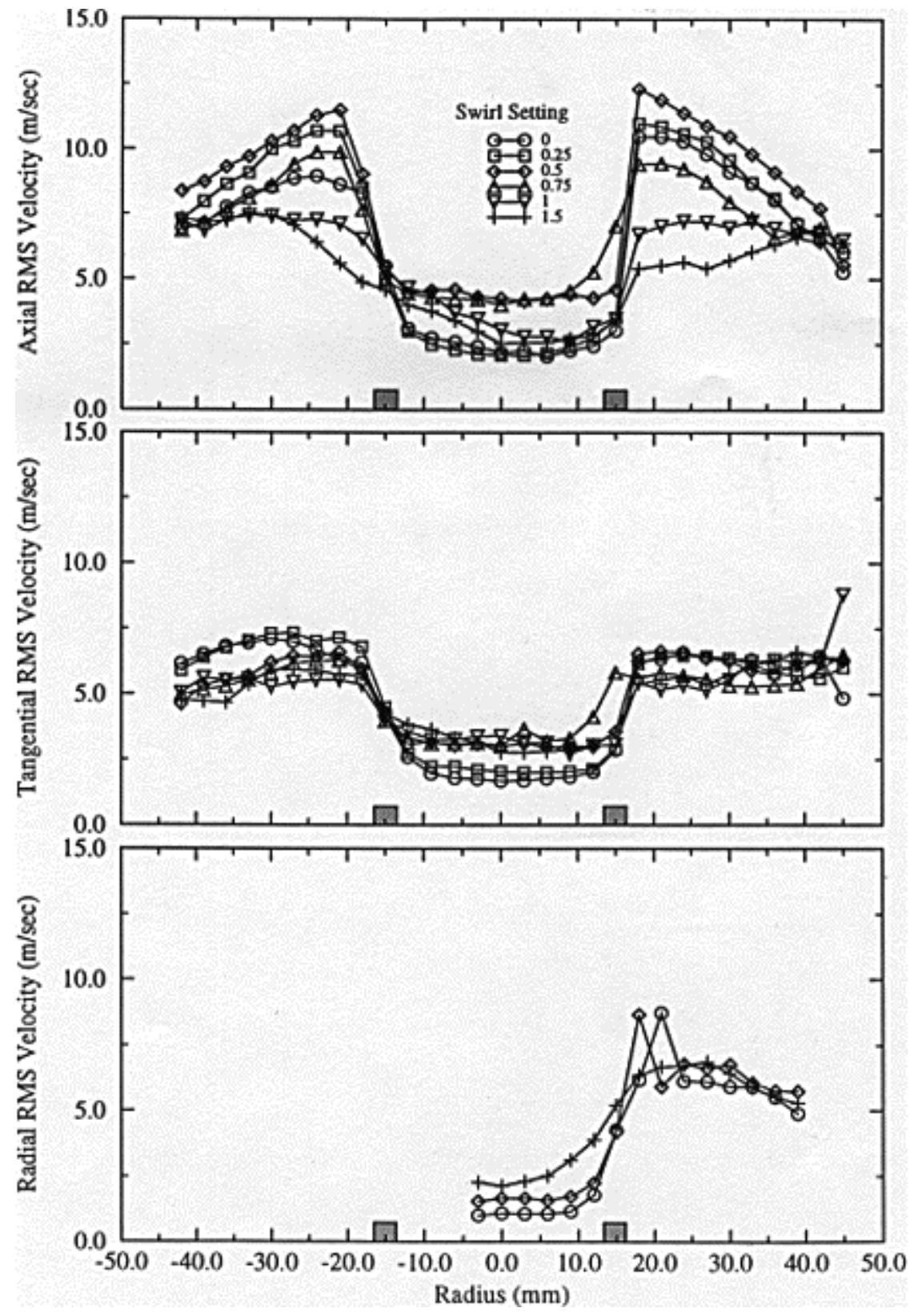

Figure 4.6 RMS axial, tangential and radial velocities $5 \mathrm{~mm}$ below the primary fuel inlet tube. 
Cold flow velocity data obtained throughout the quarl region and in the CPR are summarized by examining the general flow field as shown in Figure 4.7. The figure shows the formation of recirculating eddies directly below the primary inlet at 0 and 0.5 swirl and a central recirculation zone at 0.5 and 1.5 swirl below the quarl exit. Measurements inside the quarl would not have been possible in an actual flame because of optical access problems. Although the study was made in cold flow and without particles in the primary air stream, the information is expected to be useful in understanding the flame structure. Of particular interest are the secondary eddies that develop below the primary inlet and the high turbulence levels. The eddies and turbulence have significant effects on the mixing of the fuel and air streams and may be difficult to predict with computer models. Tabular data for these results as well as the coal flame results are available on disk by request.

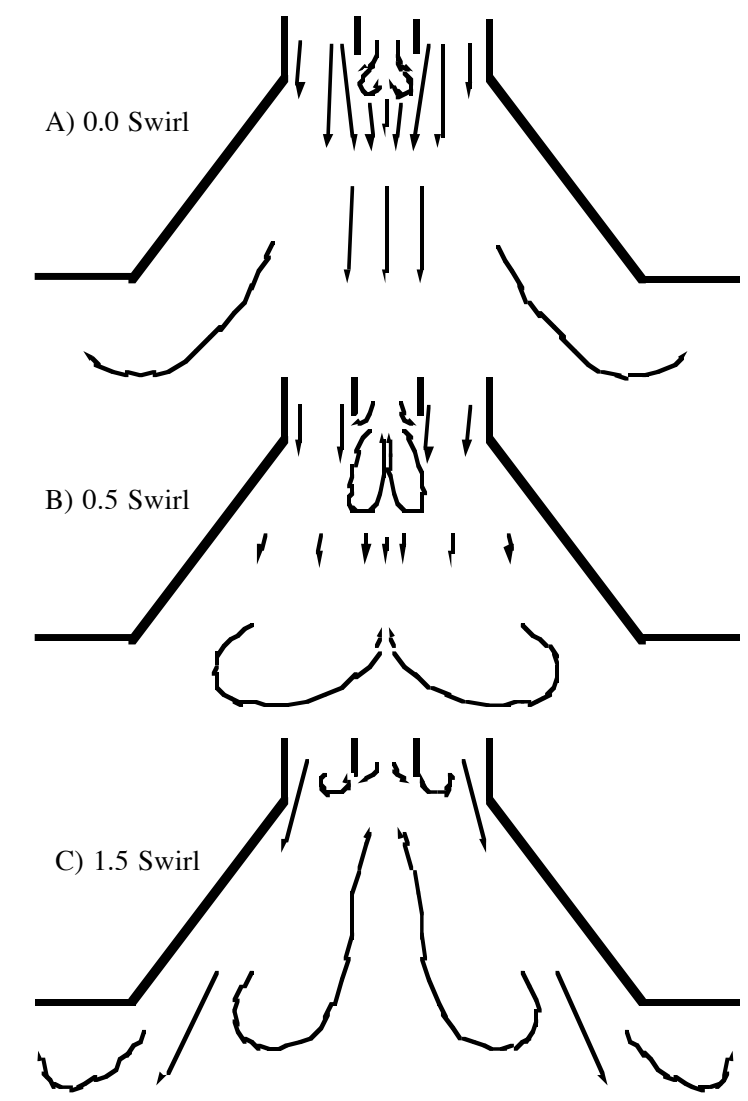

Figure 4.7 Velocity vector diagrams for three swirls in the quarl region based on detailed LDA measurements.

\subsection{Coal Flame Velocity Results}

The velocity profiles for reacting flow showed similar trends and patterns as were observed in cold flow experiments. The results for average and RMS axial and tangential velocities are presented in Figures 4.8 - 4.10 for swirls of $0.0,0.5$, and 1.5 respectively. Data acquisition was the most difficult at the top axial location at 0 and 0.5 swirl, while the bottom location was the easiest. High particle loading and flame intensity in the top central 
regions reduced the accepted data rate of the LDA signal. On the lower level, the visibility into the reactor was optically clearer and there was still enough ash to use as seed particles to make measurements across the entire reactor. At times, the scattered signal from the vertically-oriented blue beam seemed to be weak, while the green signal remained strong. This was thought to be caused by density gradients along the vertical axis which shifted the blue crossing. The symmetry of the reactor, on the other hand, gave equal gradients for the horizontally-oriented green beam, retaining proper beam crossing. In general, data acquisition rates near the wall would start out high at several hundred $\mathrm{Hz}$, but might drop to only $10 \mathrm{~Hz}$ (worst case) in the middle. PDF's of the velocity data looked normally distributed with no indication of particle bias.

Figure 4.8 shows that the 0 swirl case average axial profiles maintain a centerline jet penetrating downwards along the centerline of the reactor. The maximum velocity is 8 $\mathrm{m} / \mathrm{sec}$ at the $39 \mathrm{~cm}$ location. The 0 swirl case is not stable in maintaining exact centerline penetration at distant axial locations. Data obtained with a modified pitot tube repeatedly showed a slight shift opposite the LDA profile data. Unfortunately, due to focal length and optical access difficulties, LDA measurements past the centerline could not be made to investigate this potential asymmetry. Average tangential velocities are near zero, as expected for low swirl.

Axial and tangential RMS profiles at 0 swirl show high velocities along the same locations as the average velocity peaks. This trend was also observed in cold flow measurements and could indicate that the energy of the average flow field is being converted to turbulence. An unsteady flame arrival would also tend to cause large variations along the same location as average velocity peaks. The axial velocity fluctuation is slightly greater than the tangential fluctuation. However, compared to the average velocities the tangential fluctuation is more significant because average tangential velocities are close to zero. This may indicate that the turbulence is mostly caused by flame arrival, as fluctuations in the fuel arrival are propagated to directional fluctuations in both the axial and tangential directions.

Figures 4.9 and 4.10 show that the 0.5 and 1.5 swirl cases are characterized by a central recirculation zone. The 0.5 swirl central recirculation zone is fairly weak compared to the 1.5 swirl case. The tangential velocities at 1.5 swirl are also much stronger (note that the scale on the tangential velocities goes to $10 \mathrm{~m} / \mathrm{s}$ for $1.5 \mathrm{swirl}$ ). Though axial velocity data were not obtained at $65 \mathrm{~cm}$ for $0.5 \mathrm{swirl}$, the weak central recirculation zone at 0.5 swirl at the $39 \mathrm{~cm}$ location is an indication that the recirculation zone has almost ended. At 1.5 swirl a central recirculation zone was measured at $65 \mathrm{~cm}$. The smaller central recirculation zone at low swirl is typical for swirled flows where, in general, the length of the central recirculation zone tends to increase as swirl is increased (Beer and Chigier, 1972). 


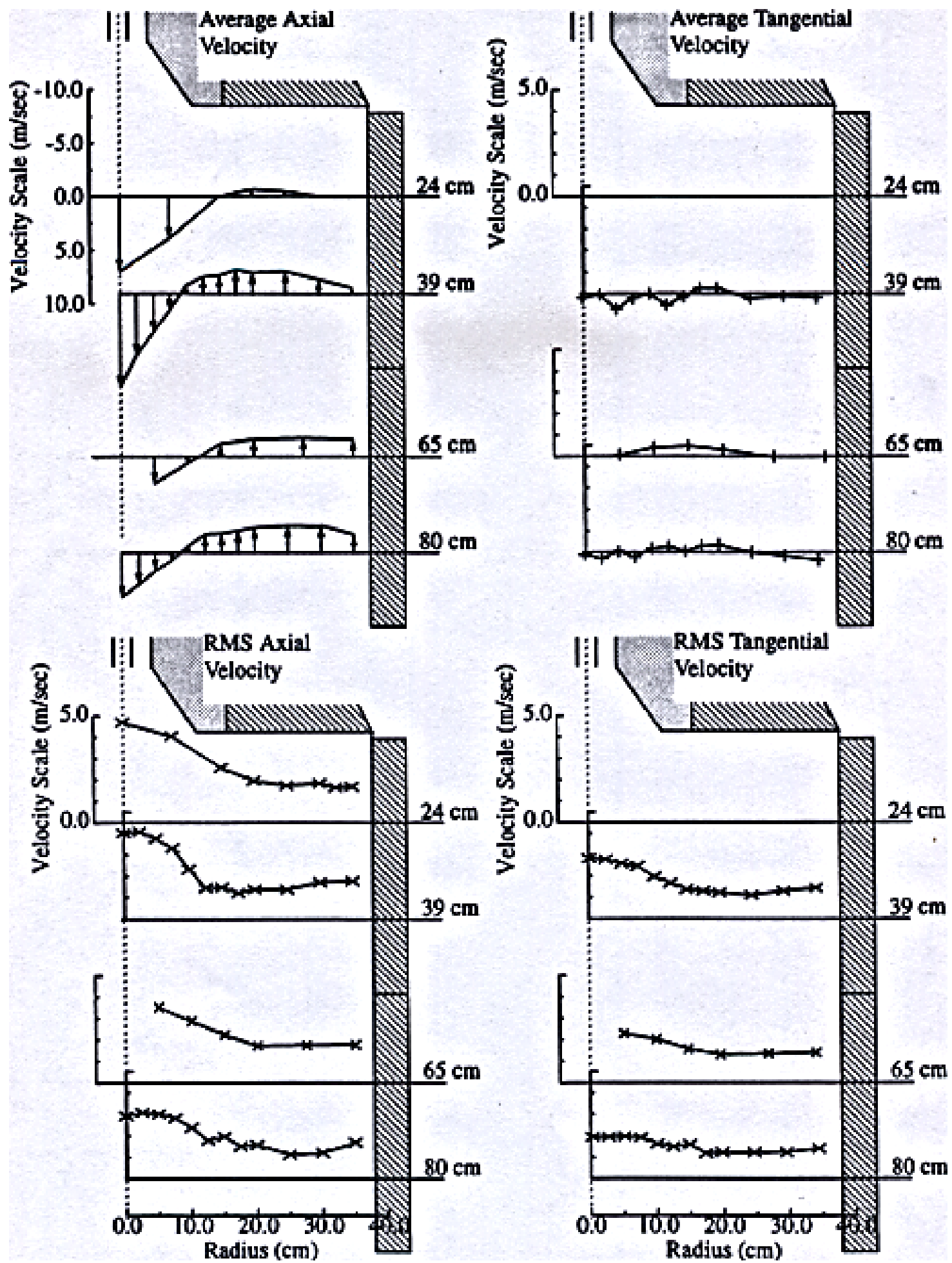

Figure 4.8 Axial and Tangential mean and RMS velocities for three axial locations in the top two sections of the reactor at 0 theoretical swirl. 

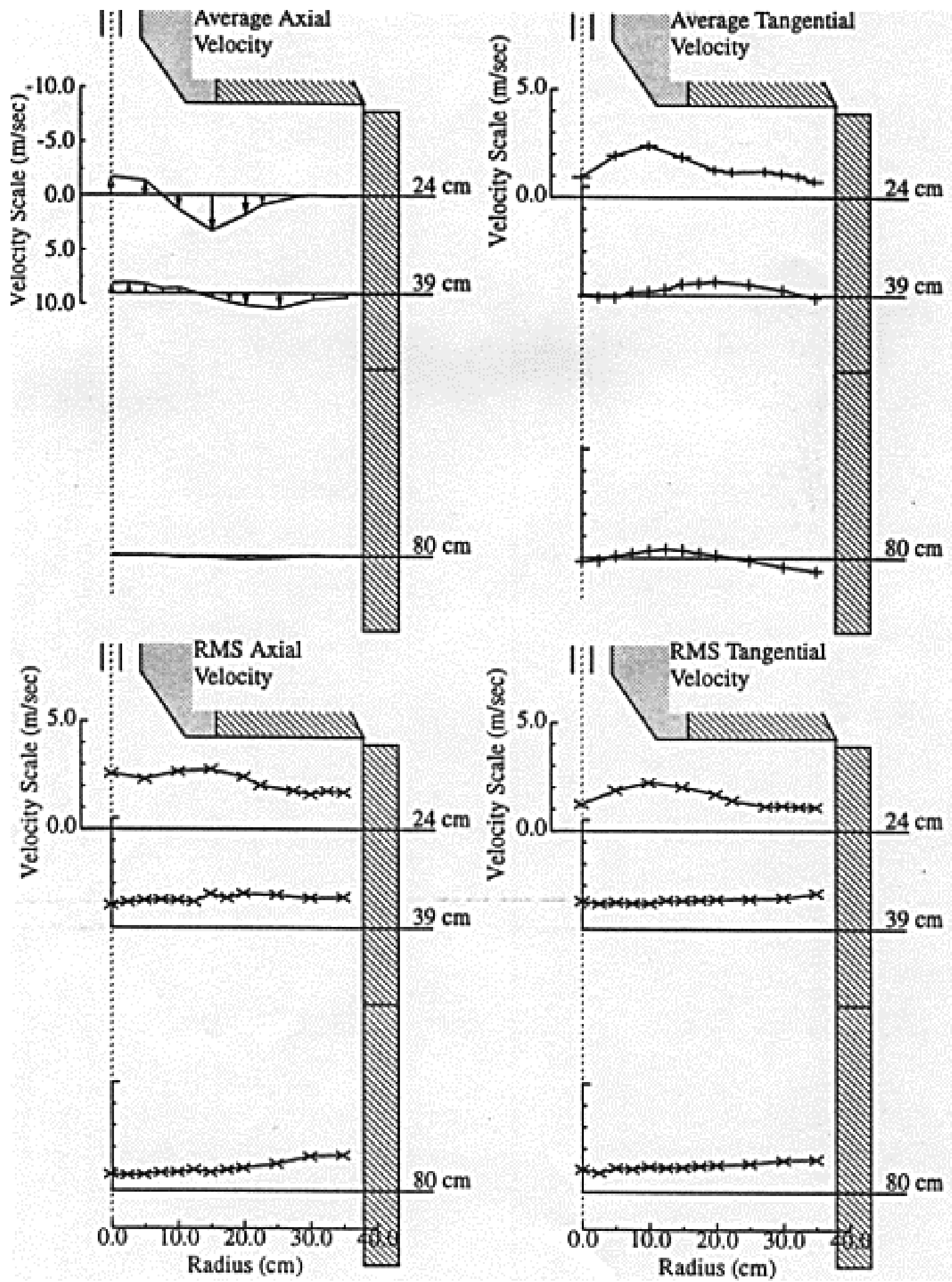

Figure 4.9 Axial and Tangential mean and RMS velocities for three axial locations in the top two sections of the reactor at 0.5 theoretical swirl. 


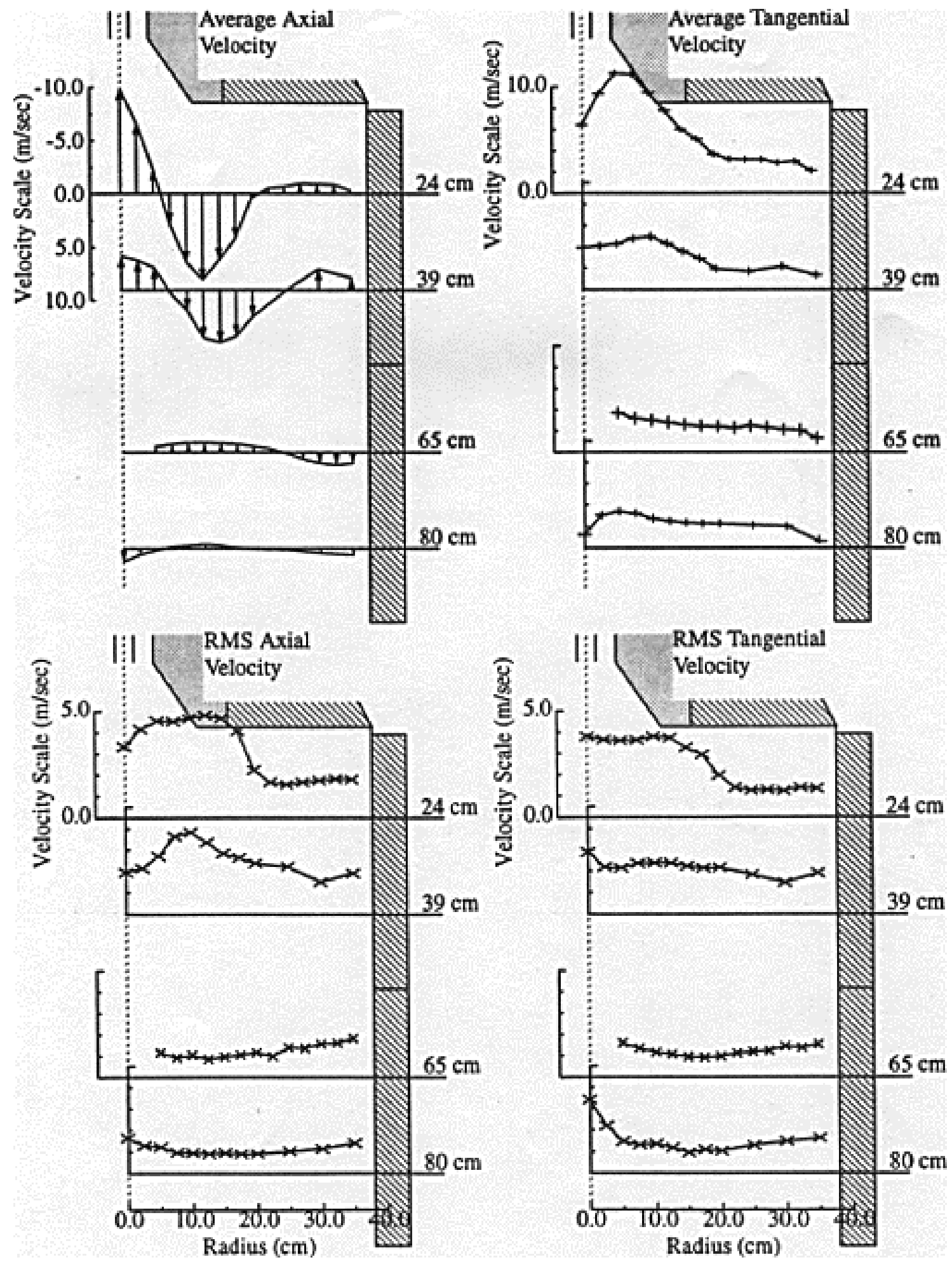

Figure 4.10 Axial and Tangential mean and RMS velocities for three axial locations in the top two sections of the reactor at 1.5 theoretical swirl. 
Average tangential velocities show peak measurements at the location between positive and negative axial velocities. This is typical of free vortex fluid motion where the highest tangential velocities are found at the funnel of the vortex. Sloan et al. (1986) has also shown that the inner recirculating vortex core will behave more like a forced vortex. This is also observed in Figures 4.9 and 4.10 where tangential velocities increase from the center to the peak where the free vortex begins. Cold flow data taken at the boundary showed a forced vortex right after the swirl generator, but further downstream the flow naturally forms a free vortex. The tangential velocities tend to flatten at downstream axial locations.

RMS velocities at 0.5 and 1.5 swirl show peaks in both directions at similar radial positions. The peaks are also located in the same region as average velocity peaks. At 1.5 swirl on the top port, RMS velocities are high out to a radius of $20 \mathrm{~cm}$ which also corresponds to average velocity peaks and indicates high mixing and flame intensity in these regions. At the $39 \mathrm{~cm}$ location there is a peak axial RMS velocity at the shear layer between negative and positive axial flow, likely caused by the shifting of this shear layer. The turbulence does not change much from the $39 \mathrm{~cm}$ to $80 \mathrm{~cm}$ locations at 0.5 swirl. The 1.5 swirl case has a higher average velocity and a more distinct flow pattern at the $39 \mathrm{~cm}$ location. However, once flow is dissipated the RMS velocities at the bottom are similar in magnitude and follow the same trends as the 0.5 case. This shows that the turbulence is directly connected to higher average velocities and indicates that the RMS velocities are probably mostly due to the pulsating nature of the flame.

\subsubsection{Summary of Baseline LDA Results}

A two-color Laser Doppler Anemometer (LDA) has provided important axial and tangential gas velocity information in a $0.2 \mathrm{MW}$ pulverized coal flame. Velocity data of this type are rare in a pulverized coal flame. New data have been obtained detailing the structure of the coal flame at the different burner swirl settings, including recirculation zone formation and mixing level. This data is available for comparison with model predictions at each swirl setting, providing a more complete set of conditions over which the model can be tested.

The experiments have shown that LDA measurements using back-scattering can be obtained throughout a coal flame, even in regions of high density gradients and particle loading. A study comparing LDA measurements using coal as a seed particle in comparison to $1 \mu \mathrm{m}$ alumina particles showed that coal seeded LDA measurements accurately represented the gas phase velocity except in the immediate vicinity of the fuel inlet where deceleration ( $\mathrm{du} / \mathrm{dx}$ ) was approximately $1200 / \mathrm{s}$. The close agreement between the coal and gas phase velocities for the measured coal combustion data is believed to be caused by the high number of small coal particles causing a high probability that small particles are measured. In the reacting and quarl secondary air sections the coal seeded average velocity was measured to be within $7 \%$ of the gas phase velocity.

Together with coal flame velocity data, detailed boundary condition inlet plane information at six swirl settings has been obtained for use in computer modeling. The movable-block swirl generator was shown to induce flow that is highly turbulent and 
follows a forced vortex-like structure at high swirls. An important transition occurs in the flow field between 0.5 and 0.75 swirl. The axial velocity profiles show a shift in flow that is very near the primary inlet to a flow that is concentrated toward the outer wall of the secondary channel. This transition in the fluid dynamics as swirl is changed has a direct link to $\mathrm{NO}_{\mathrm{x}}$ production in the effluent with a significant reduction in $\mathrm{NO}_{\mathrm{x}}$ occurring as swirl is increased above 0.5 swirl.

\subsection{Species Profile Results}

Measurements for gas species were obtained in each of the six CPR sections at six radial locations. Testing of temperature profiles in each quadrant demonstrated the CPR to be reasonably axis-symmetric. Measurements were therefore obtained on only one side of the reactor. The measurements in the top section were made at two axial locations due to higher gradients in the vicinity of the burner. In viewing the species measurements it should be remembered that the sampling probe provides a time averaged measurement over a finite volume within a highly turbulent flame. The high turbulence makes an iso-kinetic probe impossible even though it was attempted to keep the mean velocities of the measured gases and incoming probe gasses as close as possible. This was, however, more problematic for the suction pyrometer temperature measurements as the velocity of the incoming gas was large in order to allow convective heat transfer to dominate and reduce radiation losses. The net result was an increase in the effective measurement volume and a time averaging of the species and temperature data. This reduced the probes ability to detect sharp gradients and smoothed maximum and minimum values.

\subsubsection{O Swirl}

Contour maps of $\mathrm{O}_{2}, \mathrm{NO}, \mathrm{CO}$ and $\mathrm{CO}_{2}$ profile measurements at 0 swirl are shown in Figure 4.11. The point data have been curve fit and interpolated to produce a two dimensional map which is shaded with a gray scale and overlaid with contour lines. The contour plots have been used to facilitate comparisons with modeling results. Tabular data can be obtained by request. Only the upper $160 \mathrm{~cm}$ of the reactor are shown and the data has been mirrored to better show the flame structure. The structure of a centerline jet seen in the velocity measurements is clearly visible in the species data. At the first axial location, $17 \mathrm{~cm}$ below the primary tube at the centerline, an oxygen concentration of $18.6 \%, \mathrm{CO}_{2}$ concentration of $2.7 \%$ and $\mathrm{CO}$ concentration of $800 \mathrm{ppm}$ suggest that secondary air has been entrained into the primary jet and the reaction rate is not yet mixing limited. This condition can lead to increased NO formation as fuel devolatilization under lean conditions. Moving down the centerline, oxygen was seen to decrease steadily, $\mathrm{CO}$ increased to a maximum at approximately $35 \mathrm{~cm}$ before decreasing and $\mathrm{CO}_{2}$ increased steadily. The progression of $\mathrm{O}_{2}$ to $\mathrm{CO}$ and then $\mathrm{CO}_{2}$ is seen along the path of the fuel as expected. $\mathrm{CO}$ levels peak at a relatively low value of $2000 \mathrm{ppm}(0.2 \%)$ compared to the other swirl measurements as will be seen below. Gradients in concentration are steeper in the radial direction suggesting that the flame is stabilized by recirculation of products back up to the top of the reactor around the periphery of the flame. 
The NO concentration increases initially but at a decreasing rate along the centerline until approximately $80 \mathrm{~cm}$ where it then levels off and increases only slightly reaching a peak at about $110 \mathrm{~cm}$. This correlates well with the location of the outer recirculation zone seen in the velocity data which was also found to penetrate to $80 \mathrm{~cm}$ after which the velocity profile was expected to be relatively flat. The $\mathrm{NO}$ appears to be created as fuel is burned as seen in the similarity in the contour plots of $\mathrm{CO}_{2}$ (completed fuel reaction) and NO. Note the peak concentration of NO is near $700 \mathrm{ppm}$ which is the same as that observed in the effluent.

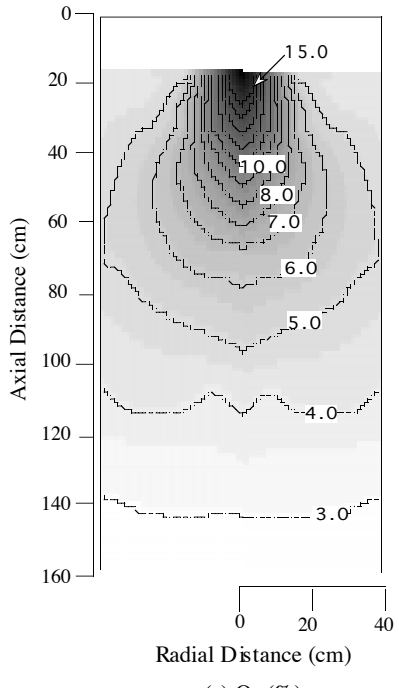

(a) $\mathrm{O}_{2}(\%)$

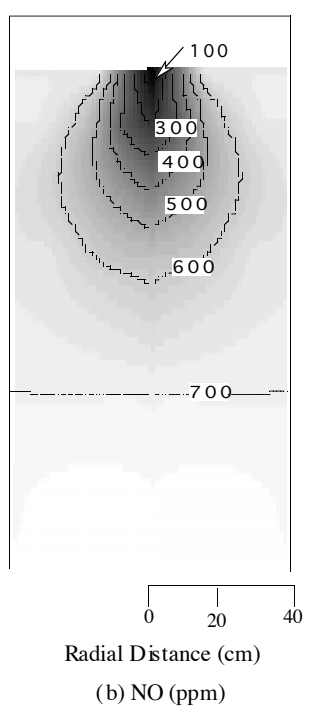

(b) $\mathrm{NO}$ (ppm)

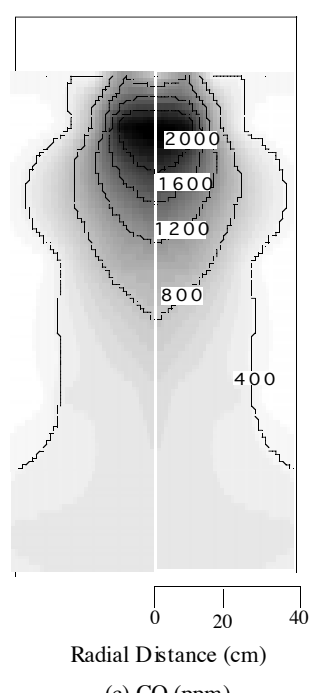

(c) $\mathrm{CO}(\mathrm{ppm})$

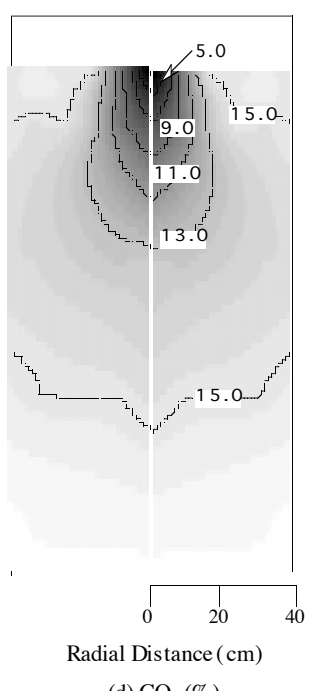

(d) $\mathrm{CO}_{2}(\%)$

Figure 4.11 Species maps for $\mathrm{O}_{2}, \mathrm{NO}, \mathrm{CO}$ and $\mathrm{CO}_{2}$ at 0 theoretical swirl.

\subsection{Swirl}

Species concentrations at 0.5 swirl are seen in Figure 4.12 and are plotted in the same format as the 0 swirl data. The species have changed dramatically from the 0 swirl case. The flame appears to be located closer to the quarl at the top of the reactor as the gradients are all steep near the quarl and become relatively flat after $60 \mathrm{~cm}$. The $\mathrm{O}_{2}$ and $\mathrm{CO}_{2}$ show evidence of a jet directed away from or split from the centerline. The $\mathrm{O}_{2}$ concentration on the centerline $17 \mathrm{~cm}$ below the primary tube is $17.9 \%$ but decreases to $2 \%$ at $32 \mathrm{~cm}$. This indicates a recirculation zone is stopping the flow of reactants, bringing combustion products back up the centerline as is also indicated by the $\mathrm{CO}$ which is at a maximum of $1.25 \%$ where the $\mathrm{O}_{2}$ is a minimum. The flame in this case appears to have moved up into and attached to the quarl. The NO forms rapidly, being relatively complete at the $32 \mathrm{~cm}$ axial location. The species suggest a highly mixed reactive area just below and perhaps into the quarl where devolatilization and combustion are rapid because both oxygen fed by the secondary air and high temperature created by recirculating products are present. 

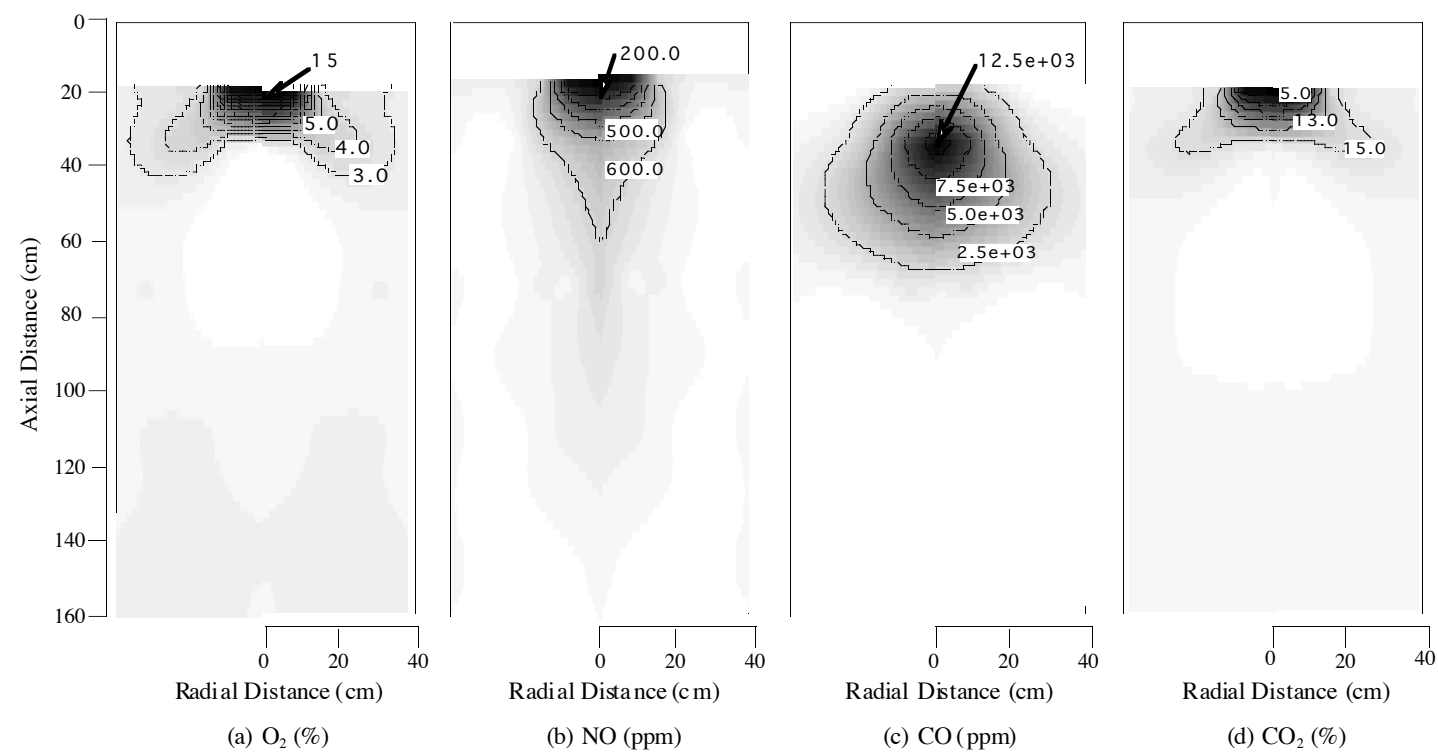

Figure 4.12 Species maps for $\mathrm{O}_{2}, \mathrm{NO}, \mathrm{CO}$ and $\mathrm{CO}_{2}$ at 0.5 theoretical swirl.

\subsection{Swirl}

In the contour plots it is immediately obvious that the species at 1.5 swirl shown in Figure 4.13 suggest a flow split away from the centerline and directed at an angle downward somewhat parallel to the angle of the quarl wall shown in Figure 3.1 The three dimensional flow is therefore spiraling downward creating an annular pocket of reacting gasses. This is again in good agreement with the measured velocity data and follows the expected trend of higher swirl producing a stronger recirculation zone. The trend of shortened combustion time does not however continue as the 1.5 swirl data has more gradual contour gradients and combustion does not appear complete until the $80 \mathrm{~cm}$ axial location. The $3 \% \mathrm{O}_{2}$ concentration penetrates twice as far axially down the reactor at 1.5 swirl ( $80 \mathrm{~cm}$ vs. 40$)$ as it did at 0.5 swirl. As with the other swirl cases, the species appear self consistent as they follow the expected trend of high $\mathrm{O}_{2}$ concentration followed down stream by $\mathrm{CO}$ then $\mathrm{CO}_{2}$.

As suggested by the velocity data, the $\mathrm{O}_{2}$ concentration shows the direction of the incoming secondary air jet moved inward, more toward the centerline, as the swirl increases. Note also that the $\mathrm{CO}$ concentration contours are split and the peak concentration is considerably lower $(0.35 \%$ vs. $1.25 \%)$ than the 0.5 swirl case. The fuel air mixture appears to be exiting the quarl and forming an inverted cone shape surrounded by products on both sides. The conical jet slows to plug flow velocities at approximately 80 $\mathrm{cm}$ where recirculation brings some products back up the centerline and others back up the walls and the remainder go down the reactor. The majority of the NO is shown to form within $40 \mathrm{~cm}$ of the quarl with a small pocket of higher concentration forming well downstream $(70 \mathrm{~cm}$ axial location) at the bottom of the recirculation zone. It appears that 
some of the NO was recirculated and reduced in the flame in order to produce the lower concentrations seen downstream, because unlike the 0 and 0.5 swirl cases, the NO decreased from the maximum seen at $90 \mathrm{~cm}$ when it was measured at lower axial locations.
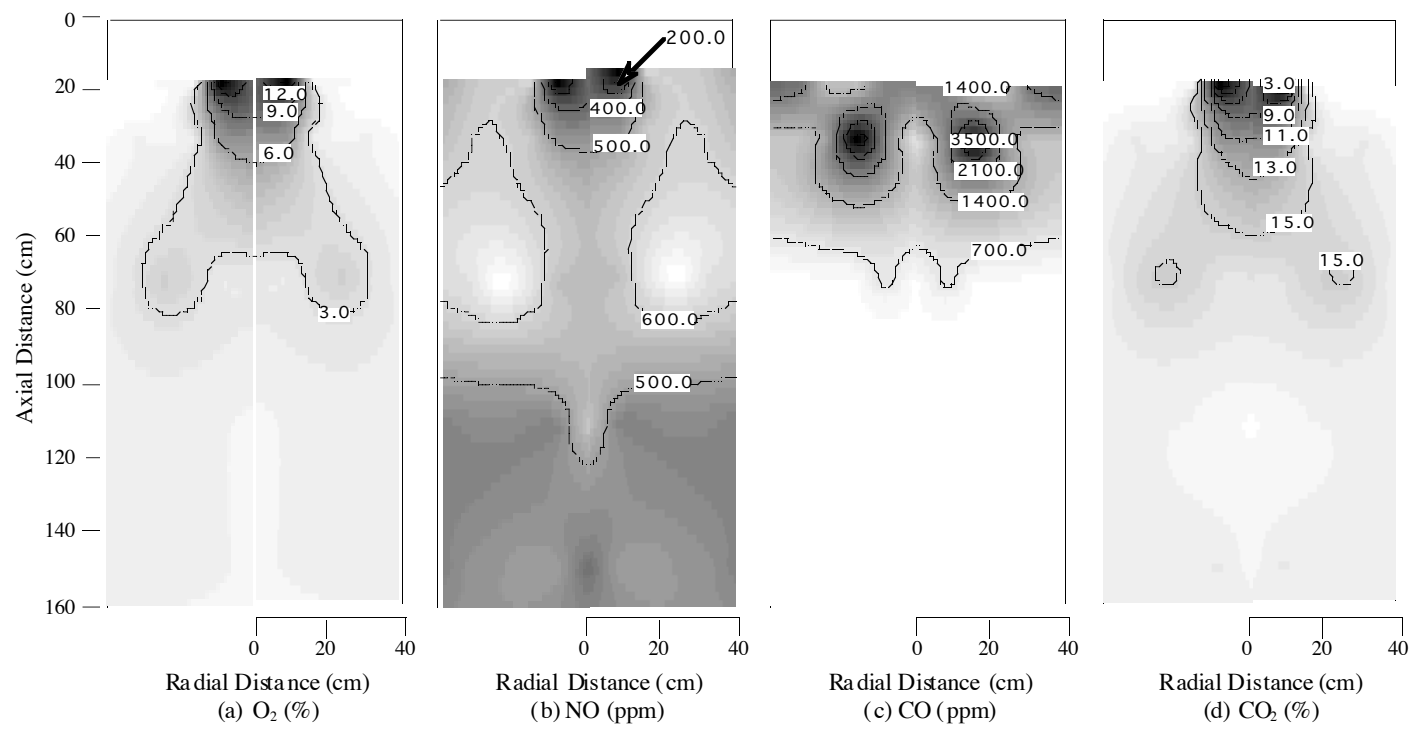

Figure 4.13 Species maps for $\mathrm{O}_{2}, \mathrm{NO}, \mathrm{CO}$ and $\mathrm{CO}_{2}$ at 1.5 theoretical swirl.

While the reason for NO reduction at high swirl is not obvious in these data, boundary condition velocity measurements at the primary tube outlet exit plane suggest an interesting explanation (Picket et al., 1998). At zero swirl, the secondary air was found to enter the quarl at a high axial velocity near the primary tube which would create a shear layer and mixing opportunity between the two jets of primary air and fuel and secondary air. As the swirl was increased, the secondary air was directed more toward the outer quarl wall which slowed the axial velocity in the middle at the primary tube. This would reduce mixing of the fuel and secondary air. Thus, the high swirl case pushes the secondary air in past the fuel and air, creating the recirculation zone without entraining as much fuel. The majority of the fuel remains in the quarl vicinity where it mixes with recirculating products before being drawn into the secondary air stream.

\subsection{Gas Temperature Profiles}

Contour maps of temperature measurements inside the CPR for various swirls are shown in Figure 4.14. Two observations apply to all three swirls. First, the peak temperatures are somewhat low, $1500-1600 \mathrm{~K}$, in comparison to larger scale reactors or boilers. Even though the secondary air was heated to $585 \mathrm{~K}$, the water cooled quarl may extract a large amount of heat from the flame. The coal was also not dried and contained a high amount of moisture (23.7\%). Additionally, the surface area to volume ratio of the flame and the sampling volume of the pyrometer to total flame volume are both large in comparison to full scale boiler flames. The former increases the impact of heat transfer on 
the temperature and the latter increases the spatial averaging effects of the probe. The second observation is that the contours show low temperatures near the access ports. This is due to induction of room air into the probe at wall measurement locations.

The temperature data are for the most part consistent with the species and velocity data. The 0 swirl case shows a large high temperature peak at the centerline where combustion is complete. Reactants flowing vertically down the reactor at zero swirl increase in temperature rapidly as they react and then more slowly as perhaps char combustion is completed. After reacting, temperature decreases gradually due to heat transfer to the walls. At 0.5 swirl the temperature profiles are split as seen in the species data. The highest temperatures appear to be outside of the secondary air jet where reactants meet the recirculating hot products. Note that the temperatures closest to the quarl are very high at 0.5 swirl indicating reactions in the quarl while at 1.5 swirl, the temperatures are lower at the centerline, supporting the idea that the 1.5 swirl case allows the air to penetrate through the reaction zone and not mix as readily with the fuel as is the case at 0.5 swirl.

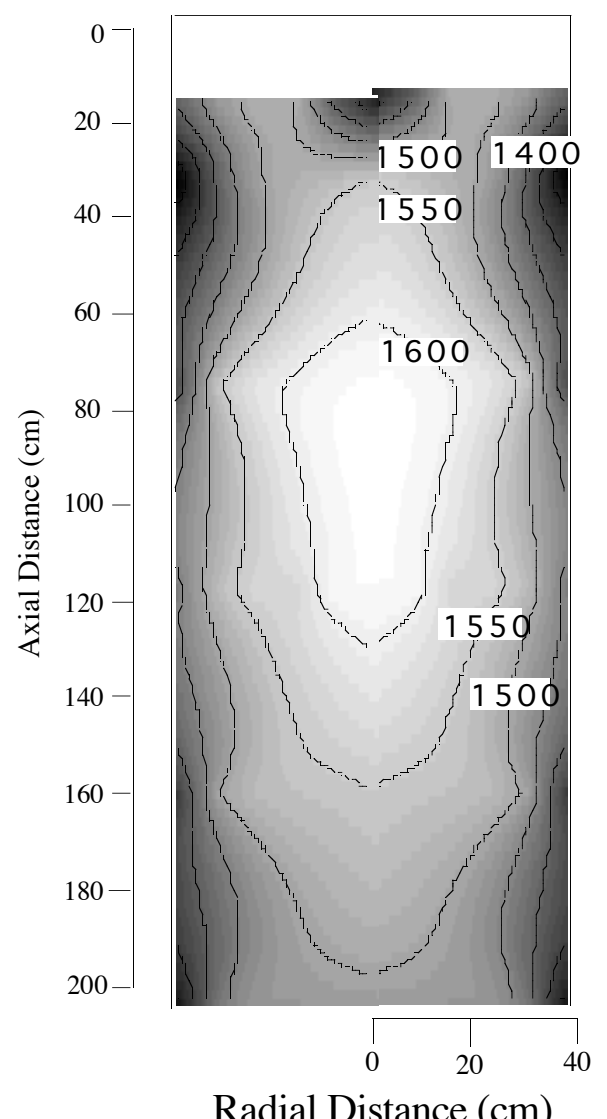

(a) O Swirl

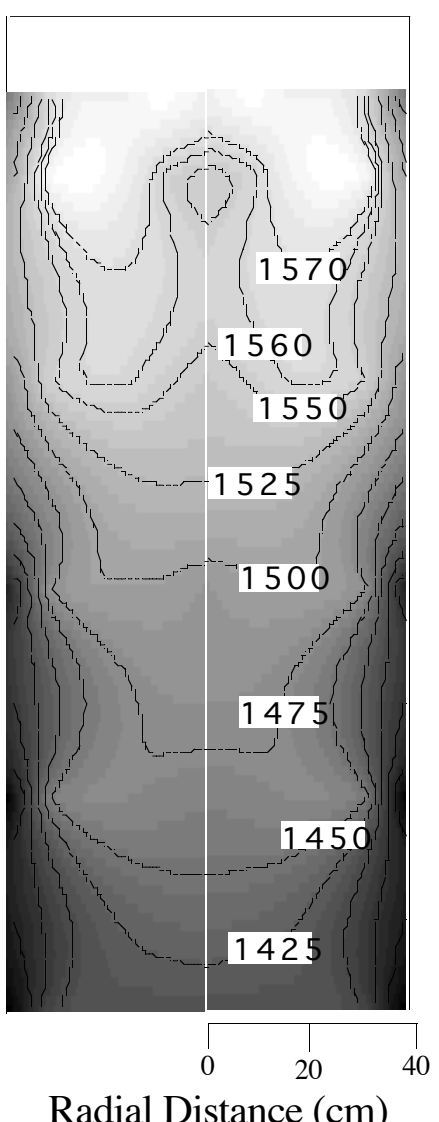

(b) 0.5 Swirl

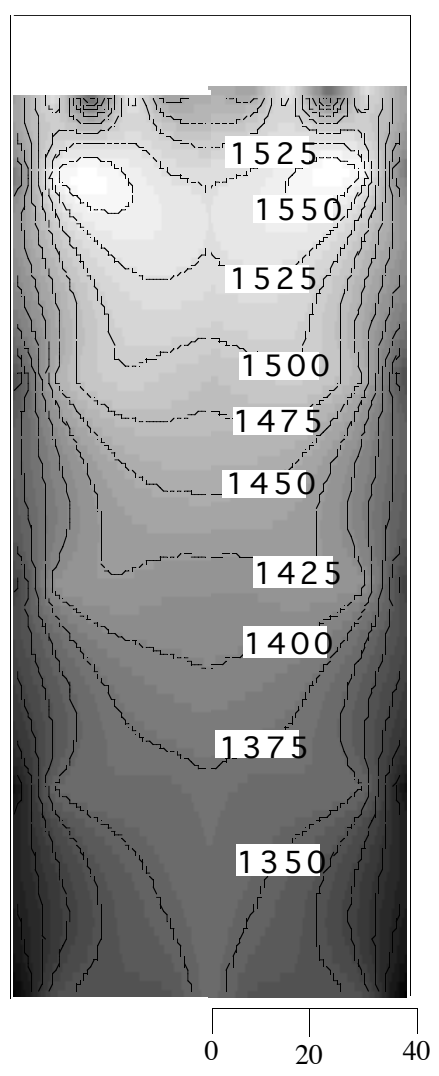

Radial Distance (cm)

(c) $1.5 \mathrm{Swirl}$

Figure 4.14 Temperature contours for each theoretical swirl in degrees K. 


\subsection{Baseline Species Measurement Conclusions}

Gas species and temperature data have been obtained in a pulverized coal reactor. The species studied were $\mathrm{O}_{2}, \mathrm{CO}_{2}, \mathrm{NO}$, and $\mathrm{CO}$ for three different secondary air swirl settings. Data at 0 swirl showed species and temperature gradients that extended along the center of the reactor. With an increase in swirl, the high gradient region moved up and broadened radially. The peak temperature at just above $1600 \mathrm{~K}$ was almost the same for lower swirl numbers and dropped to $1572 \mathrm{~K}$ at 1.5 swirl. 0 swirl also produced peak nitrogen oxide (NO) of $740 \mathrm{ppm}$ due to coal devolatilization taking place in a vicinity of oxygen rich environment. NO showed a considerable drop at 1.5 swirl due to coal devolatilization being carried in recirculated product gases containing less oxygen. This type of flame behavior can be extremely helpful in designing low- $\mathrm{NO}_{\mathbf{X}}$ burners where coal devolatilization is initiated in an oxygen lean environment and additional air is supplied around the outer fringes of the flame to complete the combustion. This completed data set provides an opportunity to test models which attempt to capture the affect of swirl on combustion and NO formation.

\section{REBURNING OPERATING CONDITIONS AND RESULTS}

\subsection{Measurement Conditions}

The CPR was operated at an overall stoichiometric ratio of 1.1 during species, temperature, and solid sample measurements. Table 5.1 shows the target operating conditions of the reactor which were held constant during all the tests. For the reburning map, the tertiary air added was enough to maintain an overall stoichiometric ratio of 1.1 . Reactor pressure was maintained just above atmospheric pressure $(86 \mathrm{kPa})$ during sampling to avoid ambient air entering the reactor through open ports. The coal used was a Wyodak, sub-bituminous, low sulfur coal. The weight percentages of individual components on an as-received basis found by proximate and ultimate analyses were the same as that of the baseline data given in Table 5.2.

Table 5.1 CPR Operating Conditions at an overall Stoichiometric Ratio of 1.1.

\begin{tabular}{|l|c|c|}
\hline Description & Flow Rate $(\mathrm{kg} / \mathrm{hr})$ & Temperature $(\mathrm{K})$ \\
\hline Secondary Air & 175.5 & 585 \\
\hline Primary Air & 15.6 & 310 \\
\hline Coal & 23.6 & 310 \\
\hline Reactor Walls & - & 1275 \\
\hline Water-cooled Quarl & - & 300 \\
\hline
\end{tabular}


Table 5.2 Wyodak Subbituminous Coal Composition

\begin{tabular}{|c|c|c|c|c|}
\hline \multicolumn{5}{|c|}{ Proximate Analysis, $\%$ by Mass } \\
\hline Moisture & Ash & Fixed Carbon & Volatiles & $\mathrm{LHV}(\mathrm{kJ} / \mathrm{kg})$ \\
\hline 23.7 & 4.7 & 51.2 (daf) & 48.8 (daf) & 20,900 \\
\hline \multicolumn{5}{|c|}{ Ultimate Analysis, $\%$ by Mass (as received) } \\
\hline Carbon & Hydrogen & Nitrogen & Oxygen (by difference) & Sulfur \\
\hline 55.8 & 3.6 & 1.0 & 10.8 & 0.4 \\
\hline
\end{tabular}

\subsection{Reburning Results and Discussion}

\subsubsection{Effluent Measurements}

Natural gas reburning in the CPR was studied for a range of reburning zone equivalence ratios, residence times, and injector opening pintle positions. The objective of these studies was to determine an appropriate position for reburning and tertiary air injection which could be used to obtain a data map. It was also of interest to investigate the effectiveness of reburning fuel injected into the NO formation region of the flame in comparison to typical downstream injection.

The reburning NO effluent data were compared to baseline NO emissions on a percent reduction in NO flux basis. This was done in order to determine if concentration decreases were the result of dilution or chemical NO reduction. There appear to be three other methods common for reporting reburning results in the literature. The first compares measured NO concentration but fails to take dilution effects into account. The second is to normalize the $\mathrm{NO}$ concentration to a standard $\mathrm{O}_{2}$ percentage and then report the change in $\mathrm{NO}$ as a percentage difference of the original value. This accounts for dilution of $\mathrm{O}_{2}$ but not of the gaseous fuel products. The third method reports NO normalized by the heating value of the fuel. A drop in $\mathrm{NO}$ can be realized when using this value if the second fuel (in our case, natural gas) produces less NO than the coal even though no reburning is accomplished. Each method of reporting has its advantages and disadvantages. The method selected here allows a determination of percentage change in NO flux which allows a better focus on changes due to the reburning process alone. The profile data to be reported later will be given as concentrations to allow comparison with modeling results.

Reburning zone equivalence ratio and residence time were investigated by placing the reburning fuel injector in location C (see Fig. 1) and varying the fuel flow rate while moving the tertiary air to locations D through G. The results are shown in Figure 5.1. At each tertiary air location, the results show an increase in reburning fuel improves NO reduction. A maximum NO reduction of approximately $70 \%$ occurred regardless of where the tertiary air was located as long as it was below port E ( $40 \mathrm{~cm}$ downstream of the reburning fuel). 
Assuming plug flow for the reactor, this would be a residence time of approximately 700 ms. Poor reduction was found when the tertiary air was located within $20 \mathrm{~cm}$ of the reburning fuel, and residence time appeared to become more important when the reburning zone stoichiometric ratio was higher.

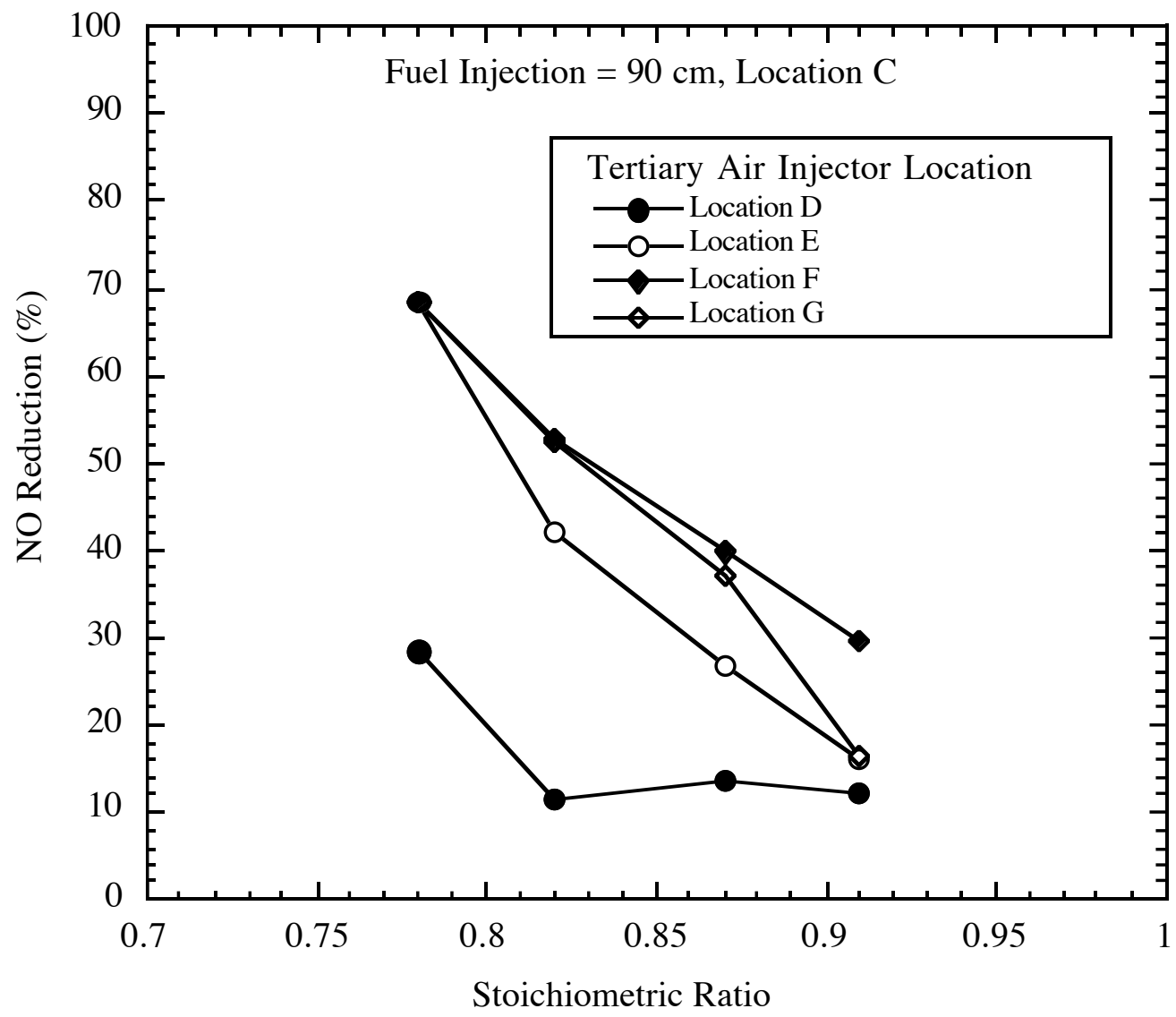

Figure 5.1 NO reduction as a function of reburning zone stoichiometric ratio and tertiary air location with reburning fuel injection at $90 \mathrm{~cm}$.

Additional investigations of reburning zone stoichiometric ratio, discussed in Nazeer et al. (1999), confirmed that additional increases in reburning fuel did not increase NO reduction and even resulted in slight decreases. This is consistent with the work of Kircherer et al. (1994), Chen et al. (1986), and Marquez et al. (1995).

NO reduction was measured at two additional locations, A and D. Results with fuel injection in D were similar to location $\mathrm{C}$ with a slightly lower NO reduction. Results with the fuel injection at location $\mathrm{A}$ are shown in Figure 5.2. As in the previous figure, the tertiary air location and stoichiometric ratio were varied at this fuel location. At this 
location, the fuel was injected into a region where NO formation was found to be incomplete in the baseline measurements (Nazeer et al., 1999). Solid sample analysis data, discussed later, shows that at this location burnout was $95 \%$ complete in the baseline case. At this location, the NO reduction follows the same trend with stoichiometric ratio as in all other locations but the magnitude of the NO reductions is smaller. In the case were the tertiary air was located in location B, $20 \mathrm{~cm}$ below the natural gas, the higher reburning zone stoichiometric ratio data points resulted in increased NO. This is not surprising as the air was located too close to the reburning fuel and the primary combustion zone. This would be expected to enhance the availability of $\mathrm{O}_{2}$ in the primary combustion zone, causing increased NO formation during devolatilization and eliminating a fuel rich zone for reburning. Figure 5.2 also demonstrates that as reburning zone residence time is increased as represented by tertiary air locations $\mathrm{C}$ and $\mathrm{D}, \mathrm{NO}$ reduction reaches a maximum beyond which additional increases in residence time do not provide further NO reduction.

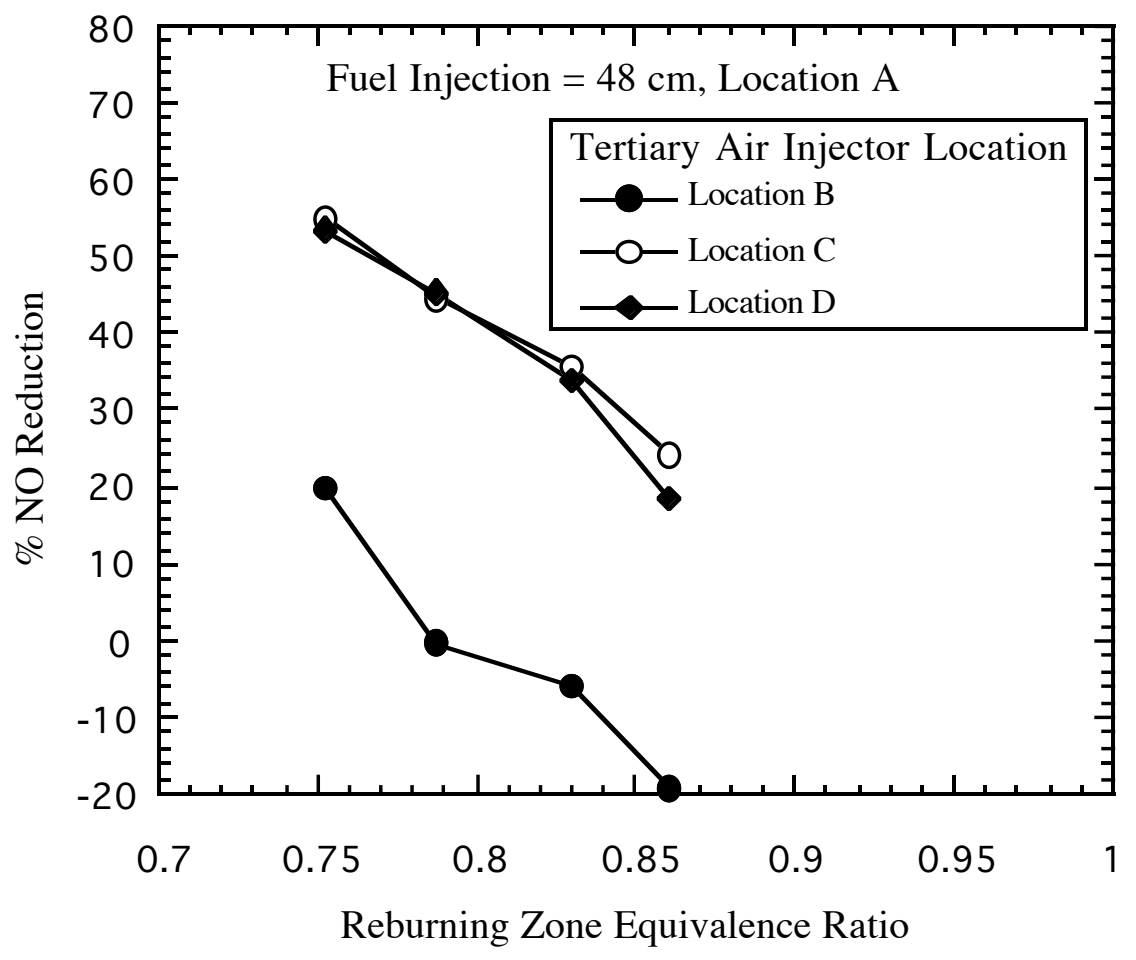

Figure 5.2 NO reduction as a function of reburning zone stoichiometric ratio and tertiary air location with reburning fuel injection at $48 \mathrm{~cm}$.

The magnitude of NO reduction was found to be greatest when the reburning fuel was located immediately downstream of the primary NO formation region or directed at the location where NO concentration was highest. In this coal flame, two dimensional mapping 
of the NO concentration (Nazeer et al., 1999a) showed that the NO concentration was not uniform in the region of formation. Previous investigations (Lanier et al., 1986) have demonstrated that NO reduction in reburning is higher when initial or primary NO concentration is higher; therefore, it is reasonable to assume that locating the natural gas injection strategically at a zone of local high NO concentration can increase the effectiveness of reburning.

Effects of pintle nozzle opening of the natural gas injector on NO reduction by reburning was also studied as shown in Figure 5.3. The equivalence ratios in the reburning and tertiary zones and axial locations of the natural gas and tertiary air injectors were kept constant in this test while the outlet area of the nozzle was varied by changing the pintle position. It was observed that when pintle height was increased (increasing the nozzle area), less NO reduction was observed. A nozzle opening of $0.6 \mathrm{~mm}$ gave $72 \% \mathrm{NO}$ reduction which was reduced to $50 \%$ at nozzle opening of $2.3 \mathrm{~mm}$. The increase in pintle height reduced reburning gas velocity and momentum, thus reducing the mixing capability of the fuel. At the increased pintle height it is likely that the fuel did not reach the outer walls of the reactor and NO escaped the reburning region without getting a chance to react with fuel radicals. A smaller pintle opening was not possible because the flow would have become choked at the nozzle tip, causing upstream flow measurement problems. An NO reduction of $72 \%$ at the smallest pintle opening is similar to results measured in plug flow reactors (Moreb and Wendt, 1994, Kircherer et al., 1994) where mixing was very rapid. This suggests that the smallest measured pintle opening obtained good mixing and that a smaller opening would not have likely increased NO reduction significantly, although this was not attempted.

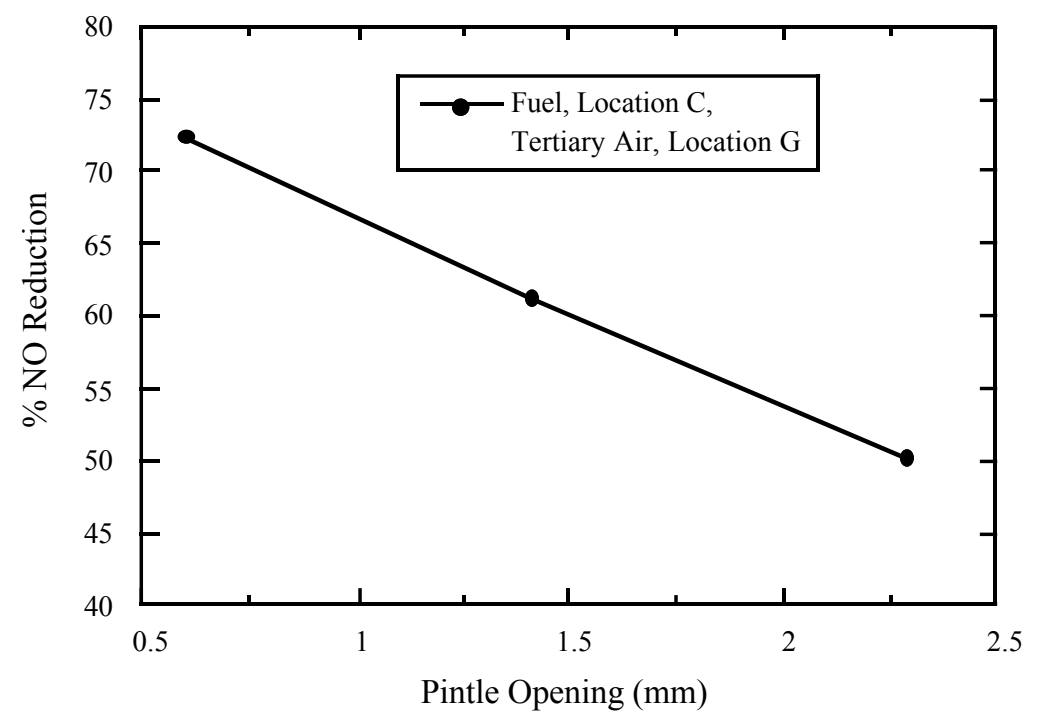

Figure 5.3 NO reduction for several pintle nozzle opening locations. 


\subsubsection{Detailed In-Situ Combustion Measurements}

\subsubsection{Species Profile and Temperature Measurements at 1.5 Swirl}

The locations chosen for the natural gas and tertiary air injectors for detailed species and temperature profile measurements with reburning were $90 \mathrm{~cm}$ and $168 \mathrm{~cm}$, respectively. The reason for selecting these locations for the injectors was that the natural gas injection was below the primary combustion and NO formation zones and the tertiary air was far enough downstream of the reburning zone to provide the residence time needed for maximum NO reduction.

Species data were collected at 6 radial and 6 axial locations in one quadrant of the reactor. The data have been interpolated and plotted in gray scale contour plots in Figures 5.4 and 5.5. Symmetry has been assumed and the contour images have been mirrored to allow a visual 2-D image of the reactor. The location of natural gas and tertiary air injection have been identified by the letters NG and TA respectively, and the arrows represent the direction of flow out of the fuel and air nozzles. These images provide an easy way of visualizing the results but can be somewhat inaccurate or misleading depending on the method used for smoothing and interpolating the data. Tabular results of the data on disk are available on request.

In Figure 5.4, a major oxygen concentration zone of 10\% was observed away from the centerline close to the top of the reactor. At that same location $\mathrm{CO}_{2}$ concentration showed a minimum of $10 \%$, indicating the region where combustion reactions were not yet complete which is created by the penetration of secondary air and fuel into the reactor. Also, a small oxygen-rich region of $3 \%$ at the centerline immediately at the quarl exit suggests penetration of the primary air stream. At approximately $45 \mathrm{~cm}$, an oxygen-lean zone was observed at the centerline which was thought to be created by the recirculation of products. The oxygen concentration decreases in the downward axial direction and is flat at the $72 \mathrm{~cm}$ axial measurement location. The injection of natural gas at the $90 \mathrm{~cm}$ axial location created a fuel-rich zone indicated by zero percent oxygen at the $112 \mathrm{~cm}$ axial location. The oxygen concentration increased to $2 \%$ at the axial location of $192 \mathrm{~cm}$ due to injection of tertiary air at the $168 \mathrm{~cm}$ axial location.

High CO concentration zones were observed away from the centerline close to the walls in the top section of the CPR indicating regions of incomplete combustion or combustion in progress. The $\mathrm{CO}$ pockets are located downstream of the high $\mathrm{O}_{2}$ and upstream of the highest $\mathrm{CO}_{2}$ regions shown in Figures 5.4a and 5.4b. These $\mathrm{CO}$ levels are over $45,000 \mathrm{ppm}$ or $4.5 \%$. The fuel-rich zone created by natural gas injection can not be easily seen in the shaded plot because the higher gradients occur in the primary combustion region but the tabular data shows an increase from approximately $8000 \mathrm{ppm}$ to $9500 \mathrm{ppm}$ between the $72 \mathrm{~cm}$ and $112 \mathrm{~cm}$ axial locations. The lack of a well defined region of high CO near the reburning fuel injector suggests the fuel did not penetrate as a well defined jet but spread out rapidly. The $\mathrm{CO}_{2}$ concentration indicated a maximum value of $16.3 \%$ occurring at an axial location of $152 \mathrm{~cm} . \mathrm{CO}_{2}$ concentrations below $14 \%$ increased to $16 \%$ directly 
above the tertiary air injector where the fuel was burning out but reached stoichiometric conditions after which $\mathrm{CO}_{2}$ dropped due to dilution with the remaining air.

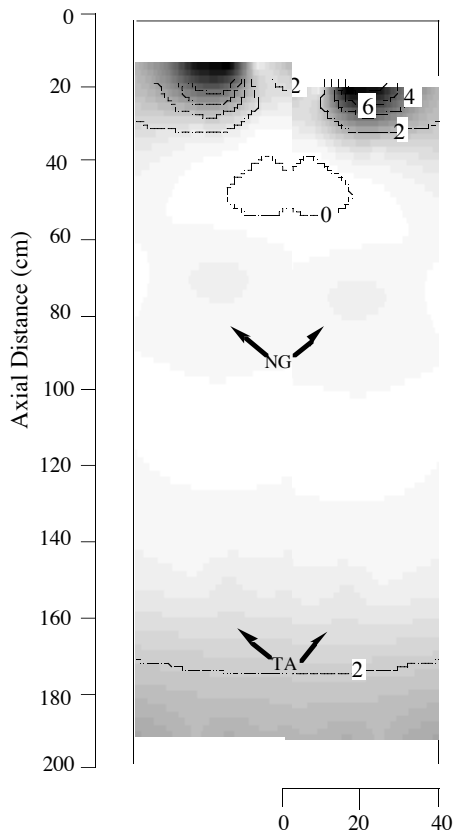

Radial Distance $(\mathrm{cm})$

(a) $\mathrm{O}_{2}(\%$ Volume $)$

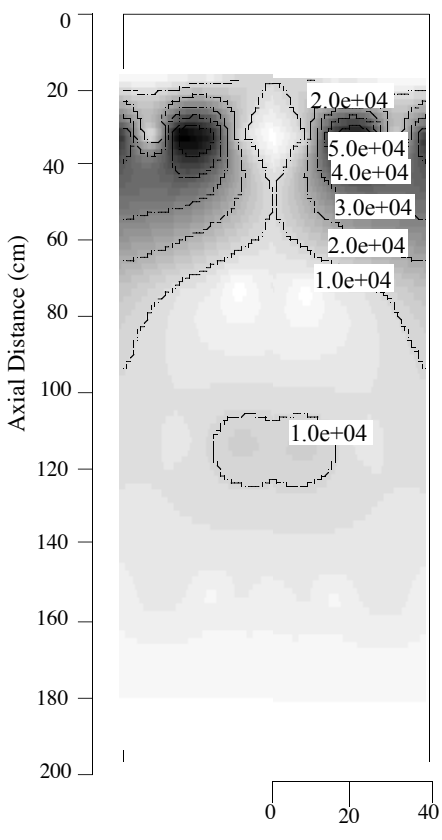

Radial Distance (cm)

(c) CO Concentration (ppm)

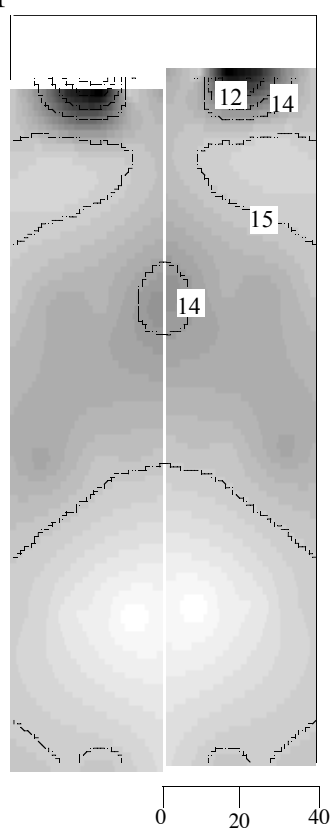

Radial Distance (cm)

(b) $\mathrm{CO}_{2}(\%$ Vol.)

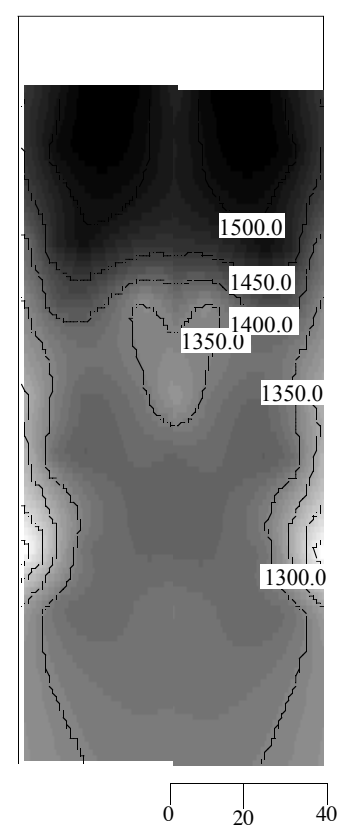

Radial Distance $(\mathrm{cm})$

(d) Temperature (K)

Figure 5.4 Two - dimensional maps of gas species (a) $\mathrm{O}_{2}$, (b) $\mathrm{CO}_{2}$, (c) $\mathrm{CO}$ and (d) temperature. 
A contour map of temperature is shown in Figure 5.4d. Peak temperatures of approximately $1600 \mathrm{~K}$ extend through and below the primary combustion zone in the top $50 \mathrm{~cm}$ of the reactor. The temperatures are lower near the wall due to heat transfer and at the centerline due to recirculation. The temperature drops significantly in the reburning zone with a local minimum at the location of fuel injection. The presence of excess fuel caused the reduced temperature in this region. The temperature then increased between 90 and $120 \mathrm{~cm}$ as the reburning fuel was oxidized. Temperatures in the CPR are lower than those measured in industrial boilers which are typically closer to $1850 \mathrm{~K}$. This can be attributed to the increased heat transfer for this reactor, particularly at the water-cooled quarl, and to the possibility that the pyrometer spatially and temporally averages temperature gradients.

Contour maps of concentration profiles of $\mathrm{NO}, \mathrm{NH}_{3}$, and $\mathrm{NO}_{2}$ are shown in Figure 5.5. The $\mathrm{NO}_{2}$ plot was determined by assuming the difference in $\mathrm{NO}_{\mathrm{x}}$ and $\mathrm{NO}$ measured by the chemiluminescence analyzer to be $\mathrm{NO}_{2}$. The $\mathrm{NO}$ profiles suggested that a major NO formation zone was located along the walls in the top section of the reactor. NO concentration reduces rapidly from the $300 \mathrm{ppm}$ level at approximately the $75 \mathrm{~cm}$ axial location to $120 \mathrm{ppm}$ at $120 \mathrm{~cm}$. This sudden drop in NO concentration and the low NO concentration at the center of the reactor can be attributed to the fuel injection at $90 \mathrm{~cm}$. Remembering the initial baseline flow in the reactor, a centerline recirculation zone would be expected to carry some of the natural gas up the centerline which is also seen in the NO data.

$\mathrm{NH}_{3}$ concentration profiles show an increase in concentration in the fuel-rich region between the axial lengths of 80 and $120 \mathrm{~cm}$ but primarily out near the wall. This is somewhat unexpected as the radicals from the reburning fuel are the expected source of the reactions which eventually produce $\mathrm{NH}_{3}$; thus, the higher $\mathrm{NH}_{3}$ concentrations were expected near the reburning fuel source. $\mathrm{An} \mathrm{NH}_{3}$ pocket is also visible just below the quarl at the end of the primary combustion zone. This ammonia also coincides with the only location of significant $\mathrm{NO}_{2}$ concentration. The $\mathrm{NO}_{2}$ concentration shows a maximum of 67 ppm just below the quarl, dropping to values below $25 \mathrm{ppm}$ in the reburning zone. After the reburning tertiary air injection, differences in $\mathrm{NO}_{\mathrm{x}}$ and $\mathrm{NO}$ were negligible. 


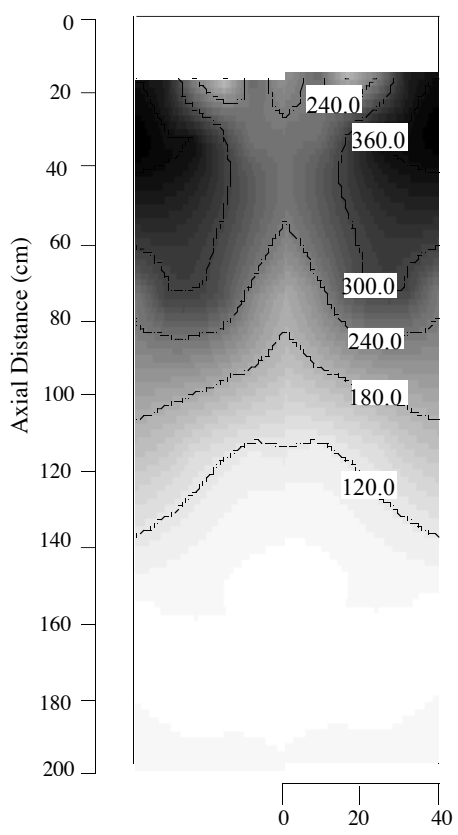

Radial Distance (cm)

(a) NO Concentration (ppm)

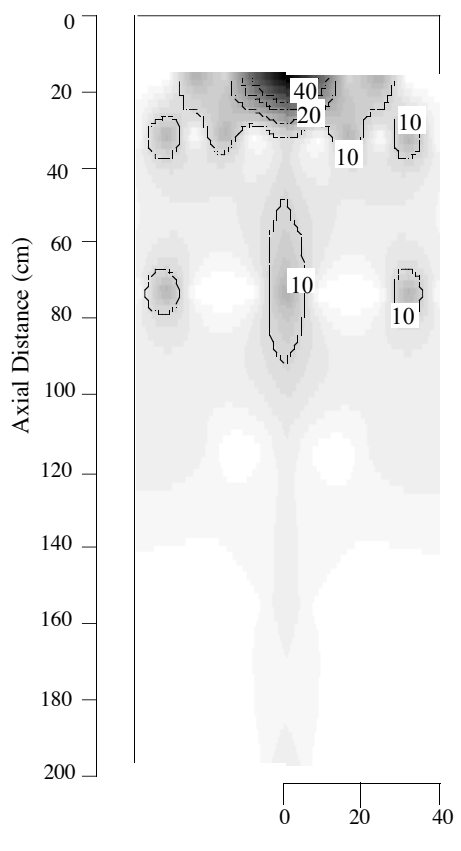

Radial Distance $(\mathrm{cm})$

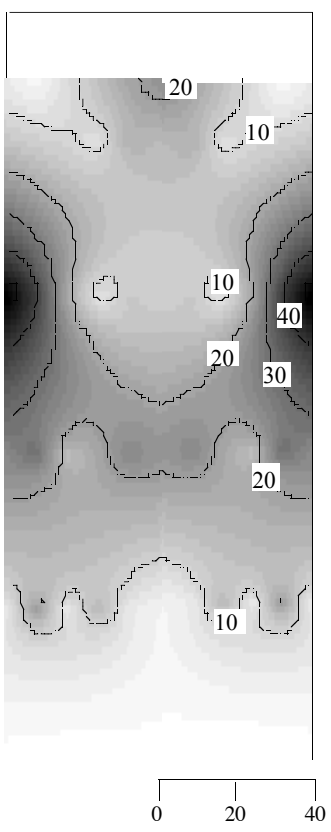

Radial Distance $(\mathrm{cm})$

(b) $\mathrm{NH}_{3}$ Concentration (ppm)

(b) $\mathrm{NO}_{2}$ Concentration (ppm)

Figure 5.5 Two dimensional maps of gas species: (a) $\mathrm{NO}$, (b) $\mathrm{NH}_{3}$, and (c) $\mathrm{NO}_{2}$. 
Carbon burnout data are shown for the baseline and reburning cases in Figure 5.6. The baseline case was obtained at the same primary zone fuel and air flow rates without reburning. The data begins $17 \mathrm{~cm}$ below the fuel inlet where carbon burnout is already greater than $60 \%$. The shape of the incoming fuel/air jet shown by the velocity data is somewhat visible in the burnout data as the burnout increases very rapidly axially along the centerline but more slowly in the direction of outward flow. Burnout has reached $95 \%$ at $50 \mathrm{~cm}$ and $99 \%$ at $90 \mathrm{~cm}$. In the case of reburning, the carbon burnout is more rapid prior to the measurement zone but then proceeds more slowly, only reaching $95 \%$ burnout at 90 $\mathrm{cm}$ and not reaching $99 \%$ burnout until after the tertiary air is added. The reason for higher burnout initially can be found in comparing the primary combustion zone temperature of the baseline and reburning cases. Reburning primary zone temperatures are 1500-1600 K while baseline temperatures are $1400-1500 \mathrm{~K}$. This is probably due to the entrainment of some of the natural gas into the lean primary zone increasing temperature and to the higher total energy input with reburning increasing reactor wall temperatures and decreasing heat transfer from the primary combustion gases. Another possibility is the radiation from soot in the reburning zone heating incoming coal and char. A luminous flame just above and swirling up the centerline was observed while reburning was occurring. Burnout proceeds more slowly than the baseline below the primary combustion zone because the char enters the fuel-rich reburning zone.

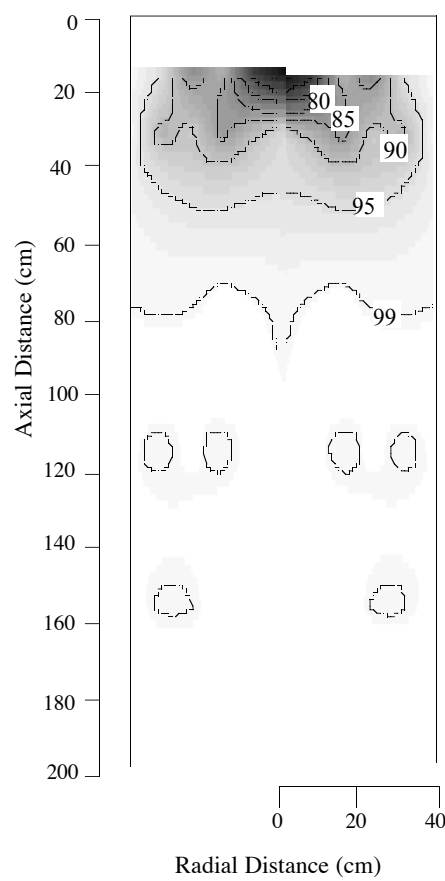

(b) Carbon burnout without reburning

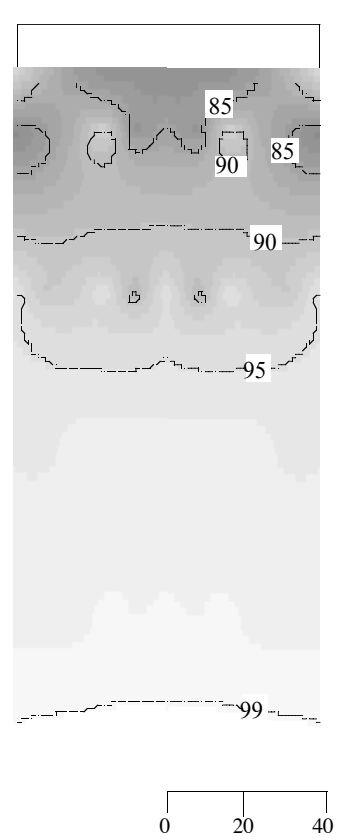

Radial Distance (cm)

(b) Carbon burnout

with reburning

Figure 5.6 Carbon burnout with and without reburning. 
In addition to carbon burnout, nitrogen, hydrogen, and sulfur data were also obtained. The Hydrogen data suggest that devolatilization is nearly complete at the $17 \mathrm{~cm}$ axial location where measurements began. The nitrogen burnout shows that $95 \%$ of the nitrogen is released at the point of reburning fuel injection $(90 \mathrm{~cm})$. Tabular results on disk are available at each measurement location for the carbon, nitrogen, hydrogen, and sulfur.

\subsubsection{Species Profile and Temperature Measurements at 0.5 Swirl}

In addition to the measurements obtained at 1.5 swirl, on-line species and temperature measurements were also obtained at 0.5 swirl. These data are reported in the data book appendix without discussion here.

\subsubsection{Reburning Velocity Data}

Velocity data obtained with a two-color system as described above for the baseline data were used to obtain axial and tangential velocity under reburning conditions. The data shown below in Figure 5.7 are at 0.5 swirl. The figure contains a schematic diagram showing the axial location of the six different measurement locations relative to the primary inlet tube and the locations of the reburning fuel and tertiary air. Data acquisition was difficult near the top of the reactor due to the thickness of the unburned particles which reduced the back scattered signal. This precluded reliable data from being obtained at the center of the reactor at the $21 \mathrm{~cm}$ axial location. The axial and radial velocities in this reburning case are similar in shape and magnitude to the baseline 0.5 swirl data. The data suggest that the reburning fuel and tertiary air injection have little influence on velocity flow in the reactor. The most significant difference appears to be an increase in the radial flow velocity at 77 and $120 \mathrm{~cm}$ just above and below the fuel injection location. 
Average Axial Velocity
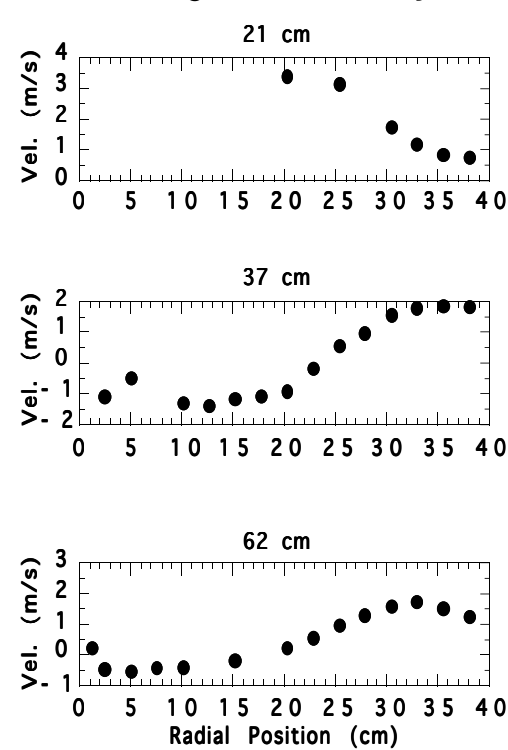

Average Axial Velocity
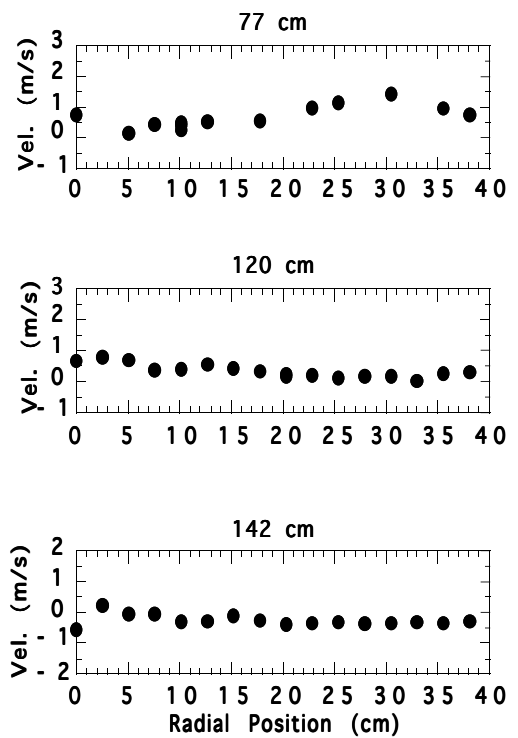

Average Tangential Velocity

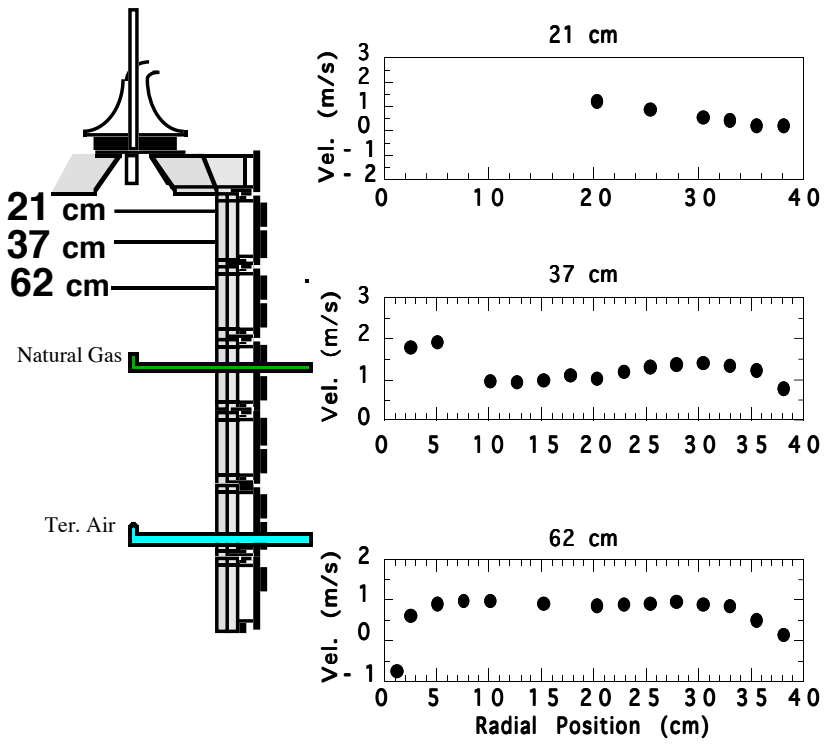

Average Tangential Velocity
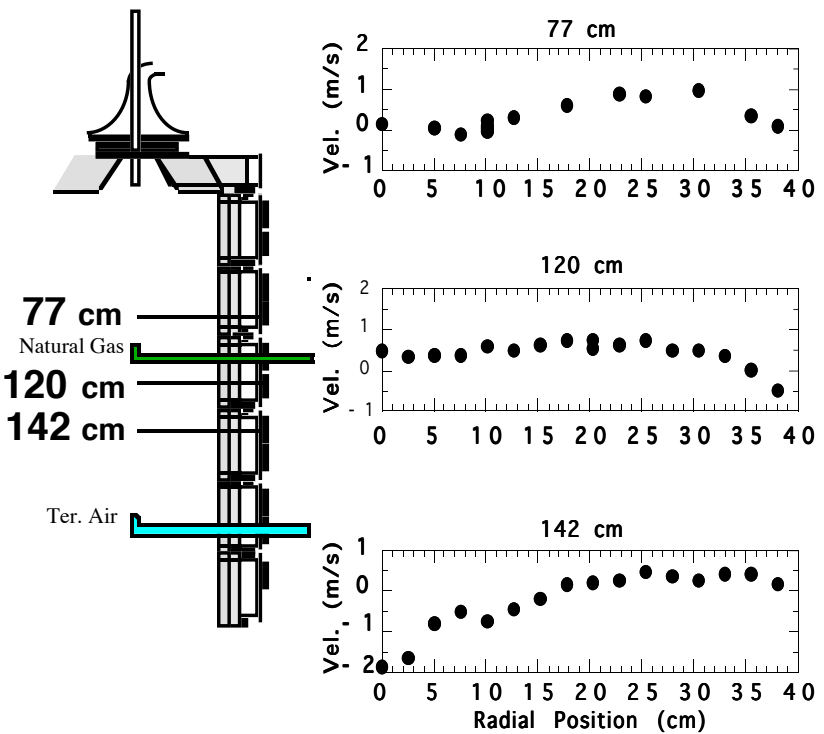

Figure 5.7 LDA velocity data with reburning at 0.5 swirl.

\subsection{Reburning Summary}

Effluent measurements demonstrated NO reduction as high as $70 \%$ can be obtained by reburning for the conditions of this study. An estimated residence time of $700 \mathrm{~ms}$ was sufficient to obtain maximum NO reduction. The reduction was highest when the reburning fuel was injected directly at the location of highest local NO concentration. The addition of reburning fuel prior to the completion of $\mathrm{NO}$ formation was not as effective at reducing 
NO. This suggests that strategically locating reburning fuel locations could be useful in obtaining higher reductions with less fuel. Increasing the momentum of the reburning jet increased NO reduction. A higher NO reduction might have been possible at higher injection velocities. At the injector locations where the highest measured NO reduction occurred, the reactor was mapped for species, temperature, and carbon burnout. The data provide a self consistent map of reburning which can be used to gain insight into the process and for model development.

\section{ADVANCED REBURNING}

\subsection{Introduction}

As a result of the need to reduce $\mathrm{NO}$ emissions in coal fired power plants, various $\mathrm{NO}$ reduction strategies have been investigated. Currently, air staging produced by low- $\mathrm{NO}_{\mathrm{x}}$ burners is being implemented as a cost effective technique but may face limited reduction capabilities due to carbon burnout and flame impingement problems (Cooper and Alley, 1994). When further NO reduction is required, Selective Catalytic Reduction (SCR) and Selective Noncatalytic Reduction (SNCR) have been implemented (Jodal et al., 1990, Jodal et al., 1992, and PETC Review, 1992). These techniques take advantage of the ability of an $\mathrm{N}$-agent such as urea or ammonia to reduce $\mathrm{NO}$ to $\mathrm{N}_{2}$ and $\mathrm{O}_{2}$. Both of these techniques require effluent gas processing which requires additional equipment, cost, and space as discussed by Pickens (1996). SCR requires an expensive catalyst while SNCR requires a narrow temperature window $(1200-1350 \mathrm{~K})$ and is only $50 \%$ effective in practice. Reburning is a promising technology which has been demonstrated in laboratory reactors by Mereb and Wendt (1994) and in full scale boilers such as reported by Folsom et al. (1997). In reburning, NO reduction occurs within the boiler region by the injection of fuel downstream of the primary combustion zone. The reburning fuel creates a rich zone where $\mathrm{NO}$ is reduced and is followed by downstream injection of air to burn out the excess fuel. Natural gas is the most common choice for reburning fuel.

Advanced reburning is a combination of reburning and $\mathrm{N}$-agent injection downstream of the primary combustion zone where NO is formed. The reburning fuel allows for a reduction in the oxygen concentration from the typical lean conditions exiting the primary combustion zone to levels that would be expected to be useful (approximately $2 \%$, Chen et al., 1988) for SNCR or $\mathrm{DeNO}_{\mathrm{x}}$ (Lyon, 1973) chemistry to effectively reduce NO. In an attempt to obtain NO reduction within the boiler, Chen et al. (1988) injected -NH and -CN compounds at various stoichiometric ratios within the reburning zone and within the burnout air. They found large NO reductions when $\mathrm{N}$-agents were injected into slightly rich $(\mathrm{S} . \mathrm{R} .=.99)$ reburning zones followed by burnout air. NO reduction was found to increase as the temperature at which the burnout air was injected was lowered toward 1200 $\mathrm{K}$. They concluded that the NO reduction was taking place as the fuel rich zone mixed with the air to provide the appropriate $\mathrm{O}_{2}$ and temperature combination. The temperature window was also determined to be broadened by the presence of $\mathrm{CO}$ which produced the necessary $\mathrm{OH}$ radicals needed to initiate $\mathrm{NO}$ reduction to $\mathrm{N}_{2}$. Subsequent research(Lyon, 
1979, Suhlmann, J., Rotzoll, 1993, Pont et al., 1993, and Brauwer, 1996) investigated the effect of $\mathrm{CO}$ on DeNOx chemistry and showed the temperature window could be lowered by $100{ }^{\circ} \mathrm{C}$ and broadened if the appropriate level of CO (approximately $3800 \mathrm{ppm}$ ) were present. Higher $\mathrm{CO}$ levels tend to increase radicals such that $\mathrm{NO}$ formation is enhanced over NO reduction. Hemberger et al. (1994) showed that the presence of hydrocarbon radicals produced from methane or ethane injection into the $\mathrm{N}$-agent zone could also broaden and lower the temperature window.

Conclusions from much of the previous work concerning the role of $\mathrm{CO}, \mathrm{O}_{2}$ and temperature in advanced reburning rely on temperature and species measurements before and after the reaction zone and kinetic modeling within the reaction zone. Previous measurements leave an uncertainty if the temperature at the point of $\mathrm{N}$-agent injection or the temperature at the point of burnout air injection controls the reaction process. The kinetic models describing $\mathrm{DeNO}_{\mathrm{x}}$ reactions have only been compared to data at the beginning and end but not within the reaction zone. The objective of this work was to obtain a detailed map of species concentration and temperature throughout the reaction zone of an advanced reburning process. These detailed measurements give insight into the NO reduction process and allow for a comparison of detailed combustion modeling with measurements.

\subsection{Advanced Reburning Method and Set-Up}

All measurements were obtained in the Controlled Profile Reactor (CPR) as discussed in previous sections. The reactor was operated at an overall stoichiometric ratio of 1.1, and two different theoretical swirl setting, 1.5 and 0.5 , were used. Gas species of $\mathrm{O}_{2}, \mathrm{CO}_{2}, \mathrm{CO}$, and $\mathrm{NO}$ were obtained using a water quenched suction probe and on-line gas analyzers. Concentrations of $\mathrm{NH}_{3}$ and $\mathrm{HCN}$ were obtained by aqueous sampling and ion electrode analysis. Advanced reburning was achieved by injecting natural gas and ammonia into the CPR along the center line using water cooled probes. The ammonia was initially stored in compressed tanks as $25 \% \mathrm{NH}_{3}$ and $75 \% \mathrm{~N}_{2}$. During injection, the $\mathrm{NH}_{3} / \mathrm{N}_{2}$ mixture (to be referred to as $\mathrm{NH}_{3}$ injection only) was further mixed with $\mathrm{N}_{2}$ as a carrier gas to increase the momentum of the injected flow to improve mixing. In an initial set of experiments, the location of the natural gas and ammonia injection were varied and only effluent gas concentrations were measured. This was used to investigate the effects of various injection locations, reburning zone equivalence ratios, and ammonia injection flow rates on the effluent NO concentration. From the effluent measurements, a location for each injector and flow rates for ammonia and natural gas were selected for a detailed map. Figure 6.1 shows the locations of natural gas, ammonia, and tertiary air injection selected for the advanced reburning map with dots representing specific measurement locations for the gaseous species. Temperature measurements were obtained at the same number of locations as the gas measurements shown but were located $5 \mathrm{~cm}$ below each gas species location due to differences in the geometry of the sampling probe tips. 


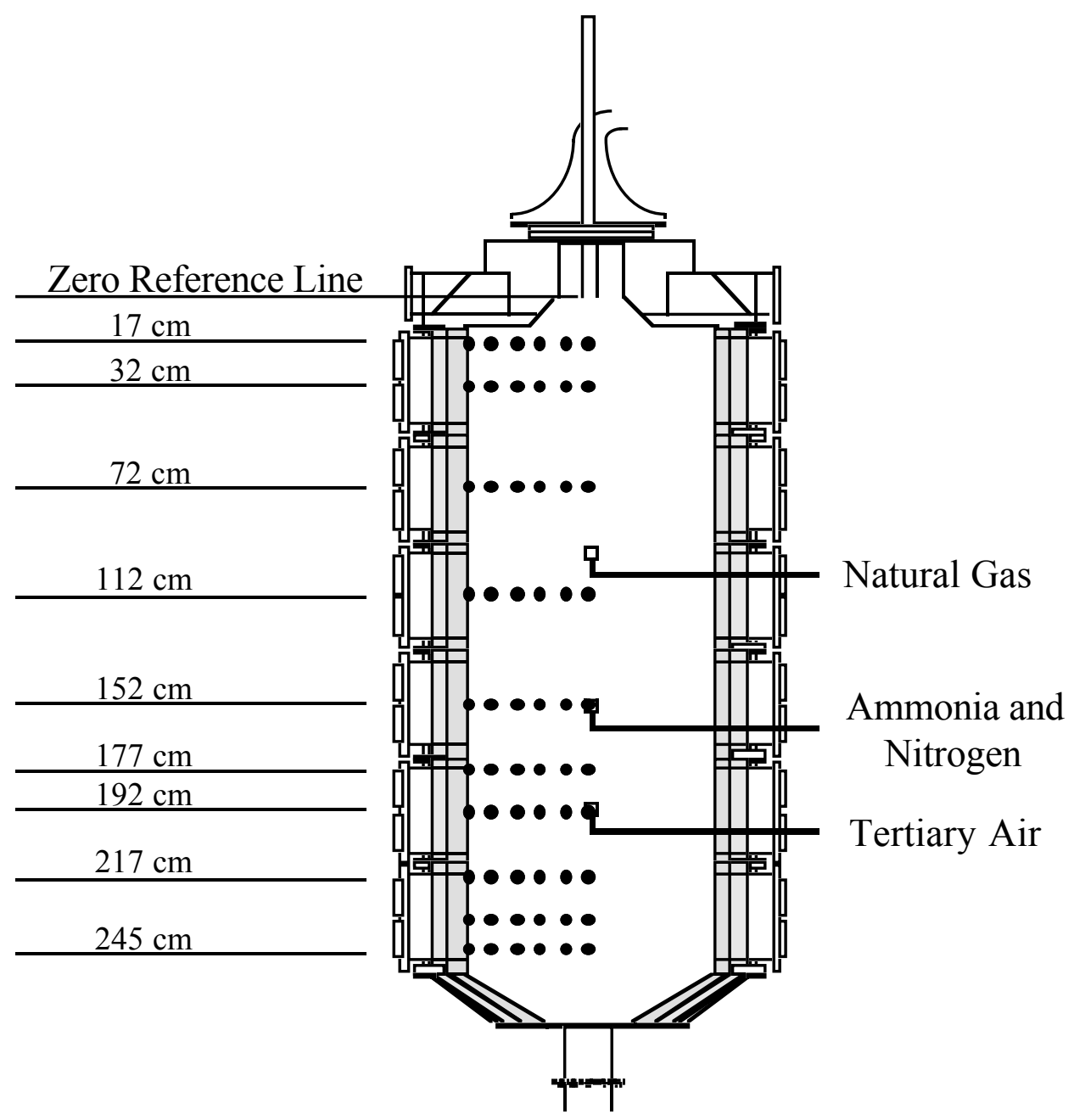

Figure 6.1 Advanced reburning implementation in the CPR. Injector and measurement locations.

All of the gas injectors (Air, Nitrogen and Ammonia) used water cooled tubes with pintle type nozzles shown in Figure 3.4. The gap between the pintle and nozzle housing through which the gasses flowed was kept at $0.6 \mathrm{~mm}$ for each of the injectors. The diameter of the nozzle was $18.1 \mathrm{~mm}$ at the outlet and angled upwards at $20^{\circ}$. The slight upward angle was used because numerical calculations suggested the flow would penetrate toward the wall in a shorter axial distance when directed slightly upstream.

Operating conditions for reactor fuel and air feed for all conditions tested are shown in Table 5.1 along with reburning fuel, advanced reburning fuel and tertiary air flow rates used in the advanced reburning map to be described later. The secondary air was heated $(600 \mathrm{~K})$ prior to the infusion of the coal. Primary air, coal and all injected gases were unheated. The same Wyodak sub-bituminous coal was used in advanced reburning studies as was used for the previous investigations described above. Properties of the coal are given in Table 5.2 Coal size was measured to have $90 \mu \mathrm{m}$ mass mean size with a distribution shown in Figure 4.1. 


\subsection{Advanced Reburning Results and Discussion}

\subsubsection{Effluent NO Measurements}

Before completing a detailed map of the reactor under an advanced reburning condition, effluent measurements of NO were obtained at numerous operating conditions which varied the reburning zone stoichiometric ratio, the swirl, and the nitrogen to ammonia stoichiometric ratio (NSR) in the advanced reburning zone. For these 1.5 swirl effluent species tests, the natural gas was injected at $89 \mathrm{~cm}$ and the tertiary air at $187 \mathrm{~cm}$. The results are shown in Figure 6.2. The dashed lines show the NO reduction due to reburning alone decreased as the reburning zone stoichiometric ratio increased. This was expected because there was less natural gas available for NO reduction at the leaner conditions. At a reburning zone S.R. of 0.95 the addition of ammonia did little to improve NO reduction, but as reburning zone S.R. increased, the total NO reduction increased for all NSR values. Because the mixtures which were slightly lean produced greater NO reduction, the data suggests that excess oxygen or reactive species created by small amounts of excess oxygen promote advanced reburning. No dependence on location or NSR was shown for the $\mathrm{NH}_{3}$ addition at 0.95 and 1.0 S.R. At a S.R. of 1.05, the data show that $\mathrm{NH}_{3}$ injection at 130 $\mathrm{cm}$ produced higher NO reductions. The reason for this location producing higher NO reductions is suspected to be related to optimal temperatures as will be discussed later.
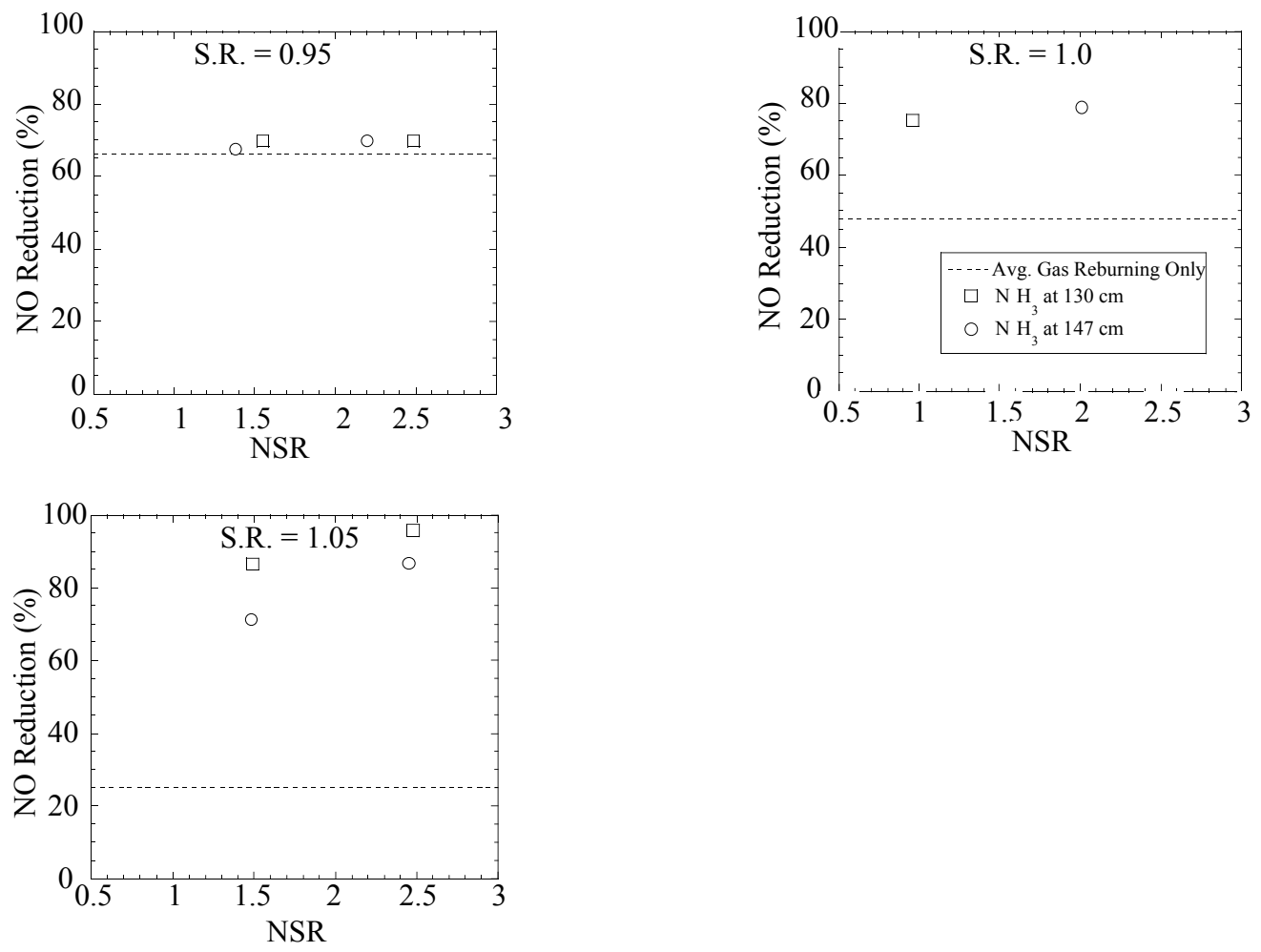

Figure 6.2 Effluent measurements of NO reduction for three stoichiometric ratios as a function of NSR at 1.5 swirl. 
Effluent measurements taken at a swirl ratio of 0.5 are shown in Figures 6.3 and 6.4. Figure 6.3 includes data from various injection locations and at several NSR values where the $\mathrm{NH}_{3}$ was injected with the assistance of additional nitrogen carrier gas. The trend of decreased NO reduction with increased S.R. for reburning alone was the same at this swirl as it was at 1.5. $\mathrm{NO}$ reduction due to $\mathrm{NH}_{3}$ injection in comparison to $\mathrm{NO}$ reduction due to reburning alone was again seen to be negligible at a reburning zone S.R. of 0.95 but increased with increasing reburning zone S.R. Reburning alone at a S.R. of 1.05 is shown to be better than the combination of reduced reburning fuel and $\mathrm{NH}_{3}$ injection except when a slightly lean (S.R. $=1.05$ ) reburning zone was followed by injection of $\mathrm{NH}_{3}$ at $169 \mathrm{~cm}$. This implies again, as in the 1.5 swirl data, that the combination of natural gas followed by ammonia injection (advanced reburning) can provide greater NO reduction than reburning alone, but the location of the $\mathrm{NH}_{3}$ injection is critical. At 0.5 swirl, maximum NO reduction was achieved at an injection location of $169 \mathrm{~cm}$ while at 1.5 swirl the injection location of maximum $\mathrm{NO}$ reduction was $130 \mathrm{~cm}$. If residence time were a limiting factor in NO reduction, the injection location furthest upstream would tend to be the best. While this was the case at 1.5 swirl it was not true at 0.5 swirl. Concentration of $\mathrm{O}_{2}$ and other gaseous species would be expected to remain relatively constant downstream of the reburning zone suggesting that they are not responsible for the dependence of NO reduction on injector location. The temperature is however changing with reactor position as the gas flows down the reactor. In the absence of additional heat release, the temperature drop in the reactor has been measured at approximately $1{ }^{\circ} \mathrm{C} / \mathrm{cm}$.
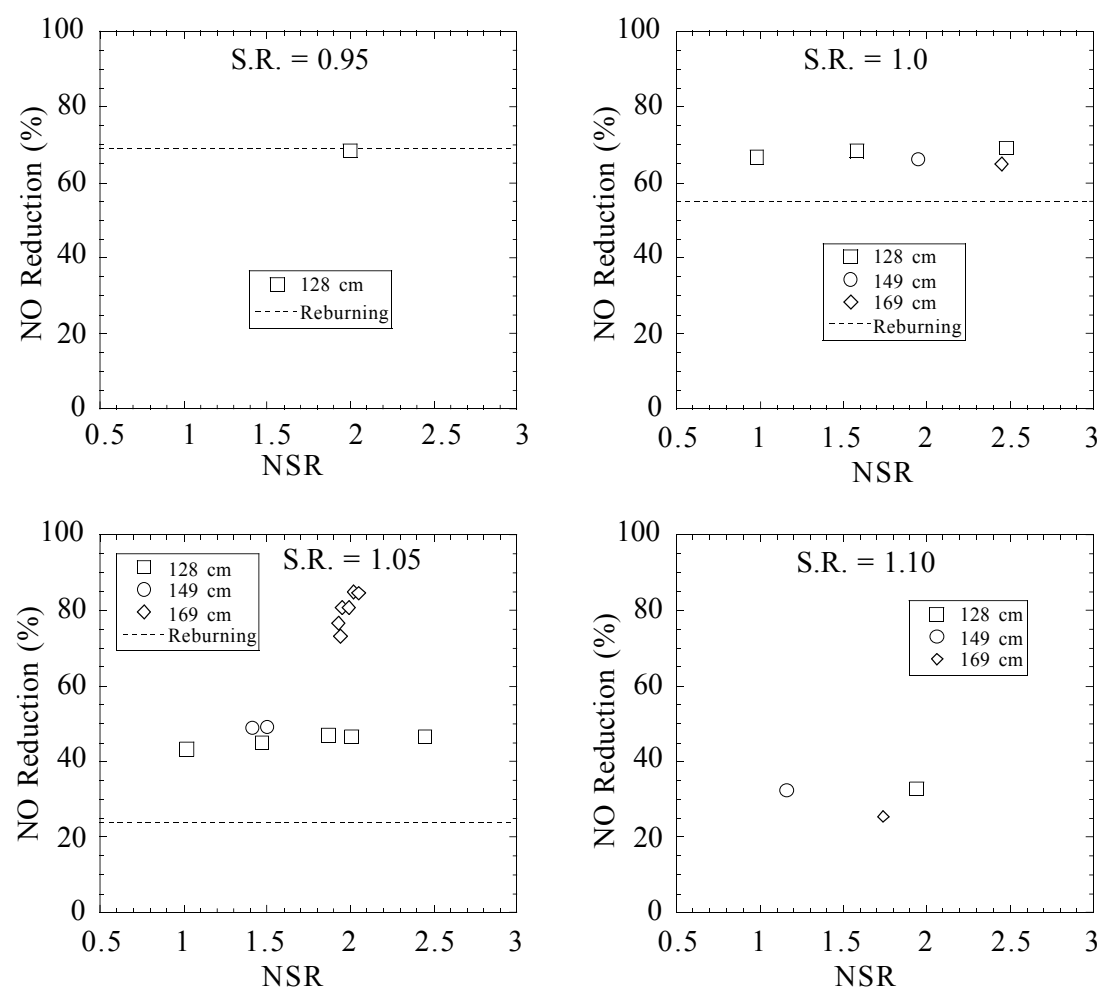

Figure 6.3 NO reduction for various reburning zone stoichiometric ratios as a function of NSR at 0.5 swirl. 
Figure 6.4 shows data for the same two conditions just previously presented (S.R. = 1.0 and 1.05) except in this case, the $\mathrm{NH}_{3}$ injection was not assisted by additional carrier gas. The primary purpose for obtaining these data was to evaluate the NO reduction at a lower injection velocity of $\mathrm{NH}_{3}$ into the product gases exiting the reburning zone. The results are similar to that of $\mathrm{NH}_{3}$ injection with carrier gas except that at the 1.05 reburning zone S.R., both the 149 and $169 \mathrm{~cm}$ injection locations produced high NO reduction, while with the carrier gas, only the $169 \mathrm{~cm}$ location was as effective.
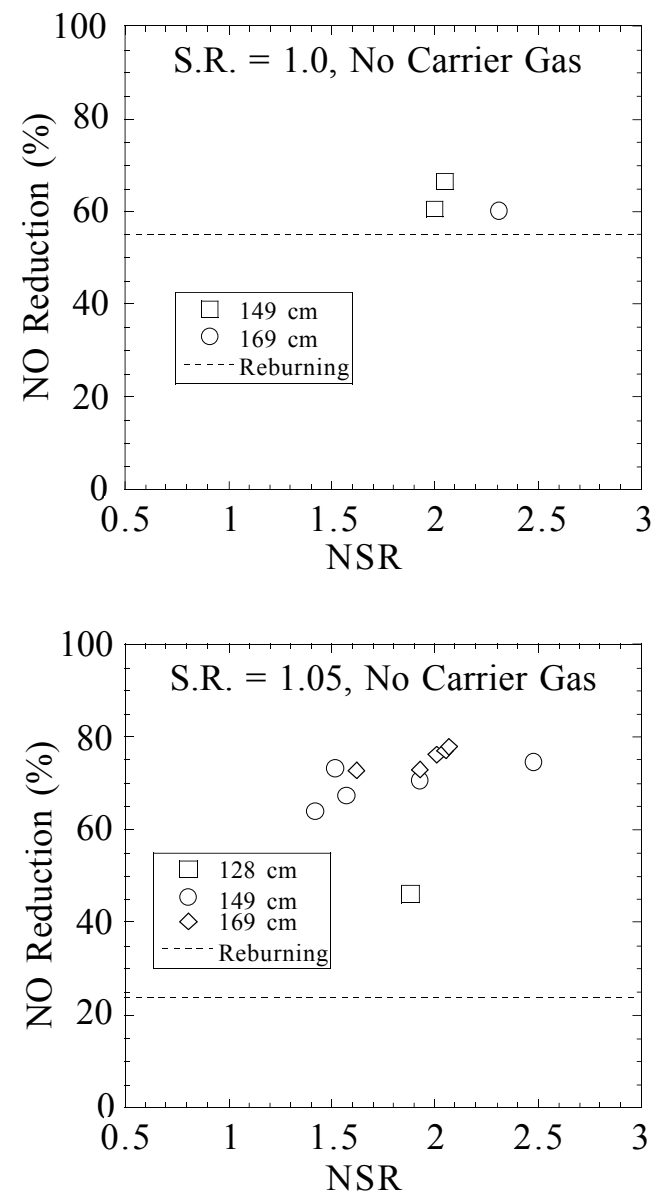

Figure 6.4 NO reduction for various reburning zone stoichiometric ratios as a function of NSR at 0.5 swirl where the injected $\mathrm{NH}_{3}$ has no carrier gas.

One explanation of the data is to assume a zone within the reactor, starting just below $149 \mathrm{~cm}$ and extending below $169 \mathrm{~cm}$ which has an optimal environment for NO reduction when $\mathrm{NH}_{3}$ is injected. When injected at low momentum, as was the case with no extra carrier gas, the $\mathrm{NH}_{3}$ injected at $149 \mathrm{~cm}$ moved downstream into the optimal region. With high injection momentum at the $149 \mathrm{~cm}$ injection location, the injector, which directed the gases at approximately $20^{\circ}$ upstream, forced the gases radially outward and slightly upstream, above the optimal zone. When injecting at $169 \mathrm{~cm}$, the injector was centered in 
the optimal zone and thus either amount of injection momentum produced adequate mixing of the $\mathrm{NH}_{3}$ with $\mathrm{NO}$ at the desired temperature. Throughout this region it would be expected that oxygen and other species concentrations remained relatively constant while temperature was dropping due to heat transfer to the walls. This reasoning suggests that the sensitivity of NO reduction to location is actually a sensitivity to temperature. Downstream of the ammonia injection, at the point of tertiary air injection, both temperature and $\mathrm{O}_{2}$ concentration change. It is possible the tertiary air creates a desirable drop in temperature at that location which facilitates NO reduction, but if this were the case, $\mathrm{NO}$ reduction would not be sensitive to the $\mathrm{NH}_{3}$ injection location.

The 1.5 swirl data showed the highest $\mathrm{NO}$ reduction when injecting the $\mathrm{NH}_{3}$ at $130 \mathrm{~cm}$ which was further upstream than the 0.5 swirl case. In order to determine what temperature and species conditions existed at the point of $\mathrm{NH}_{3}$ injection in each case, a detailed map would be needed. The resources of this work allowed only one detailed map to be obtained. Detailed mapping of baseline conditions in this reactor without reburning or advanced reburning by Nazeer et al. (1999a), however, showed that the flame at 1.5 swirl was essentially higher in the reactor than at 0.5 swirl and that the temperature dropped more rapidly. The temperature at $130 \mathrm{~cm}$ and 1.5 swirl was $1420 \mathrm{~K}$ which was approximately the same temperature at $190 \mathrm{~cm}$ at 0.5 swirl in the baseline data. It is therefore reasonable to believe that these two optimal injection locations had similar temperatures.

\subsubsection{Advanced Reburning Species Map}

The conditions selected for the reburning map are shown below in Table 6.1 The primary consideration in selecting a condition for the map was to find an advanced reburning case which was useful for comparison with comprehensive combustion models including an advanced reburning submodel. Thus it was considered important to have a significant amount of NO reduction occurring at the simplest possible advanced reburning configuration. A 0.5 swirl case was selected because it was considered to be more realistic to industrial swirl levels and because 1.5 swirl created turbulence levels and particle penetration which would be difficult to model. The $149 \mathrm{~cm}$ injection location was selected to allow the longest possible residence time prior to tertiary air injection while maintaining high $\mathrm{NO}$ reductions. The $\mathrm{NH}_{3} / \mathrm{N}_{2}$ injection without additional carrier gas was selected because it was felt that smaller $\mathrm{NH}_{3}$ velocities would be easier to model and less dependent on the fluid modeling of the injector spray.

Table 6.1 Conditions and injection locations used for mapping advanced reburning.

\begin{tabular}{|l|c|c|c|c|c|}
\hline Conditions & Swirl & Primary S.R. & Reburn S.R. & Overall S.R. & NSR \\
\hline & 0.5 & 1.10 & 1.05 & 1.15 & 1.7 \\
\hline Injector & Nat. Gas & $\mathrm{NH}_{3}+\mathrm{N}_{2}$ & Tert. Air & & \\
\hline & $88 \mathrm{~cm}$ & $149 \mathrm{~cm}$ & $189 \mathrm{~cm}$ & & \\
\hline
\end{tabular}


The mapped data were obtained during three separate test periods, two of which repeat the gaseous on-line measurements. In Test A, gaseous species and aqueous samples of the reactor were obtained. In Test B, only gaseous species were taken. Temperature data were obtained in Test $\mathrm{C}$. The species and temperature are displayed below in the form of gray scale contour plots. The contours were generated by a commercial interpolation and plotting program and mirror imaged using a graphics package. This form of presentation offers the advantage of enabling the reader to visualize the combustion phenomena and rapidly identify important regions of change or high or low concentration. The contour plots, however, do not lend themselves well to an accurate determination of precise values because or the uncertainty of interpolation routines used in the plotting software. Complete tabular data for these maps are available on request with some of the most critical data in the advanced reburning zone being presented in Table 6.2

Species data are shown comparing tests $\mathrm{A}$ and $\mathrm{B}$ in Figures 6.5 and 6.6. Test $\mathrm{B}$ contains the same number of data points but extends a little further down the reactor which may cause some difference in the way the data appear after being interpolated by the software. The two data sets show regions of high concentration and gradients which are generally the same in both data sets, and the magnitudes of the measurements are in fairly good agreement. Test A consistently showed evidence of a stronger axial penetration of the secondary air jet at the top of the reactor and a weaker recirculation zone. The two data sets demonstrate the variability of the results for a given operating condition. The largest source of variation in the reactor was determined to be the variation of the coal feed rate. Coal was delivered using a gravity and auger feed system. Vibrators were used to avoid air pockets in the coal feed bin. Variations of $5 \%$ in the coal feed were caused by compaction of coal in the feeder bin over time. Coal was delivered to the feeder from barrels which were emptied approximately every four hours. This created a $4 \mathrm{hr}$ cycle in the coal feed while the entire map required $8 \mathrm{hrs}$ of sampling. Changes in coal feed were evaluated by turning off all but the baseline fuel and air feed and monitoring the exhaust $\mathrm{O}_{2}$ concentration. When the $\mathrm{O}_{2}$ concentration was not in good agreement with expected values $( \pm 2.5 \%)$, the reburning data from the previous measurements were not accepted and the data set was retaken. This variation in the coal feed is one reason the two data sets are slightly different. Another reason is the possibility of moisture or other variations in coal content which can occur within a given load. 


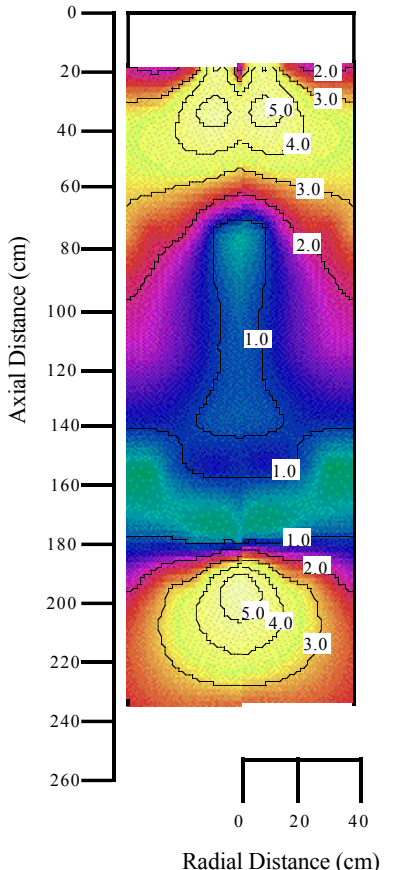

(a) $\mathrm{O}_{2}(\%)$
Test $\mathrm{A}$

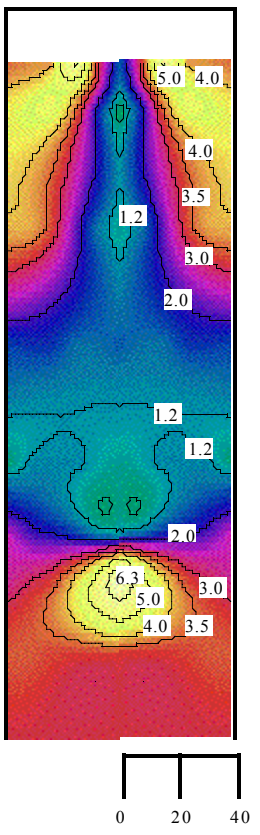

Radial Distance (cm)

(b) $\mathrm{O}_{2}(\%)$

Test B
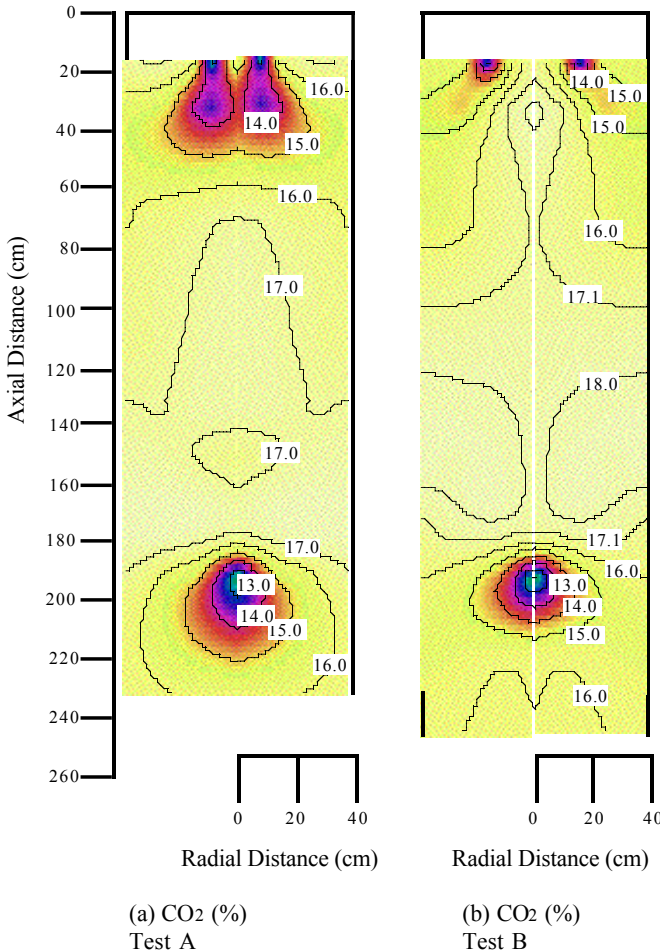

(b) $\mathrm{CO}_{2}(\%)$

Test B

Figure 6.5 Concentration contour maps of $\mathrm{O}_{2}$ and $\mathrm{CO}_{2}$ for both tests, $\mathrm{A}$ and $\mathrm{B}$.

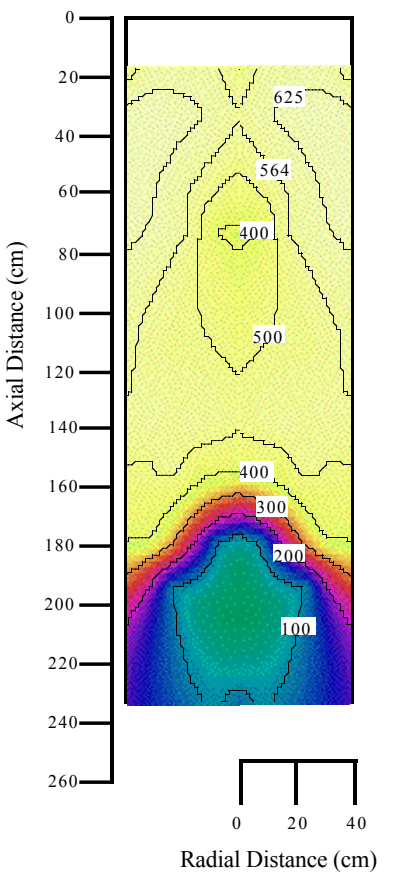

(a) $\mathrm{NO}(\mathrm{ppm})$ Test $\mathrm{A}$

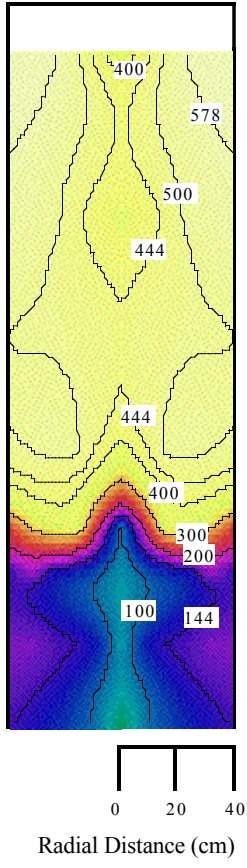

(b) $\mathrm{NO}(\mathrm{ppm})$ Test B

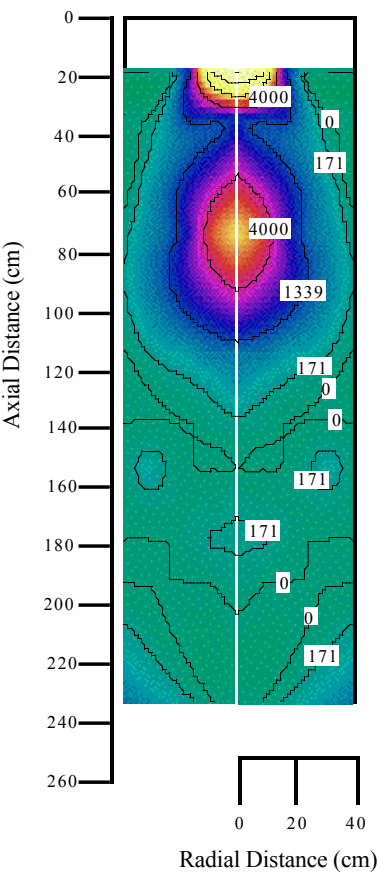

(a) $\mathrm{CO}(\mathrm{ppm})$ Test A

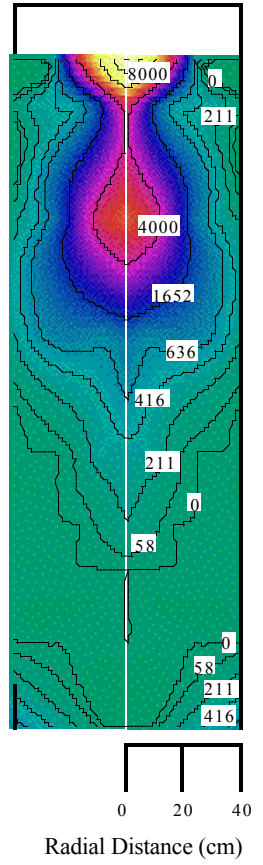

(b) $\mathrm{CO}(\mathrm{ppm})$ Test B

Figure 6.6 Concentration contour maps of $\mathrm{NO}$ and $\mathrm{CO}$ for both tests, A and B. 
Concentrating on a set of data from a single test, Test A, the primary, reburning and advanced reburning zones can clearly be identified. Near the top of the reactor, $\mathrm{O}_{2}$ is seen to penetrate to about $60 \mathrm{~cm}$ before reaching a level of approximately $3 \%$. In this same region, $\mathrm{CO}_{2}$ increases to $16 \%$, and $\mathrm{NO}$ increases to $550 \mathrm{ppm}$ (at the centerline) to $625 \mathrm{ppm}$ (near the walls). $\mathrm{CO}$ in this primary combustion region has narrow regions where the concentration is very high, representing unburned fuel, and other areas where $\mathrm{CO}$ is low suggesting $\mathrm{O}_{2}$ availability and more complete combustion.

The region from $140 \mathrm{~cm}$ down is of particular interest because it shows the conditions where the NO reduction was occurring. Before examining this region in more detail, the $\mathrm{NH}_{3}$ and $\mathrm{HCN}$ species concentrations and temperature need to be considered. Contour plots for these species are seen in Figure 6.7. Significant amounts of HCN were found directly below the quarl outlet in the primary combustion zone but not at any other location within the reactor. There is no evidence of either $\mathrm{NH}_{3}$ or $\mathrm{HCN}$ in the reburning zone. This may have been because the fuel mixed readily with the surrounding gases, and the overall S.R. in the reburning zone was lean. $\mathrm{NH}_{3}$ was found only in the vicinity of the ammonia injection. Ammonia was found primarily on the downstream side of injection suggesting that the jet, which was directed at approximately $20^{\circ}$ upward, did not contain a significant amount of momentum relative to the downward flow. The temperature, which was highest at the top of the reactor, decreased more slowly in the top half of the reactor where the reburning fuel was added than the bottom half where ammonia and tertiary air were added. This was as expected because the natural gas provided an additional source of energy while the ammonia and tertiary air cooled the gasses by dilution.
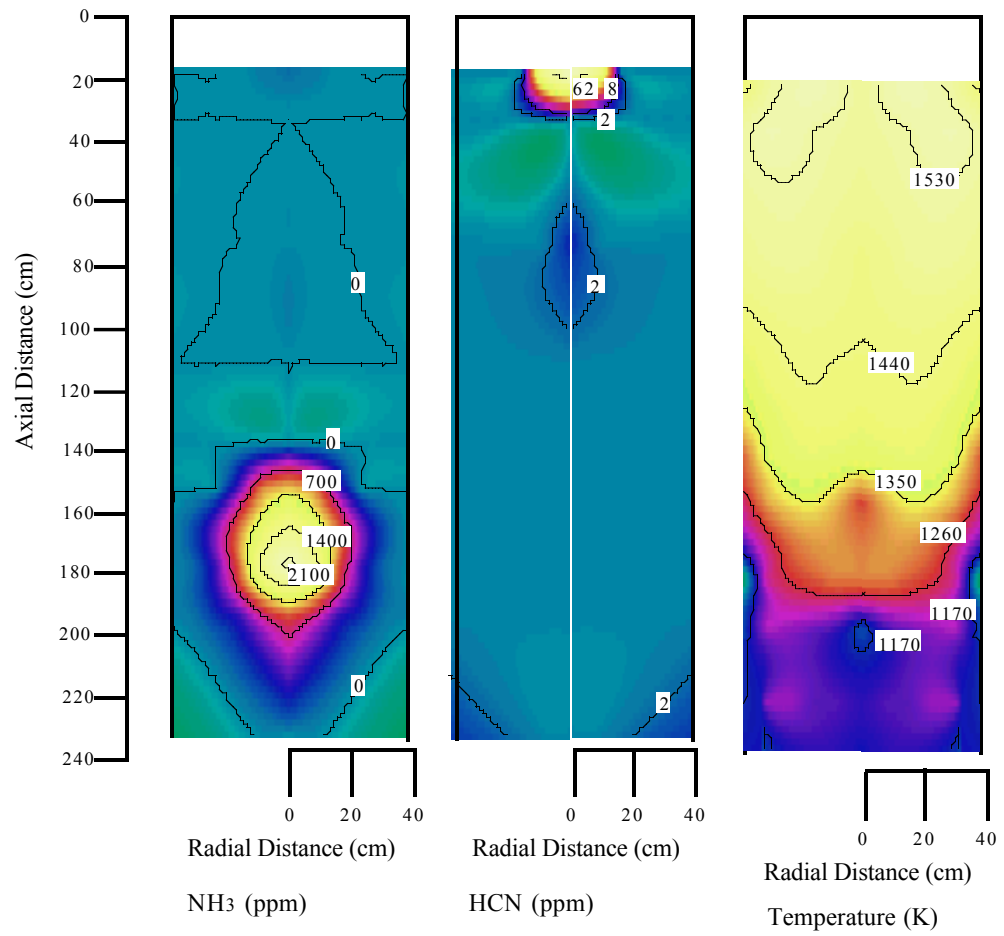

Figure 6.7 Ammonia, $\mathrm{HCN}$ and temperature profiles for advanced reburning. 
It is interesting to look closely at the data in the region of rapid NO destruction where measurements were made at the 152, 177, and $192 \mathrm{~cm}$ axial locations and 6 radial locations. Tabular data for these points are given in Table 6.2. $\mathrm{NH}_{3}$ injection occurred at $149 \mathrm{~cm}$ just above this zone, and air injection occurred at $189 \mathrm{~cm}$, near the end of this zone. Assuming a plugged flow in the downward direction, the steepest reduction in NO occurred at the centerline between 152 and $177 \mathrm{~cm}$ where the concentration dropped from 420 to $87 \mathrm{ppm}$. In this same interval, $\mathrm{NH}_{3}$ increased from 1268 to 2961 ppm, $\mathrm{O}_{2}$ was present at $0.7 \%$, and the temperature was between 1274 and $1300 \mathrm{~K}$. This means that the greatest NO reduction occurred in the presence of $\mathrm{O}_{2}$ with a high ratio of $\mathrm{NH}_{3}$ to $\mathrm{NO}$.

Table 6.2 A selection of species and temperature data in the advanced reburning zone.

\begin{tabular}{|l|l|l|l|l|l|l|l|}
\hline \multicolumn{2}{|c|}{ Radial } & \multicolumn{1}{c|}{0} & 8 & 15 & 23 & 30 & 38 \\
\hline Axial & & & & & & & \\
\hline $152^{\mathrm{a}}$ & $\mathrm{NO}(\mathrm{ppm})$ & 420 & 430 & 440 & 555 & 490 & 500 \\
\hline & $\mathrm{O}_{2}(\%)$ & 1.1 & 1.2 & 1.1 & 0.9 & 0.4 & 0.5 \\
\hline & $\mathrm{NH}_{3}(\mathrm{ppm})$ & 1268 & 1097 & 414 & 0 & 0 & 0 \\
\hline & Temp. $(\mathrm{K})$ & 1274 & 1326 & 1351 & 1343 & 1317 & 1248 \\
\hline & & & & & & & \\
\hline $177^{\mathrm{a}}$ & $\mathrm{NO}(\mathrm{ppm})$ & 87 & 115 & 220 & 330 & 400 & 400 \\
\hline & $\mathrm{O}_{2}(\%)$ & 0.7 & 0.8 & 0.8 & 1.0 & 1.0 & 1.0 \\
\hline & $\mathrm{NH}_{3}(\mathrm{ppm})$ & 2961 & 2271 & 1041 & 352 & 86 & 23 \\
\hline & Temp. $(\mathrm{K})$ & 1300 & 1300 & 1283 & 1265 & 1239 & 1106 \\
\hline & & & & & & & \\
\hline $192^{\mathrm{a}}$ & $\mathrm{NO}(\mathrm{ppm})$ & 68 & 80 & 95 & 105 & 210 & 280 \\
\hline & $\mathrm{O}_{2}(\%)$ & 6.2 & 4.6 & 3.2 & 3.0 & 2.3 & 1.6 \\
\hline & $\mathrm{NH}(\mathrm{ppm})$ & 1005 & 759 & 373 & 224 & 68 & 41 \\
\hline & Temp. $(\mathrm{K})$ & 1160 & 1195 & 1204 & 1213 & 1222 & 1160 \\
\hline
\end{tabular}

${ }^{\mathrm{a}}$ Temperature values were taken $5 \mathrm{~cm}$ downstream of the species measurements.

At the $23 \mathrm{~cm}$ radial location, moving downstream from 152 to 177 to $192 \mathrm{~cm}$ axially, the NO decreased from 555 to 330 to $105 \mathrm{ppm}$ respectively. During the first segment between 152 and $177 \mathrm{~cm}$, the $\mathrm{O}_{2}$ concentration was still relatively low between 0.9 and $1.0 \%, \mathrm{NH}_{3}$ was between 0 and $352 \mathrm{ppm}$ and the temperature was between 1343 and 1265 $\mathrm{K}$. In the second segment between 177 and $192 \mathrm{~cm}, \mathrm{NH}_{3}$ was between 352 and $224 \mathrm{ppm}$, $\mathrm{O}_{2}$ increased from 1.0 to $3.0 \%$ and temperature decreased from 1265 to $1213 \mathrm{~K}$. The second segment shows evidence of mixing with tertiary air because of the $\mathrm{O}_{2}$ increase. In both segments, the $\mathrm{NH}_{3}$ levels are of the same order of magnitude as the NO. Thus, the $\mathrm{NH}_{3}$ to $\mathrm{NO}$ ratio does not have to be significantly higher than one to achieve high NO reductions. The data also demonstrate that large NO reduction occurred under slightly lean ( 0.7 to $3 \% \mathrm{O}_{2}$ ) conditions at temperatures ranging from 1274 to $1343 \mathrm{~K}$. These conditions are close to SNCR conditions but the temperatures and $\mathrm{O}_{2}$ concentrations are on the higher end of the optimal range. It would be of interest to look at detailed maps where the ammonia was injected upstream at higher temperatures to see if NO increased initially and to determine under what conditions the NO was decreasing. 
Because of the close proximity of the $\mathrm{NH}_{3}$ injector and the tertiary air, it was uncertain from the mapped data whether or not the tertiary air helped create the temperature or species environment necessary for NO reduction. An additional effluent test was taken to determine the extent of NO reduction without tertiary air injections. The results showed a $61 \%$ reduction when no tertiary air was used in comparison to greater than $70 \%$ reduction with both $\mathrm{NH}_{3}$ and tertiary air injection. This suggested that the bulk of the NO reduction was independent of the tertiary air, but in this configuration, the tertiary air was also a contributor to NO destruction.

\subsubsection{Advanced Reburning Velocity}

Axial and tangential mean velocities profiles for advanced reburning at six locations are shown in Figure 6.8. The data have been obtained for a theoretical swirl ratio of 0.5 with the same reburning zone stoichiometry and overall operating conditions as the species data presented above. The first three locations are in the primary combustion zone above the natural gas and ammonia injection locations. The data closest to the burner is incomplete near the center of the reactor but appears to be following a similar trend to the baseline 0.5 velocity data. The axial and tangential velocities peak about half way between the centerline and the outer reactor wall. As the measurement volume approached the center of the reactor, the unburned coal, char and ash caused the back-scattered signal to be attenuated and the velocity more difficult to measure. In the baseline data the velocity became negative or directed upward toward the fuel inlet at the centerline as is seen at the $37 \mathrm{~cm}$ and $62 \mathrm{~cm}$ axial locations. For the most part, the velocity data with advanced reburning look very similar to the baseline velocity data at the same swirl. At the $77 \mathrm{~cm}$ location and below the axial velocity is relatively flat while some tangential velocity remains with a peak moving slowly towards the reactor wall. The jets entering the reactor from the natural gas, ammonia and tertiary air do not appear to significantly affect the velocity immediately above and below the injectors. 
Average Axial Velocity
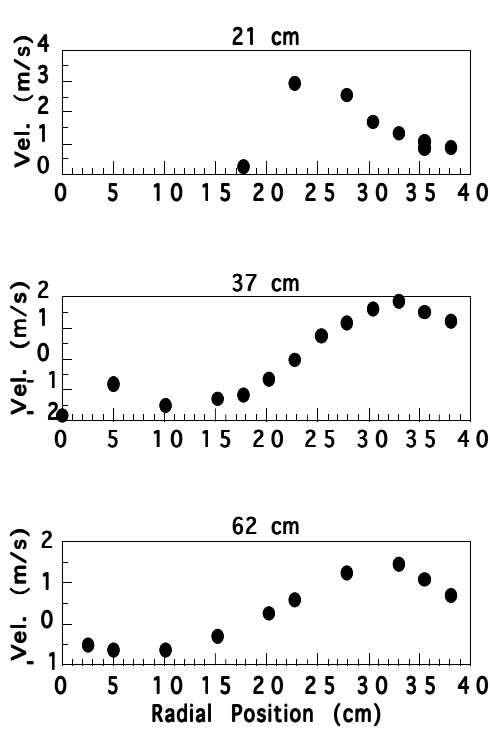

Average Axial Velocity
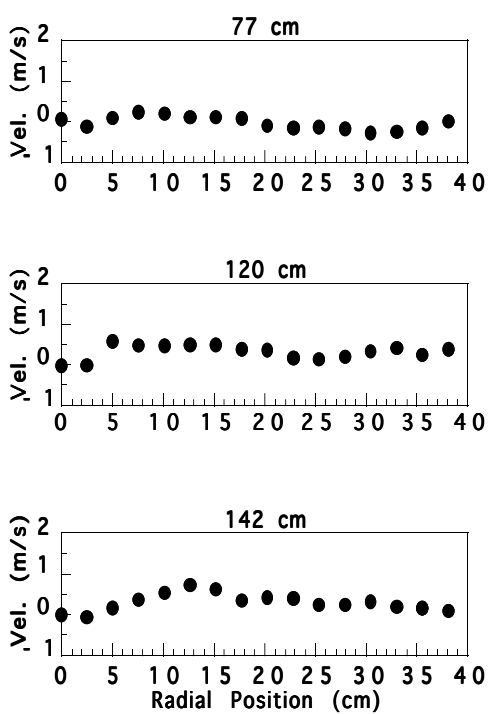

Average Tangential Velocity
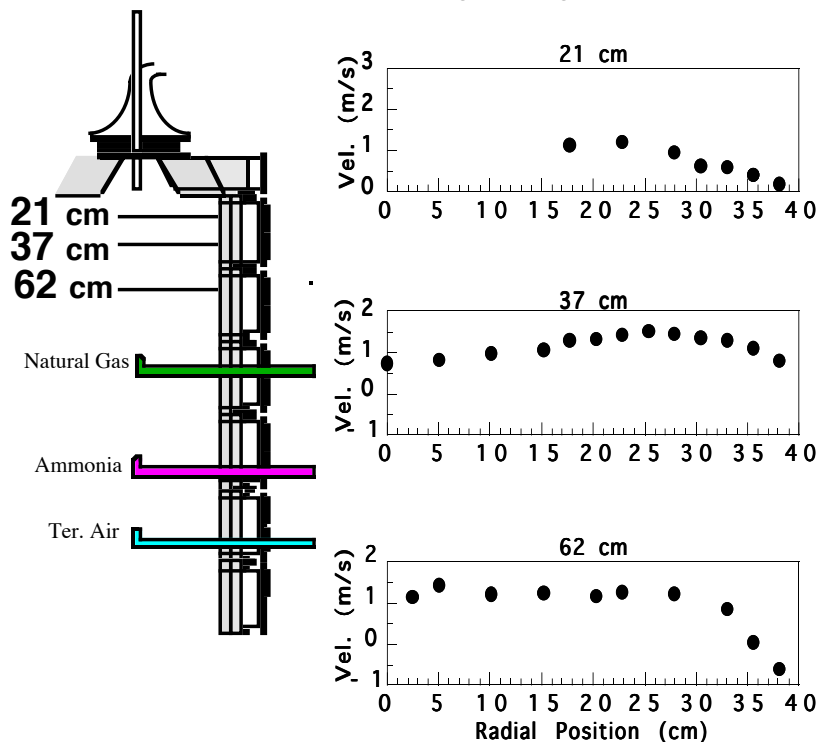

Average Tangential Velocity
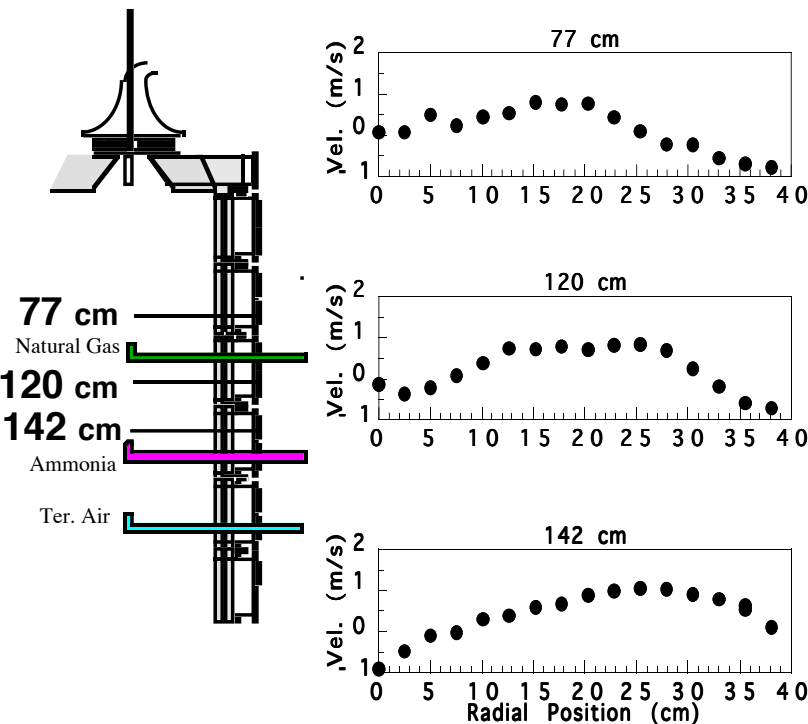

Figure 6.8 LDA velocity data with advanced reburning at 0.5 swirl.

\subsection{Advanced Reburning Summary and Conclusions}

Advanced reburning has been investigated in a $0.2 \mathrm{MW}$ pulverized coal flame by injecting a gaseous mixture of $\mathrm{NH}_{3}$ and $\mathrm{N}_{2}$ downstream of the injection point of natural gas. Various amounts and combinations of reburning fuel and ammonia injection were investigated through gaseous effluent measurements to determine the effects of parameters 
such as reburning zone S.R., advanced reburning NSR, injector location and carrier gas momentum. The results showed that while reburning and ammonia injection alone were both effective in reducing $\mathrm{NO}$, the greatest reductions were realized when both were combined. Although the testing was not extensive enough to determine an optimal condition, the highest NO reductions of over $90 \%$ were observed when a reburning zone S.R. of 1.05 was followed by ammonia injection. NO reduction was very sensitive to the $\mathrm{NH}_{3}$ injection location. The reason behind this sensitivity was thought to be variations in temperature at and below the injection location. NO reduction was found to be sensitive to NSR under conditions where NO reductions due to advanced reburning were high, but the effects of NSR were smaller than those of injection location. Maximum NO reductions of over $95 \%$ were seen at an NSR of 2.5 .

A single operating condition was selected for mapping the species and temperatures in the reactor. The map recorded $\mathrm{CO}, \mathrm{CO}_{2}, \mathrm{NO}, \mathrm{O}_{2}, \mathrm{HCN}, \mathrm{NH}_{3}$ and temperature at 60 locations in a cross sectional plane of the reactor. The data showed the region of most rapid NO reduction occurred directly below the ammonia injection location and that high NO reductions were occurring in regions where the $\mathrm{O}_{2}$ was between 0.7 and $3 \%$, the temperatures were between 1274 and $1351 \mathrm{~K}$ and $\mathrm{NH}_{3}$ was between 352 and $2961 \mathrm{ppm}$. Thus the reduction occurred at slightly lean conditions and slightly higher temperatures than typical optimums for SNCR of NO. Further detailed measurements need to be obtained to determine if the NO reduction at other global operating conditions and injection locations occurs at these same local conditions.

\section{MODELING RESULTS}

Comprehensive modeling of the CPR for comparison with the measured data has been attempted using PCGC-3, a comprehensive pulverized coal combustion model developed at Brigham Young University by the Advanced Combustion Engineering Research Center (ACERC). The code has recently be upgraded to include subroutines for reburning and advanced reburning as described by Xu and Smoot (1998) and Xu and Smoot (1999). Additionally, a commercial combustion code, FLUENT, has been used for comparison with the flow exiting the primary reaction zone. Initial modeling efforts showed that the basic flow structure of recirculation in the primary combustion zone was not accurately predicted by either PCGC-3 or fluent. A series of modeling experiments was conducted to test different turbulence models in an attempt to accurately predict the flow. When this failed, the flow was forced to match the measured data in the model by specifying specific boundary conditions and by using a bluff body to create a realistic recirculation zone. With the basic flow structure forced to match experimentally measured velocity data, the reburning and advanced reburning sub-models were implemented in PCGC-3 for comparison with the reburning and advanced reburning results. The results of this modeling effort are detailed below. 


\subsection{Baseline Flow Modeling Efforts}

Efforts to accurately predict the LDA measured flow-field using advanced combustion CFD codes have provided important insights. The turbulence model used has proved to have a rather large effect on the solutions. In contrast the inflow velocity profiles used as an inflow boundary condition (BC) proved to have a fairly minor impact on the solutions. Results of modeling efforts in these two areas are presented in this section.

\subsubsection{Turbulence Models}

Two combustion CFD codes have been used to try to model the flow conditions in the CPR, FLUENT and PCGC-3. In trying to model the swirling flow cases, such as swirl = 1.5 , both codes have had difficulty setting up the proper flow-field when using the standard k- $\varepsilon$ turbulence model. In addition to the standard k- $\varepsilon$ model a RNG k- $\varepsilon$ model and a non-linear k- $\varepsilon$ model have also been used. The RNG k- $\varepsilon$ model is available in FLUENT while the non-linear k- $\varepsilon$ model is available in PCGC-3. Both of these more advanced turbulence models show improvement over the standard k- $\varepsilon$ model. According to the FLUENT User's Guide the RNG k- $\varepsilon$ model has significantly improved capabilities for handling the turbulence characteristics of the swirling flows in the present study. FLUENT was run with non-reacting flow and the results using both this RNG and the standard k- $\varepsilon$ model were compared to the cold flow velocity data (described in Oct. 1996 report). Effects of the turbulence model, especially in the top portion of the CPR, are quite dramatic. The RNG k- $\varepsilon$ solution more closely matches the LDA data as can be seen in Figure 7.1, which includes the radial profiles for both axial and tangential velocities at $22 \mathrm{~cm}$ below the primary inlet for the 1.5 swirl condition. The RNG model is able to match the shapes of both profiles, and matches absolute levels for the axial velocities. Although the magnitudes are not as accurate for the tangential velocity, the agreement is much better than with the standard k- $\varepsilon$ model. Efforts are underway to use FLUENT to model the full coal combustion case so that a comparison between these two models can be made under reacting conditions.

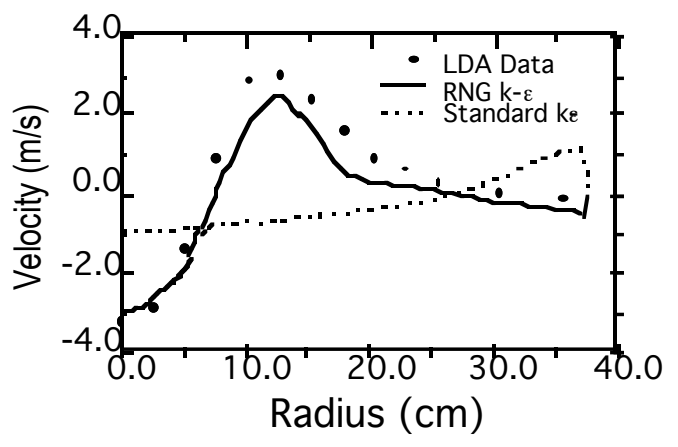

A) Average Axial Velocity

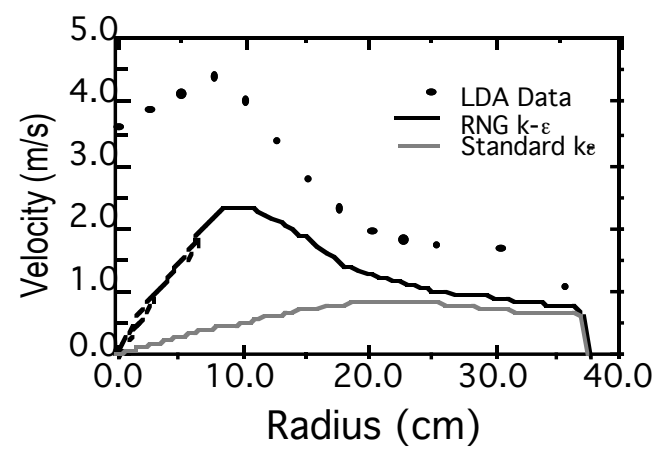

B) Average Tangential Velocity

Figure 7.1 Comparison of turbulence models from FLUENT with cold flow LDA data at $22 \mathrm{~cm}$ below the primary inlet for a swirl number of 1.5. 
Reacting flow cases with coal have been modeled using PCGC-3 with both the standard $k-\varepsilon$ model and a non-linear $k-\varepsilon$ model. The results of these runs have been compared to the LDA data taken in the CPR under reacting conditions for the swirl $=1.5$ condition. Comparisons of the velocity profiles in the upper portion of the CPR (at $22 \mathrm{~cm}$ below the primary exit) are included in Figure 7.2. While this non-linear $\mathrm{k}-\varepsilon$ model shows definite improvement over the standard $k-\varepsilon$ model it still is not able to capture the true flow physics near the centerline. The recirculation, indicated by the negative axial velocities in the LDA data, is not predicted. By comparison with the RNG model predictions of the cold flow data (Figure 7.1) it is evident that this non-linear $\mathrm{k}-\varepsilon$ model does nearly as well except for this centerline region, where the RNG model did predict recirculation in the cold flow cases.

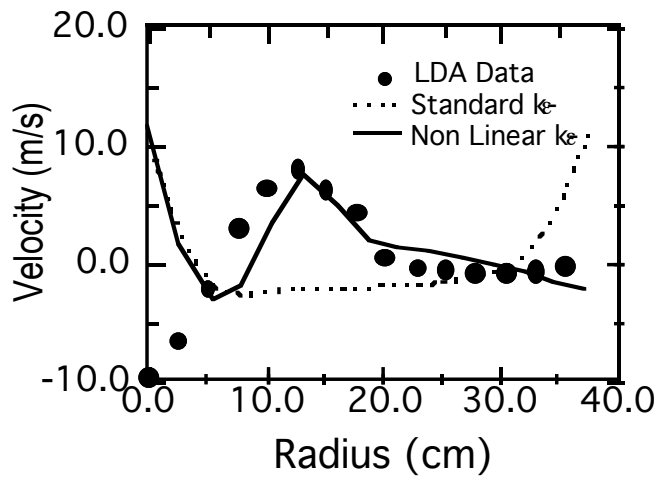

A) Average Axial Velocity

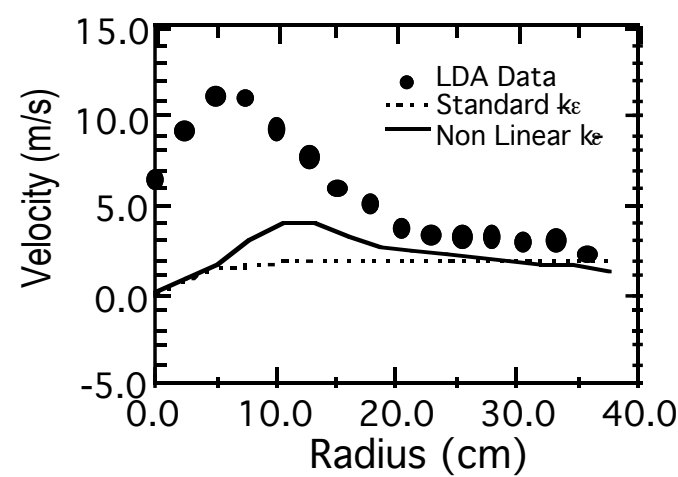

B) Average Tangential Velocity

Figure 7.2 Comparison of turbulence models to LDA data for coal combustion cases.

\subsubsection{Inflow $B C$}

A comparison of the old and new BC velocity profiles is provided in Figure 7.3 for two swirl settings, 0 and 1.5. The old $\mathrm{BC}$ had profiles, both axial and tangential, that peaked on the inner section close to the primary. The new BC data peak much closer to the outer radius for the higher swirl numbers, and although they look somewhat similar for the low swirl settings are still skewed slightly more towards the outer radius. The relatively smaller flow area for the inner radial peaks accounts for the disparity in peak velocity magnitudes.

The fairly major change in velocity profiles, particularly for the higher swirl settings, seemed to have a minor impact on the solutions. 


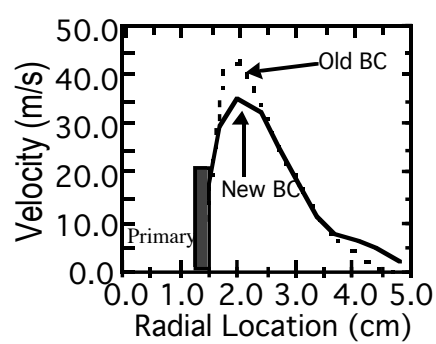

A) Axial, $\mathrm{Sw}=0$

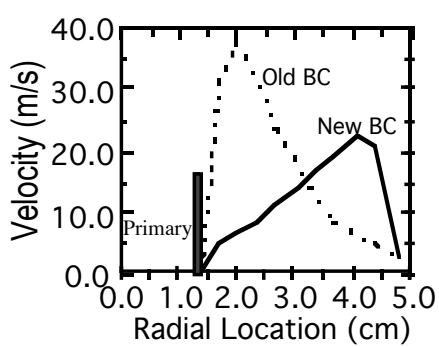

B)Axial, $\mathrm{Sw}=1.5$

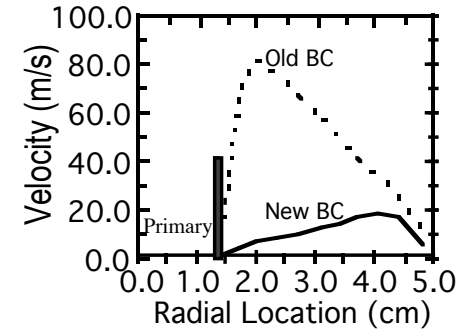

C) Tangential, $\mathrm{Sw}=1.5$

Figure 7.3 Comparison of velocity profiles for the old and new boundary conditions at a swirl of 0 and 1.5.

Differences due to the inflow BC in the coal combustion solutions at $22 \mathrm{~cm}$ below the primary for both the zero and 1.5 swirl conditions are shown in Figure 7.4. It is possible that the poor performance of the standard $k-\varepsilon$ model, which was used in each of these cases, could be the limiting factor for the higher swirl cases where there is the greatest difference between the old and the new BC. More work with an improved turbulence model is warranted, but preliminary indications suggest that the solutions are not particularly sensitive to changes in the inflow BC.

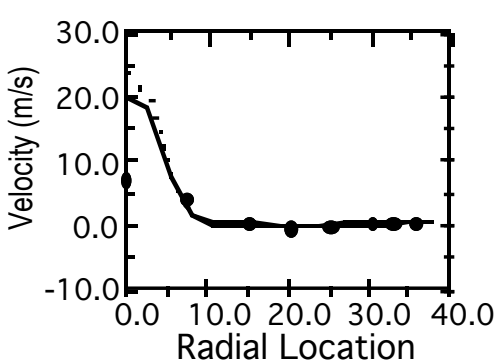

A) Axial, Swirl $=0$

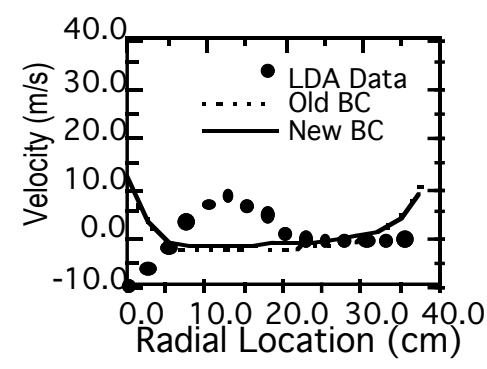

B) Axial, Swirl $=1.5$

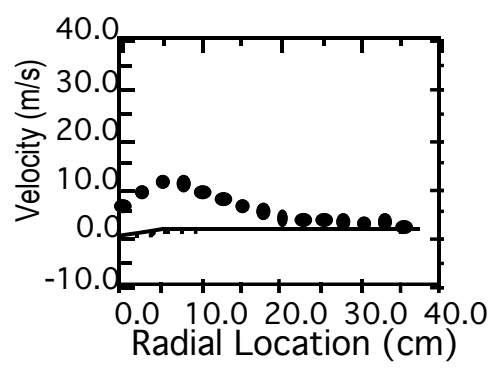

C) Tangential, Swirl $=1.5$

Figure 7.4 Comparison of old and new boundary conditions. PCGC-3 solutions, 22 $\mathrm{cm}$ below the primary fuel tube.

\subsubsection{Matching Baseline Flow Data with The Model}

Since modeling efforts were hindered by an inability to accurately predict the flowfield in the CPR, a second effort was undertaken to force the code to produce the proper flow-field in the CPR predictions, so that the testing of the reburning and advanced reburning sub-models could proceed. As part of this second approach, a grid was developed with a bluff body immediately downstream of the primary exit. The top portion of this grid is shown in Figure 7.5. The light gray shaded cells represent solid material while the dark cells are part of the solution domain. The thin line of gray cells running horizontally from the left bottom corner to the center is the primary fuel tube. The light shaded cells forming a triangle at the exit of the primary inlet are the bluff body. This approach has developed a much-improved flow-field for the 1.5 swirl case, as shown in 
Figure 7.6. Using the same bluff body grid a prediction was made for the 0.5 swirl baseline case. As shown in Figure 7.7 these results are not as satisfactory.

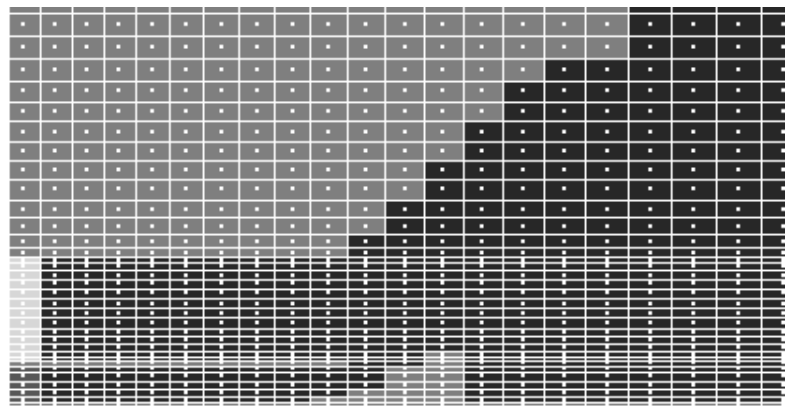

Figure 7.5 Grid with a bluff body inserted at the exit of the primary inlet.
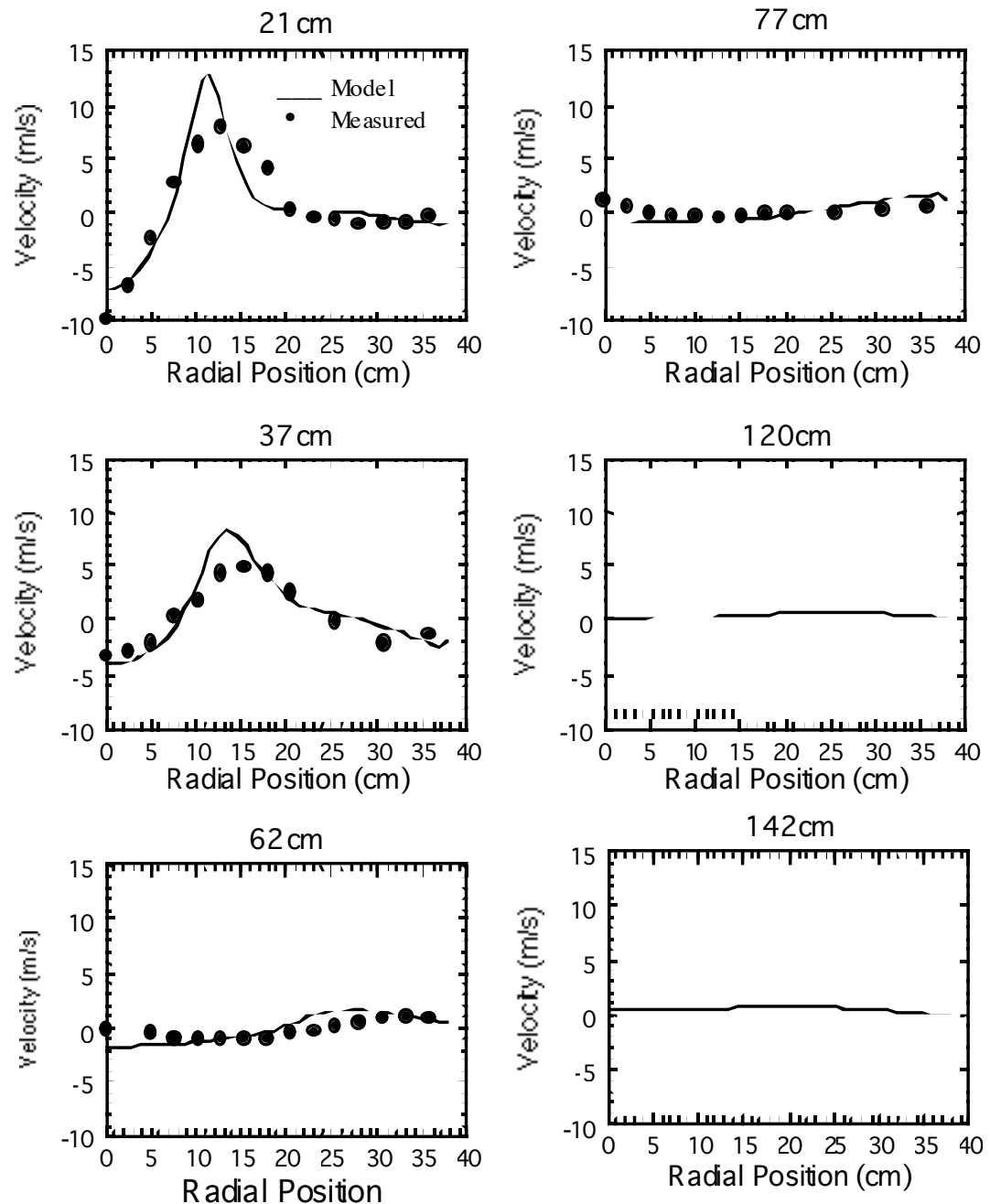

Figure 7.6 Comparison of 1996, 1.5 swirl, LDA data with model predictions using bluff body to set up recirculation zone. 
$21 \mathrm{~cm}$

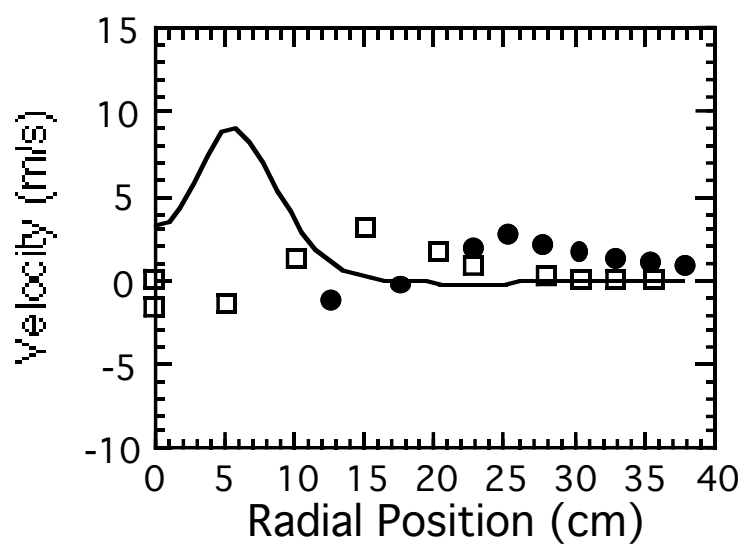

$37 \mathrm{~cm}$

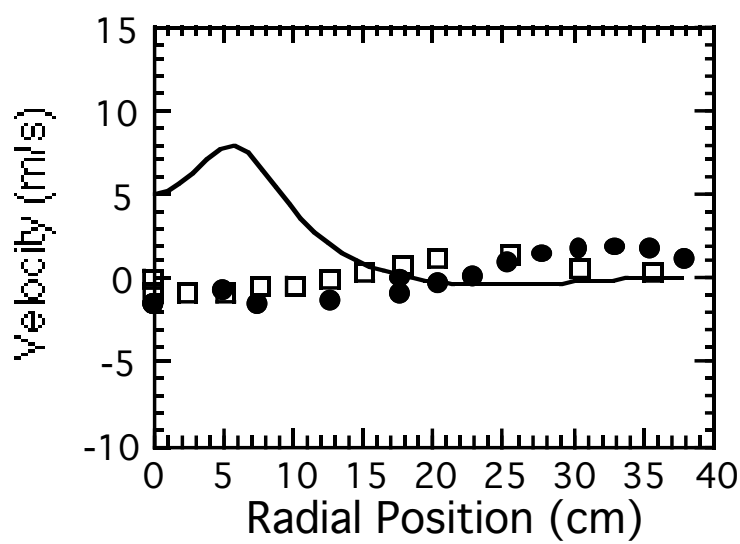

$62 \mathrm{~cm}$

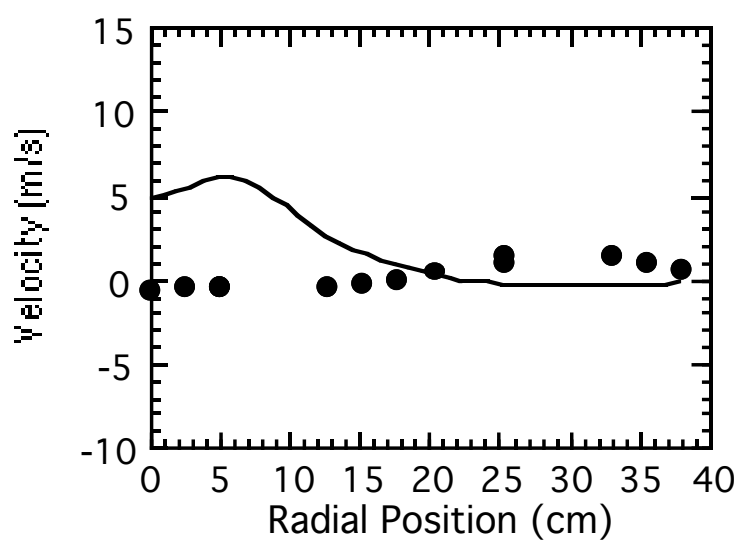

$77 \mathrm{~cm}$

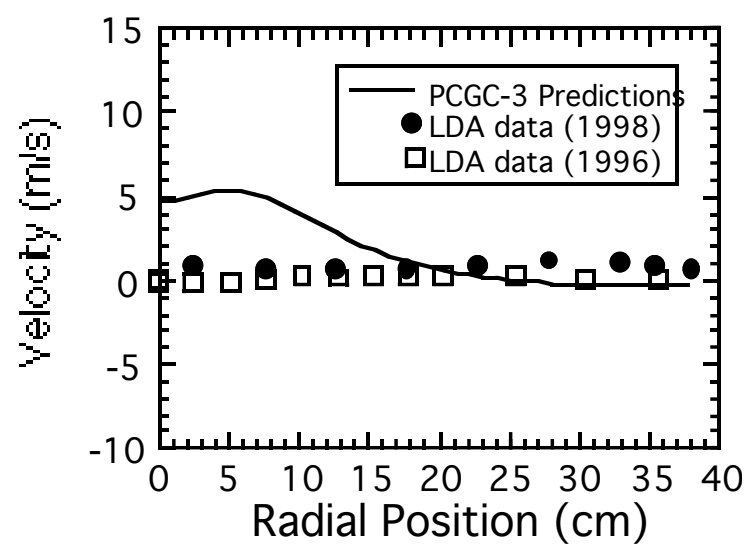

$120 \mathrm{~cm}$

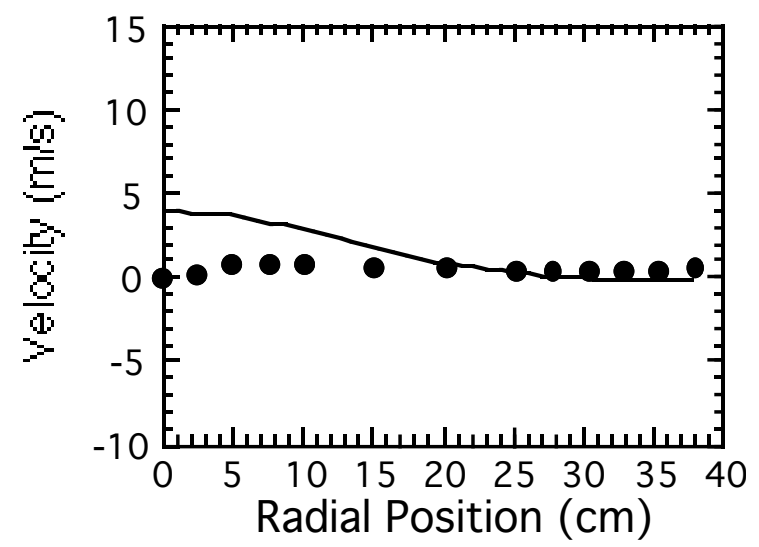

$142 \mathrm{~cm}$

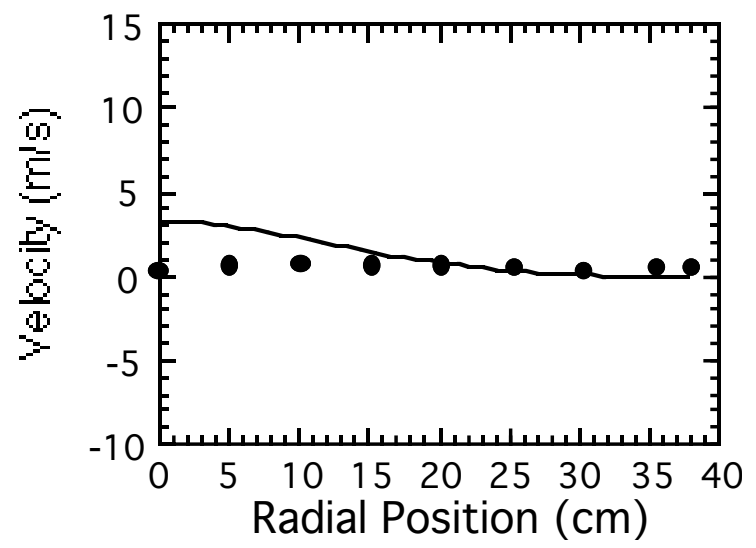

Figure 7.7 Comparison of 0.5 swirl LDA data with model predictions using bluff body to set up a recirculation zone.

A second method of achieving a recirculation zone that matches the data is to impose a radial velocity component to the secondary air at the inlet which is set at the entrance plane 
of the primary air. This method improves the prediction of the code and allows the primary combustion zone to remain in the topmost section of the reactor as seen in the species data. This is the technique which was used to evaluate the reburning and advanced reburning sub-models discussed in the next section.

\subsection{Reburning and Advanced Reburning Modeling}

PCGC-3 uses an iterative Lagrangian - Eulerian solver to model coal combustion. The fluid flow, species, and reactions are first determined in an Eulerian reference frame followed by a Lagrangian solution for particle location and reactions in the given flow field. The formation and destruction of $\mathrm{NO}$ is assumed to contain very little energy relative to the rest of the flame and leave little influence on other primary combustion properties. For this reason, $\mathrm{NO}$ reactions can be left out of the initial solution and solved using a post processing routine where the velocity and temperature fields are well known. Using this approach, a sub-model for NO reduction which includes reactions applicable to both reburning and advanced reburning has been developed by Xu and Smoot (1999) that attempts to predict combustion NO levels.

\subsubsection{A Four-Step Reduced Mechanism for Advanced Reburning Process}

Under independent funding, a four-step, eight-species (i.e., $\mathrm{CO}_{2}, \mathrm{H}_{2} \mathrm{O}, \mathrm{N}_{2}, \mathrm{O}_{2}, \mathrm{NO}$, $\mathrm{NH}_{3}, \mathrm{CO}$, and $\mathrm{OH}$ ) reduced mechanism for $\mathrm{NO}$ reduction by ammonia-based advanced reburning has been developed from a carefully chosen 312-step, 50-species full mechanism through use of a systematic reduction method and data fitting technique, as discussed by Xu and Smoot $(1998,1999)$.

$$
\begin{array}{ll}
\text { I: } & \mathrm{O}_{2}+\mathrm{CO}+\mathrm{H}_{2} \mathrm{O}->2 \mathrm{OH}+\mathrm{CO}_{2} \\
\text { II: } & \mathrm{O}_{2}+2 \mathrm{CO}->2 \mathrm{CO}_{2} \\
\text { III: } & \mathrm{O}_{2}+\mathrm{N}_{2}-2 \mathrm{NO} \\
\text { IV: } & \mathrm{OH}+3 \mathrm{NO}+\mathrm{NH}_{3}->\mathrm{O}_{2}+2 \mathrm{H}_{2} \mathrm{O}+2 \mathrm{~N}_{2}
\end{array}
$$

The four-step reduced mechanism was evaluated through the comparisons with the full mechanism within the application window of interest for advanced reburning processes, and other experimental data in laminar flames. It was found that the reduced mechanism was in good agreement with the full mechanism, and also agreed qualitatively with three sets of experimental data, including the influences of temperature, $\mathrm{CO}$ concentration, $\mathrm{O}_{2}$ concentration, and the ratio $\left(\mathrm{NH}_{3} / \mathrm{NO}\right)_{\text {in }}$. The advanced reburning reduced mechanism can be applied for coal-, gas-, and oil-fired combustion. The four-step reaction sequence has been integrated into a comprehensive CFD combustion code for turbulent combustion, PCGC-3. Five species continuity equations for $\mathrm{NO}, \mathrm{NH}_{3}, \mathrm{CO}, \mathrm{O}_{2}$ and $\mathrm{OH}$ were included into the PCGC-3, while $\mathrm{CO}_{2}, \mathrm{H}_{2} \mathrm{O}$ and $\mathrm{N}_{2}$ were taken to be local equilibrium, which substantially reduces computational times for the $\mathrm{NO}$ sub model calculation. Illustrative calculations with PCGC-3 for turbulent, pulverized coal combustion showed that the predictions are reasonable and realistic, including effects of temperature and concentrations of $\mathrm{CO}, \mathrm{O}_{2}$, and $\mathrm{NH}_{3}$ on $\mathrm{NO}$ reduction. The comparisons with the advanced reburning 
experimental data obtained from this investigation in the CPR showed that the model calculations agreed reasonable well with measured NO concentrations and parametric studies, including the change of swirl number, reburning zone stoichiometric ratio, $\mathrm{NH}_{3}$ in $/ \mathrm{NO}_{\text {in }}$, and $\mathrm{NH}_{3}$ injection location.

\subsubsection{Model and Data Comparison}

A comparison of NO mole fraction vs. axial distance in the CPR is shown in Figure 7.8. The NO values in each computational cell at a given level have been mass averaged for comparison with mass averaged NO data. The model was unable to predict the NO concentrations produced in the baseline data using realistic inputs. When the coal nitrogen was increased to 2.5 times the measured coal nitrogen, the results shown in the figure were obtained. The need to increase coal nitrogen to obtain a reasonable NO prediction suggests that the primary combustion zone is not adequately being modeled. This may be related to the inability of the model to predict the primary combustion zone flow field. With the increased coal nitrogen, the predictions are in reasonable agreement with the data. While the prediction shows a more rapid increase in NO near the burner, the important thing to note is that the NO concentrations entering the reburning and advanced reburning zones which are located down stream of the $0.5 \mathrm{~m}$ axial location are accurately predicted.

Similarly the temperature is also accurately predicted below the $0.8 \mathrm{~m}$ axial location also shown in Figure 7.8 .

Results for reburning are shown in Figure 7.9. This case models the same operating condition discussed in Section 6 above and 1.5 swirl. In this case the reburning zone stoichiometric ratio was 0.78 so there was a considerable amount of reburning fuel injected at the $90 \mathrm{~cm}$ axial location. From the NO data it is clear that the natural gas injection at 90 $\mathrm{cm}$ affects the amount of NO formed upstream because the maximum values in the primary combustion zone region (less than $40 \mathrm{~cm}$ ) are lower than the baseline case. This is reasonable because of the recirculation zone which can draw natural gas up into that region. The model appears to over predict this reduction of NO in the primary combustion zone as NO values are lower than those measured during the first $50 \mathrm{~cm}$. The model then over predicts NO in the reburning zone and below from 0.9 to $2.0 \mathrm{~m}$ before accurately predicting the effluent value. Temperature is under predicted in the primary combustion zone from zero to $0.8 \mathrm{~m}$, then slightly over predicted from 0.8 to $2 \mathrm{~m}$ before accurately predicting the effluent values. The data suggests the model is reacting the reburning fuel too slowly. A comparison with model and measured turbulence in this region should be investigated further. 

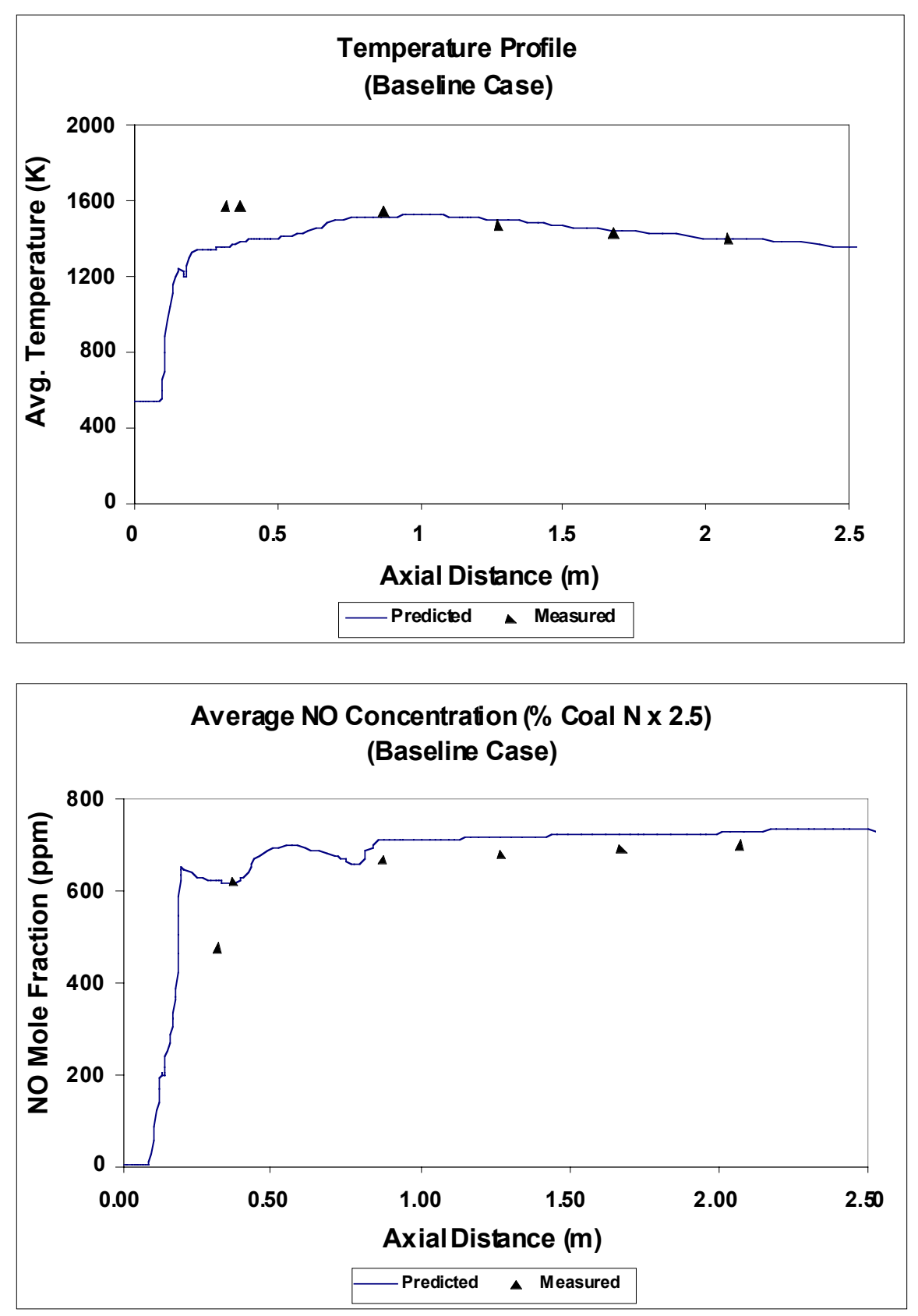

Figure 7.8 Baseline measured and predicted axial temperature and NO profiles at 0.5 swirl. 

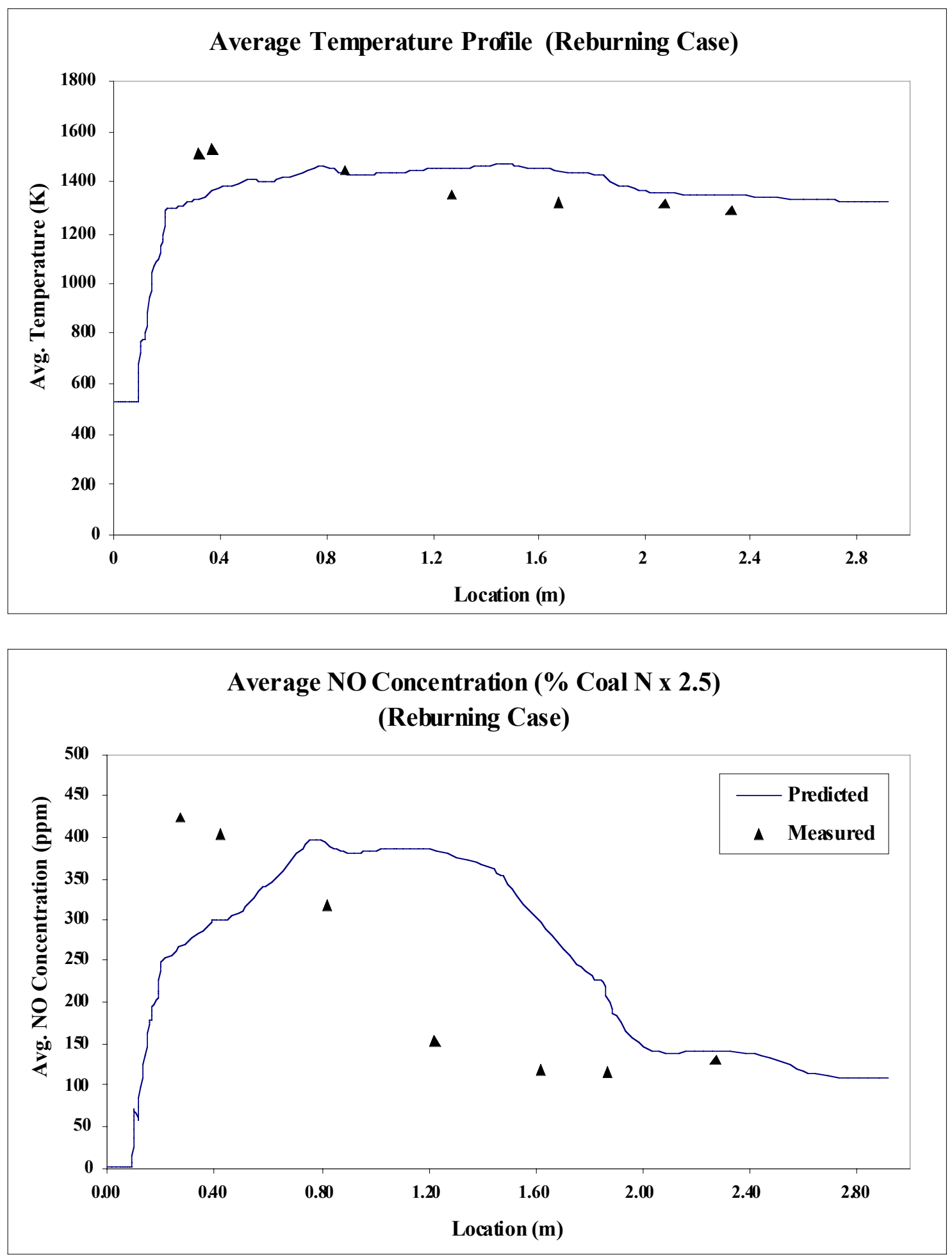

Figure 7.9 Comparison of measured and modeled pulverized coal flame with reburning at 1.5 swirl and a reburning zone stoichiometric ratio of 0.78 . 
Comparisons of advanced reburning measurements with modeling are shown in Figure 7.10. These data model the same advanced reburning case shown in Section 7 with a reburning zone stoichiometric ratio of 1.05 , natural gas injected at $0.88 \mathrm{~m}$, ammonia injected at $1.49 \mathrm{~m}$, and tertiary air at $1.89 \mathrm{~m}$. Again the temperature data are under predicted in the primary zone by the model but appear accurately predicted just prior to natural gas injection. The predicted temperature then stays relatively flat while the data decrease linearly until just before the exit. As in the previous data with natural gas, the prediction appears to suggest heat release from the natural gas down stream from where the data suggests. Predicted NO values in the primary combustion zone are again well below the measurements but are accurately predicted by the model in the reburning and advanced reburning zones. The poor agreement in the primary combustion zone is again not surprising given the poor agreement with velocity data in this region. Because the natural gas flow rate is small, the failure of the model shown in the previous figure appears to have less of an affect while the ammonia injection seems to be reasonably modeled.
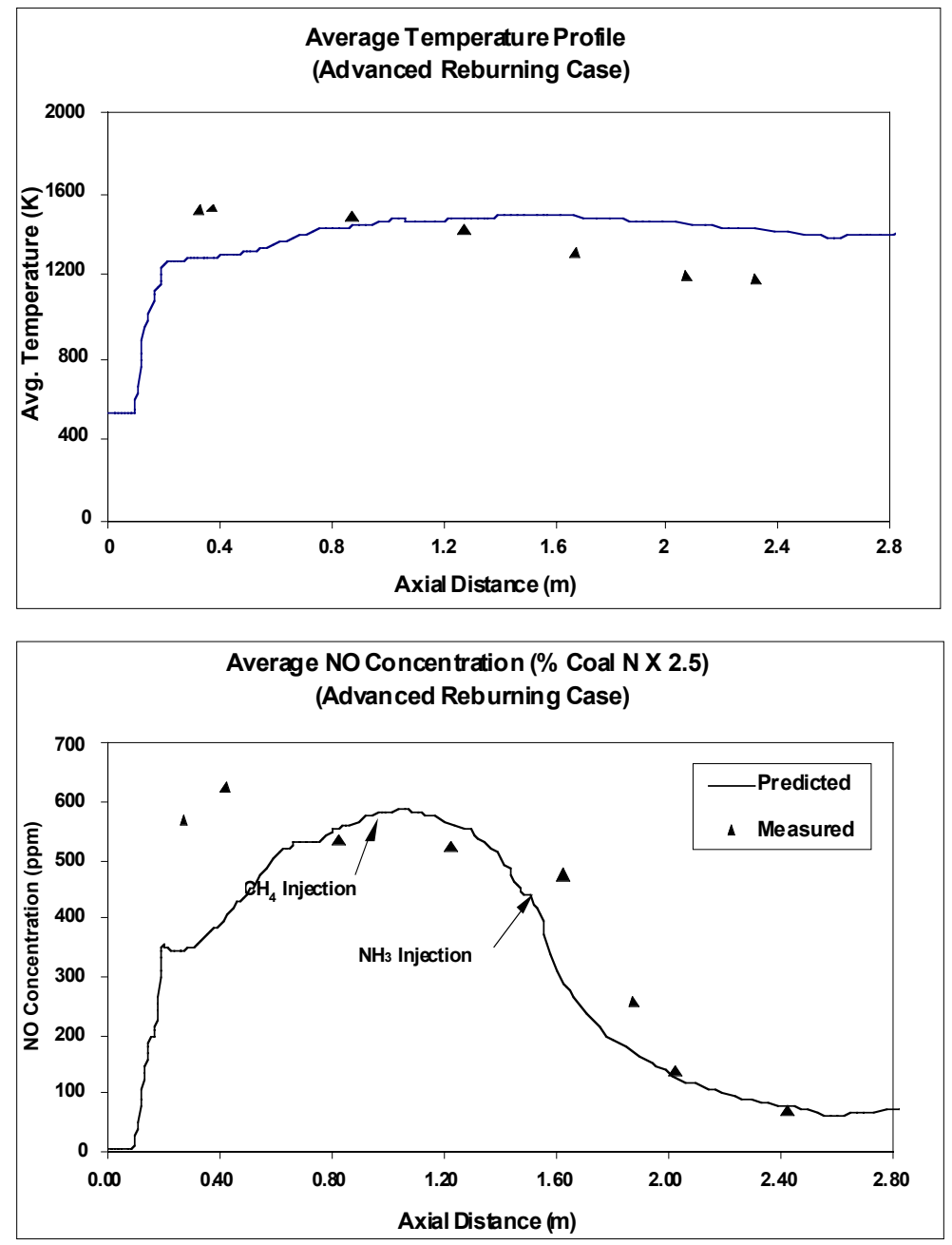

Figure 7.10 Comparison of axial temperature and NO profile for a pulverized coal flame at 0.5 swirl. Reburning zone stoichiometric ratio 1.05 . 


\subsection{Modeling Summary}

Comparisons of modeling results with measured species and velocity data have been made for baseline, reburning and advanced reburning cases. While the modeling results are not as extensive as the data, some conclusions can be formulated concerning modeling capabilities. The first is that the current codes or at least the two codes used in this study are not adequate at describing highly turbulent recirculating flows. Combustion does not appear to dampen turbulence enough to allow simple k- $\varepsilon$ models to be used to describe highly swirling flows. Once the flow is poorly predicted the rest of the combustion process is poorly predicted as well. Given a correct flow, the remainder of the sub models within the PCGC-3 code performed reasonably well. Temperature and species concentrations for NO were accurately predicted in the cases that were tested. The results are promising for the reduced mechanism which is used to describe reburning and advanced reburning NO reduction but certainly a larger number of simulations need to be done to improve confidence in the NO model. The model should also be compared with other data sets. Both were beyond the current focus of this work.

\section{CONCLUSIONS AND RECOMMENDATIONS}

Detailed sets of measurements have been obtained for pulverized coal flames in three baseline, two reburning, and one advanced reburning configuration. The data document species, temperature, and velocity fields in these flames. The data are self consistent and provide a high level of confidence that they are accurate and representative of steady operating conditions which makes them useful for developing and comparing with numerical models. The baseline data show a correlation between inlet flow characteristics and effluent NO demonstrating the importance of measuring and understanding flow profiles in designing low $\mathrm{NO}_{\mathrm{x}}$ burners. The baseline data are the only known data set where detailed measurements of species, temperature, and velocity have been measured at different swirl conditions, thus allowing a test of the ability of comprehensive codes to model fluid flow correctly. The combustion model, PCGC-3, used in this study failed to predict flows correctly with simple $\mathrm{k}-\varepsilon$ turbulence models. An improved version also failed to predict the flows with non-linear and RNG k- $\mathrm{k}$ turbulence models.

Reburning measurements confirmed, as has been previously demonstrated, that significant NO reduction (up to $78 \%$ in this study) can be achieved from natural gas injection into combustion products. The two detailed sets of measurements show how rapidly and where within the reactor the reduction is taking place. This again allows for a

more detailed comparison with modeling data. The modeling results predicted a longer time period was necessary before NO reduction occurred than was seen in the data. The detailed velocity data can now be used to determine if the slow rate of reaction can be attributed to a poor reaction mechanism or poor modeling of the mixing process.

Advanced reburning measurements showed that NO reduction above $90 \%$ was possible under certain specific operating conditions. The highest NO reductions were seen 
when the reburning zone stoichiometric ratio was held near 1.05, and ammonia was injected at an NSR of 2.0 or higher. The NO reduction was very sensitive to ammonia injection location which was attributed to a sensitivity to temperature. Detailed measurements showed that maximum NO reduction occurred at slightly lean conditions with temperatures near $1275 \mathrm{~K}$ and NSRs of 1 or greater. These are typical of SNCR operating conditions. Detailed species and temperature data are very important in advanced reburning because of the dependence of the reduction zone on temperature. In this work only one detailed data set was obtained. There was no way to determine from the single data set if advanced reburning could be implemented over a broader range of operating conditions as would be desirable in a full scale boiler. Ammonia injection may be effective if injected at higher temperatures and then passed through the optimal temperature window downstream but this was not investigated. It is recommended that additional detailed advanced reburning measurements be obtained to investigate more closely under what conditions NO is reduced within the reactor.

\section{LISTOF REFERENCES}

Abbott, M.P. (1989) "Two Phase Velocity and Turbulence Measurements in a $0.5 \mathrm{MW}$ Pulverized Coal Fired Furnace," IFRF 9th Members' Conference.

Beer, J.M., Chigier, N.A., (1972) Combustion Aerodynamics, Applied Science Publisher Ltd., London.

Berman, N.S., (1972) "Particle-Fluid Interaction Corrections for Flow Measurements with a Laser Doppler Flowmeter," NASA-CR-124254.

Brauwer, J., Heap, M.P., Pershing, D.W., and Smith, P.J. (1996) “A Model Prediction of Selective Noncatalytic Reduction of Nitrogen Oxides by Ammonia, Urea, and Cyanuric Acid with Mixing Limitations in the Presence of CO," Twenty-Sixth Symposium (International) on Combustion, The Combustion Institute, pp. 2117-2124.

Chen, S. L., McCarthy, J. M., Clark, W. D., Heap, M. P., Seeker, W. R., and Pershing, D. W. (1986) "Bench and Pilot Scale Process Evaluation of Reburning for In-furnace $\mathrm{NO}_{\mathrm{X}}$ Reduction," Twenty-first Symposium (International) on Combustion, p. 1159, The Combustion Institute.

Chen, S.L., Cole, J.A., Heap, M.P., Kramlich, J.C., McCarthy, J.M., and Pershing, D.W. (1988) "Advanced NOx Reduction Processes Using -NH and -CN Compounds in Conjunction with Staged Air Addition," Twenty-Second (Symposium) International on Combustion, The Combustion Institute, pp. 1135-1145.

Cooper, C.D. and Alley, F.C. (1994) Air Pollution Control: A Design Approach, John Wiley \& Sons, 2nd Ed. 
Durst, F., Melling, A. and Whitelaw, J.H. (1981) Principles and Practice of Laser Doppler Anemometry, Academic Press, London.

Folsom, , B.A., Sommer, T.M., Latham, C.E., Moyeda, D.K., Gaufillet, G.D. Janik, G.S. and Whelen, M.P. (1997) "Demonstration of Advanced Gas Reburning for $\mathrm{NO}_{\mathrm{x}}$ Emission Control," 1997 Joint Power Generation Conference, pp. 1-7, Nov. 3-6.

Gupta, A.K., Lilley, G.D., Syred, N. (1984) Swirl Flows, Abacus Press, Malta.

Hemberger, R., Muris, S. Pleban, K.U. and Wolfrum, J. (1994) "An Experimental and Modeling Study of the Selective Noncatalytic Reduction of NO by Ammonia in the Presence of Hydrocarbons," Combustion and Flame, Vol. 99, pp 660-668.

Jodal, M, Lauridsen, T.L. and Dam-Jahansen, K. (1992) " $\mathrm{NO}_{\mathrm{x}}$ Removal on a Coal-Fired Utility Boiler by Selective Non-Catalytic Reduction," Environmental Progress, Vol. 11, No. 4.

Jodal, M., Nielsen, C., Hulgaard, T., Dam-Johansen, K. (1990) "Pilot-Scale Experiments with Ammonia and Urea as Reductants in Selective Non-Catalytic Reduction of Nitric Oxide," Twenty-Third Symposium (International) on Combustion, The Combustion Institute, pp. 237-243.

Kicherer, A., Splietoff, H., Maier, H., and Hein, K. R. G. (1994) “The Effect of Different Reburning Fuels on $\mathrm{NO}_{\mathrm{X}}$ Reduction," Fuel, vol. 73, p. 1443.

Lanier, W. S., Mulholland, J. A. and Beard, J. T. (1986) "Reburning Thermal and Chemical Processes in a Two-dimensional Pilot-Scale System," Twenty-First Symposium (International) on Combustion, The Combustion Institute, Pittsburgh pp. 1171.

Lyon, R.K. (1979) “Thermal DeNOx: how it works," Hydrocarbon Processing, Vol 58:10, pp. 109-112.

Marquez, A., Moyeda, D. K., Nguyen, Q. H., and Payne, R. (1995) "Pilot Scale Studies of the Impacts of Coal Properties on the Effectiveness of Reburning for $\mathrm{NO}_{\mathrm{X}}$ Control," Joint Technical Meeting of the Central/ Western/ Mexican National Sections, The Combustion Institute, April.

Mereb, J., and Wendt, J. (1994) "Air Staging and Reburning Mechanisms for $\mathrm{NO}_{\mathrm{x}}$ Abatement in a Laboratory Coal Combustor," Fuel, vol. 73, pp. 1020. 
Nazeer, W. A., Pickett, L.M., and Tree, D.R. (1999a) "Comprehensive Combustion Code Predictions of the Flow Field for Pulverized Coal Combustion," Combustion and Science Technology, In Press.

Nazeer, W.A., Jackson, R.E., Peart, J.A. and Tree, D.R. (1999b) "Detailed Measurements in a Pulverized Coal Flame With Reburning," Fuel, Vol. 78:6 pp 689-699.

Pershing, D.W., and Wendt, J.O.L. (1977) Sixteenth Symposium on Combustion. The Combustion Institute. pp. 389-399.

PETC Review (1995) Update on $\mathrm{NO}_{\mathrm{x}}$ Control Technologies (Spring).

Pickens, R.D. (1996) "Add-on Control Techniques for Nitrogen Oxide Emission During Municipal Waste Combustion,” Journal of Hazardous Materials, Vol. 47, pp. 195-204.

Pickett, L.M., Jackson, R.E. and Tree, D.R. (1999) "LDA Measurements in a Pulverized Coal Flame at Three Swirl Ratios," Submitted to Combustion and Science Technology, In Press.

Pont, J., Evans, A., England, G., Lyon, R., Seeker, W. (1993) "Evaluation of the CombiNO $_{\mathrm{X}}$ Process at Pilot Scale," Environmental Progress, vol. 12, No. 2, pp. 140-145.

Probstle, G., Wenz, W. (1988) "Velocity Measurements in a Swirl Driven Pulverized Coal Fired Furnace," Combustion and Flame, Vol. 72, pp. 193.

Schnell, U., Kaess, M., and Brodbek, H. (1993) "Experimental and Numerical Investigation of $\mathrm{NO}_{\mathrm{x}}$ Formation and its Basic Interdependencies on Pulverized Coal flame Characteristics," Combustion Science and Technology, Vol. 93, pp. 91-109.

Sloan, D.G., Smith, P.J., and Smoot, L.D. (1986) "Modeling of Swirl in Turbulent Flow Systems," Progress in Energy and Combustion Science, Vol. 12, pp. 163-250.

Smart, J.P., and Weber, R. (1989) "Reduction of $\mathrm{NO}_{\mathrm{x}}$ and Optimisation of Burnout with an Aerodynamically Air-Staged Burner and an Air-Staged Pre-combustor Burner," Journal of the Institute of Energy, Vol. 92:453, pp. 237-245.

Suhlmann, J., Rotzoll, G., (1993) "Experimental Characterization of the Influence of CO on the High-Temperature Reduction of $\mathrm{NO}$ by $\mathrm{NH}_{3}$," Fuel, Vol. 72, pp. 175-179.

Syred, N., Beer, J.M., and Chigier, N. (1971) Thirteenth Symposium on Combustion, The Combustion Institute, pp. 563-570.

TSI Incorporated (1980) “Laser Velocimetry Systems,” LDA System Catalogue. 
Weber, R. Dugue, J., Sayre, A., and Visser, B. M. (1992) "Quarl zone flow field and chemistry of swirling pulverized coal flames: measurements and computations," TwentyFourth Symposium (International) on Combustion. The Combustion Institute, pp. 13731380.

Xu, H., L.D. Smoot, and S.C. Hill (1999) "A Computational Model for $\mathrm{NO}_{\mathrm{x}}$ Reduction through Advanced Reburning," Energy \& Fuels, Vol. 13, 2, pp. 411-420.

Xu, H., Smoot, L.D. and Hill, S.C. (1997) "A Reduced Kinetic Model for $\mathrm{NO}_{\mathrm{x}}$ Reduction by Advanced Reburning," Western States Section of The Combustion Institute, WSS/CI 97F-134.

Xu, H., Smoot, L.D. and S.C. Hill, (1998) "A Reduced Kinetic Model for $\mathrm{NO}_{\mathrm{x}}$ Reduction through Advanced Reburning," Energy \& Fuels, Vol. 12, 6, 1278-1289. 